\title{
International Trade, Technology, and the Skill Premium*
}

\author{
Ariel Burstein \\ UCLA and NBER \\ Jonathan Vogel \\ Columbia University and NBER
}

February 2016

\begin{abstract}
What are the consequences of international trade on the wage of college relative to non-college workers (the skill premium)? We incorporate skill intensity differences across firms and sectors and skill abundance differences across countries into an otherwise standard Ricardian model of international trade. In our model, reductions in trade costs reallocate factors towards a country's comparative advantage sectors, increasing the skill premium in countries with a comparative advantage in skillintensive sectors and decreasing it elsewhere. Reductions in trade costs also reallocate factors towards more productive and skill-intensive firms within sectors and towards skill-intensive sectors in all countries, increasing the skill premium in all countries. We parameterize the model for 60 countries using firm, sector, and aggregate data. Trade cost reductions raise the real wage for both skilled and unskilled workers in all countries in our model. The skill premium also rises in almost all countries, even in those that are skill scarce. We also revisit three alternative approaches that have been used in the literature to study the impact of trade on the skill premium, showing, through the lens of our model, that they tend to underestimate the rise in the skill premium generated by trade cost reductions.
\end{abstract}

${ }^{*}$ We thank Francisco Alcalá, Chris Kurz, and especially Marc Muendler and Eric Verhoogen for help with their data. We are grateful to Andrew Atkeson, Arnaud Costinot, Javier Cravino, Jonathan Eaton, Gene Grossman, Oleg Itskhoki, Sam Kortum, Ellen McGrattan, Andrés Rodríguez-Clare, Esteban RossiHansberg, Stephen Yeaple, and Mike Waugh for very useful comments as well as Andres Schneider for excellent research assistance. Previous versions of this paper circulated under the names "Globalization, Technology, and the Skill Premium" and "Globalization, Technology, and the Skill Premium: A Quantitative Analysis." 


\section{Introduction}

What are the consequences of international trade on the relative wage of skilled to unskilled workers, i.e. the skill premium? Most previous empirical and quantitative studies of the impact of international trade on the skill premium are based on the predictions of the Heckscher-Ohlin model. In that model, the ratio of skilled workers, $h$, to unskilled workers, $l$, of a sector $j$ producer in country $n$ may be expressed as

$$
\frac{h}{l}=\frac{\alpha_{j}}{1-\alpha_{j}}\left(\frac{s_{n}}{w_{n}}\right)^{-\rho},
$$

where $\alpha_{j} \in(0,1)$ is a sector characteristic; $s_{n}$ and $w_{n}$ are skilled and unskilled wages, respectively; and $\rho$ is the elasticity of substitution between skilled and unskilled workers. According to this theory, reductions in trade costs shift factors of production towards a country's comparative advantage sectors and raise the relative return to the factor that is used intensively in these sectors, a force we refer to as the Heckscher-Ohlin (H-O) mechanism. Specifically, international trade increases the skill premium in countries that have a comparative advantage in skill-intensive sectors (high $\alpha_{j}$ sectors) and decreases it elsewhere. Previous work has cast doubt on the importance of international trade in affecting the skill premium because the $\mathrm{H}-\mathrm{O}$ model is qualitatively inconsistent with a number of broad outcomes in a range of countries; e.g. inequality has increased in many countries abundant in unskilled labor, as discussed in Goldberg and Pavcnik (2007). ${ }^{1}$ An alternative interpretation is that the $\mathrm{H}-\mathrm{O}$ model abstracts from other potentially important channels through which trade affects the skill premium; see e.g. Acemoglu (2003).

We build a multi-country quantitative trade model that extends the standard $\mathrm{H}-\mathrm{O}$ model, introducing heterogeneity in productivity across firms within sectors and, consistent with evidence that within sectors larger and exporting producers tend to be more skill intensive than their smaller and domestic competitors, ${ }^{2}$ allowing for skill-biased productivity at the producer level. Specifically, we consider a production function such that the equilibrium ratio of skilled workers to unskilled workers of a sector $j$ firm in country

\footnotetext{
${ }^{1}$ More recent work focusing on the link between trade and labor market outcomes across regions within individual countries—see e.g. Dix-Carneiro and Kovak (2015) and Adao (2015) - argues that, through the $\mathrm{H}-\mathrm{O}$ mechanism, trade shocks can partly account for the the observed differential changes in skill premia across regions within a country. In this paper we abstract from regional considerations within countries and focus instead on changes in the economy-wide skill premium of a given trade shock across multiple countries.

${ }^{2}$ See e.g. Bernard et al. (2007a) for evidence for the U.S., Verhoogen (2008) for Mexico, Alcala and Hernandez (2010) for Spain, Bustos (2011) for Argentina, Molina and Muendler (2013) for Brazil, and Eslava et al. (2015) for Colombia.
} 
$n$ with productivity $z$ is given by

$$
\frac{h}{l}=\frac{\alpha_{j}}{1-\alpha_{j}}\left(\frac{s_{n}}{w_{n}}\right)^{-\rho} z^{\phi(\rho-1)},
$$

where $\phi(\rho-1)$ governs the skill-bias of productivity. ${ }^{3}$ Reductions in trade costs shift factors of production towards higher productivity firms, raising the relative demand for skill within sectors and the skill premium if $\phi(\rho-1)>0$, a force we refer to as the skillbiased productivity (SBP) mechanism. This mechanism tends to increase the skill premium in all countries. We discipline our choice of $\phi(\rho-1)$ using data on the elasticity of skill intensity to producer size in Mexico, Brazil, and the U.S.

The H-O and SBP mechanisms do not operate in isolation. If productivity is skill biased, the same dispersion of productivity across firms in different sectors leads to higher unit cost dispersion across firms in more skill-intensive sectors. Intuitively, if productivity is biased towards skilled workers, then productivity differences are magnified in sectors hiring relatively more of them. This force, which we refer to as the between-sector SBP mechanism, implies that the elasticity of trade to trade costs is lower in more skill-intensive sectors and, all else equal, that trade shares are higher in more skill-intensive sectors. We find empirical support for both of these implications. The between-sector SBP mechanism also shapes the impact of a reduction in trade costs on the skill premium. Specifically, in response to a trade liberalization, this mechanism reallocates factors towards more skillintensive sectors in all countries (when the elasticity of demand across sectors is greater than one) and raises the relative demand for skill and the skill premium in all countries.

We embed these mechanisms into an otherwise standard heterogeneous-firm quantitative model of international trade based on Bernard et al. (2003), henceforth BEJK. ${ }^{4}$

\footnotetext{
${ }^{3}$ We follow a large matching literature in which assumptions on production technologies give rise to assortative matching; see e.g. Sattinger (1993) and Eeckhout and Kircher (2010). Acemoglu (2009) defines the skill bias of technology considering variation over time in a technology that is common across producers whereas we define the skill bias of productivity considering variation across firms in productivity at a moment in time. In either case, technology or productivity $z$ is skill biased if an increase in $z$ (whether over time or across firms) raises the marginal product of skilled labor relative to unskilled labor at given factor proportions.

${ }^{4}$ To link firms in our model to individual establishments in the data when parameterizing the model, we assume Bertrand competition, which uniquely determines firm size, as in BEJK, rather than perfect competition, as in Eaton and Kortum (2002). We show that the results on the impact of trade on the skill premium, for given parameter values, are very similar under both market structures. While the central economic forces are similar to those in our model, we do not use a model with monopolistic competition with fixed costs as in Melitz (2003) to reduce the number of parameters that need to be assigned. In our model, Bertrand competition also gives rise to a simple form of variable markups, which affect how information on changes in producer prices of skill-intensive relative to unskill-intensive sectors can be used to infer the impact of international trade on inequality.
} 
Because the sign and strength of the impact of these mechanisms on the skill premium depend on bilateral trade volumes with each trade partner, we parametrize a 60-country version of our model (plus the rest of the world) to match, among other moments of the data, relative country sizes and bilateral merchandise exports in 2005-2007 (henceforth 2006). Because our model with skill-biased productivity does not give rise to a closedform gravity equation at any level of aggregation, we cannot use the now-standard approach introduced in Dekle et al. (2008) for computing the general equilibrium effect of changes in trade costs between equilibria without having to assign values to trade costs or productivities in the original equilibrium. Instead, we use a computational approach that quite accurately matches bilateral exports but does not require an analytic gravity equation at any level of aggregation. This approach may be used more broadly in other applications that do not yield analytic gravity.

We use the parameterized model to conduct a series of counterfactuals, including moving countries from autarky to the 2006 baseline parameterization, moving countries from autarky to an alternative parameterization based on data for 1976, and reducing trade costs ten percent from the baseline. To focus on the direct effect of such changes in trade costs, in these exercises we hold endowments and technologies fixed. Reductions in trade costs in our model have the following implications. First, real wages rise for both factors in all countries. Second, however, the rise in the real wage is larger for skilled workers than for unskilled workers, i.e. the skill premium rises in almost all countries. For example, the maximum, minimum, and mean changes in the skill premium moving each country from autarky to the baseline are roughly $+12 \%,-0.4 \%$, and $+5 \%$, respectively. The skill premium rises in most countries (all except for one), even in skillscarce countries such as China, because the change in relative demand for skill resulting from reallocating factors towards comparative advantage sectors (the H-O mechanism) is smaller than the increase in relative demand for skill resulting from the combination of reallocating factors towards more productive firms within sectors (the SBP mechanism) and towards more skill-intensive sectors in all countries (the between-sector SBP mechanism). Third, the impact of reductions in trade costs on the rise in the skill premium implied by our model varies systematically with country characteristics. It is greater in smaller countries, in more open countries, and in countries that tend to be net exporters of skill-intensive goods, but, in contrast to the $\mathrm{H}-\mathrm{O}$ model, not necessarily in skill-abundant countries like the U.S. We also study the implications of growth in China as well as global skill-biased technical change.

Finally, we revisit three alternative approaches that have been used in the literature to study the impact of trade on the skill premium. These alternative approaches, rather 
than specifying a full GE model, focus on the factor content of trade, e.g. Katz and Murphy (1992); the extent of between-sector factor reallocation, e.g. Berman et al. (1994); and changes in prices, e.g. Feenstra and Hanson (1999). Using data generated by our model, we show that these approaches underestimate by a large margin the rise in the skill premium in countries with a comparative advantage in skill-intensive sectors and predict a counterfactual fall in the skill premium elsewhere. This is because the first two approaches are designed to capture the $\mathrm{H}-\mathrm{O}$ mechanism but abstract from the SBP mechanisms whereas the third approach assumes-in contrast to our model with variable markups and skill-biased productivity—-that changes in markups do not vary systematically across sectors.

We are not the first to model the interaction between skill-biased productivity, international trade, and inequality; see e.g. Yeaple (2005). ${ }^{5}$ We build on these approaches by introducing this mechanism into an otherwise standard quantitative trade model in a relatively simple way, with a single parameter, $\phi$, controlling the degree of complementarity between productivity and skill, that we discipline using cross-sectional evidence on the relationship between producer size and skill intensity. We also combine this mechanism with the H-O mechanism. ${ }^{6}$

Our paper is also related to Burstein et al. (2013) and Parro (2013), who build multicountry perfectly competitive models to study the impact of international trade on the skill premium when capital is complementary to skilled labor, a mechanism from which our model abstracts. Different from those papers, our model allows for firm heterogeneity in skill intensity, which allows us to discipline our parameters using cross-sectional firm-level evidence. While this firm heterogeneity in skill intensity appears to come at a cost-our model no longer generates analytic gravity equations at any level of aggregation - we show that this feature does not hamper our ability either to match key moments such as trade flows and country sizes or to conduct counterfactual analyses. Finally, relative to Helpman et al. (2012), we quantify the impact of trade on between-group in-

\footnotetext{
${ }^{5}$ See also the work of Epifani and Gancia (2006), Verhoogen (2008), Costinot and Vogel (2010), Vannoorenberghe (2011), and Harrigan and Reshef (Forthcoming). An alternative modeling approach that yields similar qualitative results is to assume instead that trade costs are skill biased; see e.g. Matsuyama (2007). We choose our approach because, in the data, larger firms are more skill intensive than less productive firms both within the set of non-exporting firms and within the set of exporting firms. For example, from unpublished Mexican manufacturing plant-level data for 1998 (from the Encuesta Industrial Anual) Verhoogen (2008) finds that within industries in Mexico the elasticity of the share of plant workers with tertiary degrees to plant sales is about 0.12 among exporting plants and 0.13 among non-exporting plants.

${ }^{6}$ To the best of our knowledge, we are the first to embed either the H-O or SBP mechanism into the new multi-country quantitative trade models to study inequality. Other models that combine elements of $\mathrm{H}-\mathrm{O}$ and either Ricardian or Krugman-style models include Trefler (1995), Davis (1995), Davis and Weinstein (2001), Romalis (2004), Bernard et al. (2007b), Chor (2010), and Hsieh and Ossa (2015). Unlike these papers, our focus is on the impact of globalization on the skill premium.
} 
equality using a 60-country model, whereas they build and structurally estimate a model to account for the link between trade and within-group inequality in Brazil. While our objective is to study the impact of trade on between-group inequality, if we allowed for unobservable differences in individuals' effective units of skill, our model would give rise to changes in measured within-group inequality.

\section{The Environment}

Our model economy features $N$ countries, indexed by $n$. In each country a final nontradable good, used for consumption and as an intermediate input in production, aggregates absorption of $J$ sectors. Sectors are divided into tradable merchandise sectors, $j=1, \ldots, J_{M}$, and non-tradable service sectors, $j=J_{M}+1, \ldots, J$. Sectoral absorption is a CES aggregator of a continuum of varieties, each of which can be produced domestically or imported from abroad subject to an iceberg trade cost. Producing individual varieties requires the intermediate input and skilled and unskilled labor. Aggregate quantities of inelastically supplied skilled and unskilled labor in country $n$ are $L_{n}$ and $H_{n}$, respectively. Labor is immobile across countries and, in our baseline, is perfectly mobile across firms and sectors within each country. Labor markets and final goods are perfectly competitive. Individual varieties are produced by firms that engage in Bertrand competition. We allow some parameters to vary across countries and some to vary across sectors; these choices are largely based on data availability. We now provide the details of this environment.

Production of the final good: Production of the final good, whose quantity in country $n$ is denoted by $Q_{n}$, is

$$
Q_{n}=\left(\sum_{j=1}^{J_{M}} Q_{n}(j)^{\frac{\sigma-1}{\sigma}}\right)^{\frac{\gamma_{n} \sigma}{\sigma-1}}\left(\sum_{j=J_{M}+1}^{J} Q_{n}(j)^{\frac{\sigma-1}{\sigma}}\right)^{\frac{\left(1-\gamma_{n}\right) \sigma}{\sigma-1}},
$$

where $\gamma_{n} \in[0,1]$ is the constant share of tradable merchandise in the final good in country $n$ (we relax this Cobb-Douglas assumption in sensitivity analysis) and $\sigma>0$ is the elasticity of substitution between sectors within merchandise and within services. Sector $j$ absorption, $Q_{n}(j)$, an input in the production of the final good $Q_{n}$, is

$$
Q_{n}(j)=\left(\int_{0}^{1} q_{n}(\omega, j)^{\frac{\eta-1}{\eta}} d \omega\right)^{\frac{\eta}{\eta-1}}
$$

where $q_{n}(\omega, j)$ is the absorption of variety $(\omega, j)$ in country $n$ and $\eta>0$ is the elasticity of 
substitution between varieties within each sector. Given prices $P_{n}, P_{n}(j)$ and $p_{n}(\omega, j)$ for the final good, sector $j$ absorption, and variety $(\omega, j)$, respectively, profit maximization by a competitive final good producer gives rise to the following demands

$$
Q_{n}(j)=\left(\frac{P_{n}(j)}{P_{n}}\right)^{-\sigma} Q_{n}
$$

and

$$
q_{n}(\omega, j)=\left(\frac{p_{n}(\omega, j)}{P_{n}(j)}\right)^{-\eta} Q_{n}(j)
$$

Goods within each $(\omega, j)$ are perfect substitutes and potentially produced in every country. The final good producer purchases each variety from the lowest-cost source in the world.

Production of individual varieties and international trade: In each country there are two potential producers per variety $(\omega, j)$. We denote by $z_{n}(\omega, j)$ and $z_{n}^{\prime}(\omega, j)$ the firmspecific productivity of the low and high cost producer of variety $(\omega, j)$ in country $n$. If the low cost country $n$ firm in variety $(\omega, j)$ employs $h$ and $l$ units of skilled and unskilled labor, respectively, and uses $m$ units of the final good as an intermediate input, it produces output $y$ according to the constant returns to scale production function

$$
y=A_{n}(j) z_{n}(\omega, j)\left[\alpha_{j}^{\frac{1}{\rho}}\left(z_{n}(\omega, j)^{\frac{\phi}{2}} h\right)^{\frac{\rho-1}{\rho}}+\left(1-\alpha_{j}\right)^{\frac{1}{\rho}}\left(z_{n}(\omega, j)^{\frac{-\phi}{2}} l\right)^{\frac{\rho-1}{\rho}}\right]^{\frac{\chi_{n} \rho}{\rho-1}} m^{1-\chi_{n}}
$$

where $\rho>0$ is the elasticity of substitution between skilled and unskilled workers at the level of an individual producer, $\chi_{n} \in(0,1]$ is the value added share of output in country $n$, and $A_{n}(j) \geq 0$ is the level of country-sector total factor productivity (TFP). The high cost country $n$ producer has the same production function but with $z_{n}^{\prime}(\omega, j)$ replacing $z_{n}(\omega, j)$. Both $\alpha_{j} \in(0,1)$ and $\phi \in\left[-2 / \chi_{n}, 2 / \chi_{n}\right]$ shape the skill-intensity of production, as we describe below in Section 3.

We introduce trade barriers using iceberg transportation costs. Delivering one unit of merchandise variety $(\omega, j)$ from country $i$ to country $n$ requires shipping $\tau_{\text {in }}(j) \geq 1$ units, where $\tau_{n n}(j)=1$ for all $n$ and $j$. We assume that there is no international trade in service sectors, setting $\tau_{\text {in }}(j)=\infty$ if $i \neq n$ in any service sector. We abstract from entrepôt trade by assuming that countries cannot re-export imported goods. Let $c_{i n}(\omega, j)$ and $c_{i n}^{\prime}(\omega, j)$ denote the unit cost for the low cost and high cost firms in country $i$ of supplying $(\omega, j)$ 
to country $n$,

$$
\begin{aligned}
c_{i n}(\omega, j)= & \left(1-\chi_{i}\right)^{\chi_{i}-1} \chi_{i}^{-\chi_{i}} \frac{\tau_{i n}(j)}{A_{i}(j) z_{i}(\omega, j)} P_{i}^{1-\chi_{i}} \\
& \times\left(\alpha_{j}\left(z_{i}(\omega, j)^{\frac{-\phi}{2}} s_{i}\right)^{1-\rho}+\left(1-\alpha_{j}\right)\left(z_{i}(\omega, j)^{\frac{\phi}{2}} w_{i}\right)^{1-\rho}\right)^{\frac{\chi_{i}}{1-\rho}}
\end{aligned}
$$

where marginal costs are decreasing in $z_{i}(\omega, j)$ in any sector $j$ given our restriction on $\phi$ and where $c_{i n}^{\prime}(\omega, j)$ is equivalent but with $z_{i}(\omega, j)$ replaced with $z_{i}^{\prime}(\omega, j)$. Firm productivities are i.i.d. random variables $z=u^{-\theta}$, where $u$ is exponentially distributed with mean and variance 1 in all countries. ${ }^{7} \mathrm{~A}$ higher value of $\theta>0$ increases the dispersion of productivity across firms. ${ }^{8}$

Competition and prices: Firms engage in Bertrand competition within each variety. With undifferentiated goods within each $(\omega, j)$, each country $n$ is supplied only by the lowestcost supplier in the world, and this supplier is constrained not to charge a price above the cost of the second-lowest cost supplier. With CES preferences across varieties within a sector, the unconstrained markup of the lowest-cost supplier is $\eta /(\eta-1)$. Denote the first- and second-lowest costs of supplying variety $(\omega, j)$ to country $n$ by $C_{n}(\omega, j)$ and $C_{n}^{\prime}(\omega, j)$, respectively, which are displayed in Appendix A. The price of variety $(\omega, j)$ in country $n$ is the minimum of the unconstrained monopoly price and the cost of the second lowest cost supplier,

$$
p_{n}(\omega, j)=\min \left\{C_{n}^{\prime}(\omega, j), \frac{\eta}{\eta-1} C_{n}(\omega, j)\right\} .
$$

Profits earned by country $n$ producers are distributed across country $n$ workers.

Aggregates: Expressions for aggregate prices $P_{n}$ and $P_{n}(j)$ are displayed in Appendix A. Sales from $n$ to $i$ in sector $j$ are given by

$$
X_{n i}(j)=\int_{\omega} p_{i}(\omega, j) q_{i}(\omega, j) \mathbb{I}_{n i}(\omega, j) d \omega
$$

where $\mathbb{I}_{n i}(\omega, j)$ is an indicator function that equals one if country $n$ exports variety $(\omega, j)$

\footnotetext{
${ }^{7}$ Specifically, for each $(i, \omega, j)$, we take two draws from the exponential distribution, $u_{i 1}(\omega, j)$ and $u_{i 2}(\omega, j)$, and set $z_{i}(\omega, j)=\max _{k \in\{1,2\}}\left\{u_{i k}(\omega, j)^{-\theta}\right\}$ and $z_{i}^{\prime}(\omega, j)=\min _{k \in\{1,2\}}\left\{u_{i k}(\omega, j)^{-\theta}\right\}$.

${ }^{8}$ Here we follow the convention of Alvarez and Lucas (2007), rather than Eaton and Kortum (2002), of letting a higher $\theta$ increase dispersion. As in these papers, we must constrain the values of $\eta$ and $\theta$ to have a well-defined price index when there is a continuum of varieties. With a finite number of varieties, as we assume in our quantitative analysis, the price level is always well defined.
} 
to country $i$ and equals zero otherwise. Country $n$ 's total exports to $i$ are $X_{n i}=\sum_{j} X_{n i}(j)$, gross output in country $n$ is $Y_{n}=\sum_{i} X_{n i}$, and net exports across all sectors in country $n$ are $N X_{n}=\sum_{i}\left(X_{n i}-X_{i n}\right)$. Finally, aggregate profits in country $n$ are

$$
\Pi_{n}=\sum_{j} \sum_{i} \int_{0}^{1}\left[p_{i}(\omega, j)-c_{n i}(\omega, j)\right] q_{i}(\omega, j) \mathbb{I}_{n i}(\omega, j) d \omega
$$

and GDP in country $n$ is equal to $s_{n} H_{n}+w_{n} L_{n}+\Pi_{n}$.

Market clearing: Total output of each variety $(\omega, j)$ in country $n$ must equal its world demand

$$
y_{n}(\omega, j)=\sum_{i} \tau_{n i}(j) q_{i}(\omega, j) \mathbb{I}_{n i}(\omega, j)
$$

Labor market clearing in each country requires

$$
L_{n}=\sum_{j} \int_{0}^{1} l_{n}(\omega, j) d \omega
$$

and

$$
H_{n}=\sum_{j} \int_{0}^{1} h_{n}(\omega, j) d \omega
$$

where $l_{n}(\omega, j)$ and $h_{n}(\omega, j)$ are the amounts of unskilled and skilled labor, respectively, used by the country $n$ firm selling variety $(\omega, j)$, displayed in Appendix A together with $m_{n}(\omega, j)$, the amount of intermediates used by this firm.

Denoting by $n x_{n}=N X_{n} / Y_{n}$ the value of net exports relative to gross output in country $n$, total absorption can be expressed as $P_{n} Q_{n}=\sum_{i} X_{i n}=Y_{n}\left(1-n x_{n}\right)$, which-together with the fact that gross output is equal to $Y_{n}=\left(s_{n} H_{n}+w_{n} L_{n}\right) / \chi_{n}+\Pi_{n}$-implies

$$
P_{n} Q_{n}=\left(\left(s_{n} H_{n}+w_{n} L_{n}\right) / \chi_{n}+\Pi_{n}\right)\left(1-n x_{n}\right) .
$$

We follow Dekle et al. (2008) in not fully specifying the determination of trade deficits. ${ }^{9}$ Specifically, we assume that the ratio of net exports to output, $n x_{n}$, is exogenously given in countries $n=1, \ldots, N-1$ and, in order to satisfy balanced trade at the world level,

$$
n x_{N}=-\sum_{n=1}^{N-1} n x_{n} Y_{n} / Y_{N}
$$

\footnotetext{
${ }^{9}$ As we show in sensitivity analysis in Appendix F, our results do not change much if we assume balanced trade in every country, $n x_{n}=0$. To endogenize net exports relative to output in every country, one could, for example, assume that countries have different levels of net foreign assets so that countries with positive net foreign assets run trade deficits. While this would leave our baseline parameterization unaffected-as net foreign assets would have to be chosen to match net exports in the data-solving our counterfactuals would require taking a stand on the details of the determination of asset positions and prices in general equilibrium.
} 
Finally, aggregate consumption in country $n$, is equal to $Q_{n}$ minus the aggregate use of the intermediate input in country $n$.

Equilibrium: An equilibrium of the world economy is a set of prices $P_{n}, P_{n}(j), p_{n}(\omega, j)$; indicator functions $\mathbb{I}_{n i}(\omega, j)$; wages $w_{n}, s_{n}$; quantities demanded $Q_{n}, Q_{n}(j), q_{n}(\omega, j)$; quantities produced $y_{n}(\omega, j)$; demand for factors $l_{n}(\omega, j), h_{n}(\omega, j)$ and intermediate inputs $m_{n}(\omega, j)$, and net exports relative to output in country $N, n x_{N}$, and aggregate consumption that satisfy, in each country: profit maximization by intermediate good firms (equation (5) and equations (22)-(24) in Appendix A); profit maximization by final good firms (equations (1) and (2)); goods and factor market clearing conditions (equations (8), (9), and (10)); budget constraints (equation (11)); trade balance at the world level (equation (12)); and the resource constraint for the final good. To solve for an equilibrium for a given set of parameter values, we guess a vector of wages, aggregate prices, and profits, solve for prices of individual varieties using equation (5), sectoral prices using equation (26) in Appendix A, aggregate absorption $Q_{n}$ using equation (11), net exports in country $N$ using equation (12), quantities $Q_{n}(j)$ and $q_{n}(\omega, j)$ using equations (1) and (2), and factor demands for individual varieties $l_{n}(\omega, j)$ and $h_{n}(\omega, j)$ using equations (22) and (23) in Appendix A. The equilibrium vector of wages, aggregate prices and profits must satisfy equations (7), (9), (10) and (25) in each country. ${ }^{10}$

\section{International Trade and the Skill Premium}

Three mechanisms link international trade and the skill premium in our model. The intuition for these mechanisms follows from the production function in equation (3), from which the equilibrium ratio of skilled to unskilled workers employed in a country $n$ firm producing variety $(\omega, j)$ is

$$
\frac{h_{n}(\omega, j)}{l_{n}(\omega, j)}=\frac{\alpha_{j}}{1-\alpha_{j}}\left(\frac{s_{n}}{w_{n}}\right)^{-\rho} z_{n}(\omega, j)^{\phi(\rho-1)} .
$$

The parameter $\alpha_{j}$ shapes skill intensity of production across sectors: if $\alpha_{j_{2}}>\alpha_{j_{1}}$, then in any country a firm in sector $j_{2}$ is more skill intensive than an equally productive firm in sector $j_{1}$. The parameter $\phi$, together with $\rho$, shapes the skill intensity of production across firms within sectors: if $\phi(\rho-1)>0$, then in any country a firm with productivity $z_{2}$ is more skill intensive than a firm in the same sector with productivity $z_{1}<z_{2}$, and we say

\footnotetext{
${ }^{10}$ Given that our model does not yield analytic gravity at any level of aggregation, we cannot use the existence and uniqueness results of Alvarez and Lucas (2007) or Allen et al. (2015). We only demonstrate existence numerically. We have not found any indications of multiple equilibria in our numerical work.
} 
that productivity is skill biased.

As in the Heckscher-Ohlin model, there is a force in our model such that reductions in trade costs cause factors to reallocate towards a country's comparative advantage sectors. If a country has a comparative advantage (as defined below) in skill-intensive sectors (those with high $\alpha_{j}$ s) then this between-sector reallocation will raise its skill premium; the opposite will occur in a country with a comparative advantage in unskill-intensive sectors. We call this the Heckscher-Ohlin $(\mathrm{H}-\mathrm{O})$ mechanism. As in standard heterogeneousfirm models such as BEJK and Melitz (2003), reductions in trade costs cause factors to reallocate towards exporting and away from domestic firms within each sector. Given that exporters are more productive than domestic producers on average, with skill biased productivity this within-sector reallocation will tend to raise the skill premium in all countries. We call this the skill-biased productivity (SBP) mechanism. Finally, the key assumptions that separately generate each mechanism — sectoral skill-intensity heterogeneity and skill-biased productivity-interact so that reductions in trade costs reallocate factors towards skill-intensive sectors and raise the skill premium in all countries. We call this the between-sector SBP mechanism.

In what follows we study each of these mechanisms analytically. Details are provided in Appendix D. To study the H-O and SBP mechanisms, in this section only we impose a number of restrictions on our general model. We assume that productivity is common across the two firms that can produce a given variety $(\omega, j)$ in each country so that the Bertrand outcome is equivalent to the perfectly competitive outcome. We assume that there are two countries, $n=1,2$; that trade costs are equal across sectors and symmetric across countries, $\tau=\tau_{12}(j)=\tau_{21}(j)$; that the elasticity of substitution between sectors is one, $\sigma=1$; that trade is balanced, $Y_{n}=P_{n} Q_{n}$; that all sectors are tradable, $\gamma_{n}=1$; and that the share of value added in production is one, $\chi_{n}=1$.

\subsection{The Heckscher-Ohlin (H-O) mechanism}

Here we additionally assume that there are two sectors, $j=x, y$ where sector $x$ is skill intensive, $\alpha_{y}<\alpha_{x}$; that production functions are Cobb Douglas, $\rho=1$; and that productivity is not biased towards either factor, $\phi=0$. Under these restrictions, the unit cost of country $n$ firms supplying variety $(\omega, j)$ to country $i$ simplifies to $c_{n i}(\omega, j)=$ $\tau_{n i} v_{n}(j) / z_{n}(\omega, j)$, where $v_{n}(j) \equiv \tilde{\alpha}_{j} s_{n}^{\alpha_{j}} w_{n}^{1-\alpha_{j}} / A_{n}(j)$ is the cost of sector $j^{\prime}$ s composite input in country $n$ and $\tilde{\alpha}_{j}$ is a constant.

In order to study the effects of trade on the skill premium under the assumptions imposed here, we introduce the concept of comparative advantage. We say that country 
1 has a comparative advantage in sector $x$ if country 1's unit cost of purchasing the sector $x$ composite input relative to the sector $y$ composite input is lower than country 2 's in autarky. As we show in Appendix D, country 1 has a comparative advantage in sector $x$ if

$$
a\left(\left(H_{1} / L_{1}\right) /\left(H_{2} / L_{2}\right)\right)^{\alpha_{x}-\alpha_{y}} \geq 1,
$$

where $a \equiv\left(A_{1}(x) / A_{1}(y)\right) /\left(A_{2}(x) / A_{2}(y)\right)$. Equation (14) is a generalization of comparative advantage in the Ricardian and H-O models. If $a=1$, so that there is no Ricardian comparative advantage, then country 1 has a comparative advantage in sector $x$ if it is skill abundant, $H_{1} / L_{1} \geq H_{2} / L_{2}$, exactly as in the Heckscher-Ohlin model. If endowment ratios are the same across countries, $H_{1} / L_{1}=H_{2} / L_{2}$, so that there is no H-O-based comparative advantage, then country 1 has a comparative advantage in sector $x$ if $a \geq 1$, exactly as in the Ricardian model. While comparative advantage is defined as a condition on relative costs in autarky, it is straightforward to show (see Appendix D) that if country 1 has a comparative advantage in sector $x$, then in any trade equilibrium country 1 's unit cost in sector $x$ relative to $y$ is lower than in country 2 for any given productivity $z$, $v_{1}(x) / v_{1}(y) \leq v_{2}(x) / v_{2}(y)$.

We impose equation (14) throughout this section so that country 1 has a comparative advantage in sector $x$; this is obviously without loss of generality. Hence, starting in autarky, a reduction in trade costs leads factors to reallocate towards the skill-intensive $x$ sector in country 1 and towards the unskill-intensive $y$ sector in country 2 . This increases the relative demand and, therefore, the relative wage of skilled labor in country 1 and unskilled labor in country 2. This result is summarized in the following Proposition.

Proposition 1. Under the assumptions of this section, moving from autarky to any positive level of trade increases $s_{1} / w_{1}$ and decreases $s_{2} / w_{2}$.

What determines the strength of the H-O mechanism? When there are no productivity differences between sectors and between varieties within sectors (as in the standard Heckscher-Ohlin model), the location of production of each variety is determined solely by trade costs and factor prices (which are determined by endowment ratio differences). Larger differences in relative endowments generate larger differences in relative factor prices and magnify the strength of the H-O mechanism.

However, in our model a given variety's location of production is determined not only by trade costs and factor prices, but also by country-sector-level productivities, $A_{n}(j)$, and variety-specific idiosyncratic productivities, $z_{n}(\omega, j)$. A higher value of $\theta$ raises the dispersion of firm-specific productivity draws. As in standard quantitative trade models, this reduces the partial elasticity of exports in each sector with respect to variable trade 
costs (the trade elasticity). Here, for the same reason, a higher value of $\theta$ also reduces the partial elasticity of exports in each sector with respect to composite input costs, $v_{n}(j)$, which are functions of country-sector-level productivities, $A_{n}(j)$, and wages, $s_{n}$ and $w_{n}$. This implies that between-sector comparative advantage is relatively less important for shaping trade patterns. Hence, a higher value of $\theta$ reduces the extent of between-sector factor reallocation and, therefore, changes in relative wages in response to a trade liberalization. On the contrary, a higher value of $a$ raises country 1's comparative advantage in sector $x$. This increases the extent of between-sector factor reallocation and, therefore, changes in relative wages in response to a trade liberalization. ${ }^{11}$ This result is summarized in the following Proposition, in which we vary parameters $a$ and $\theta$ holding trade shares (exports and imports relative to gross output) in each country fixed. ${ }^{12}$

Proposition 2. Under the assumptions of this section, if $\tau$ and $A_{1}(1) / A_{2}(1)$ are chosen to match fixed values of trade shares in each country, then the increase in $s_{1} / w_{1}$ and the decrease in $s_{2} / w_{2}$ caused by moving from autarky to these trade shares is decreasing in $\theta$ and increasing in $a$.

\subsection{The skill-biased productivity (SBP) mechanism}

Here, instead of the assumptions imposed in Section 3.1, we assume that there is one sector, $J=1$; the sector-level aggregator is Cobb Douglas, $\eta=1$; productivity is skilled biased, $\phi(\rho-1)>0$; and countries are symmetric, $H=H_{n}, L=L_{n}$, and $A_{n}(j)=1$ for $n=1,2$.

If $\phi$ were zero then reductions in trade costs would not affect the relative demand for skilled labor or the skill premium. Since we assume in this section that productivity is skill biased, $\phi(\rho-1)>0$, reductions in trade costs increase the skill premium by generating a reallocation of labor from low productivity and low skill-intensity firms to high productivity and high skill-intensity firms, on average. This result is summarized in Proposition 3.

Proposition 3. Under the assumptions in this section, $s / w$ is strictly decreasing in $\tau$.

The strength of the SBT mechanism is shaped by $\theta$ and $\phi$. A higher value of $\theta$ raises the dispersion of firm-specific productivity draws, which tends to increase the difference

\footnotetext{
${ }^{11}$ These results also hold in monopolistically competitive environments with heterogeneous firms; see e.g. Burstein and Vogel (2011a).

${ }^{12}$ In Proposition 2 we hold trade shares constant, rather than holding trade costs constant, while varying $\theta$ and $a$ for two reasons. First, as we increase $\theta$ holding trade costs constant, the impact on the skill premium is ambiguous because trade shares rise and greater volumes of trade tend to strengthen the $\mathrm{H}-\mathrm{O}$ effect, all else equal. Second, in our quantitative analysis we assess the strength of the $\mathrm{H}-\mathrm{O}$ effect by calibrating the model to match observed trade shares rather than (unobserved) trade costs.
} 
between the productivities of exporting firms and domestic firms. This raises the relative difference in skill intensities between these types of firms and, therefore, generates larger increases in the relative demand for skill and the skill premium in response to a trade liberalization. From equation (13), $\phi(\rho-1)$ is the elasticity of firm skill intensity to firm productivity. With $\phi(\rho-1)>0$, a higher value of $|\phi|$ (since $\rho$ need not exceed 1 ) increases the skill intensity of a high productivity firm relative to that of a low productivity firm, so that within-sector factor reallocation from contracting to expanding firms in response to a trade liberalization tends to raise by more the relative demand for skill and, therefore, the skill premium. ${ }^{13}$

\subsection{The between-sector SBP mechanism}

In our general model, i.e. not imposing any of the assumptions made for analytic tractability throughout Section 3, the interaction between factor-biased productivity (which requires $\phi \neq 0$ and $\rho \neq 1)$ and skill-intensity variation across sectors $\left(\alpha_{j} \neq \alpha_{j^{\prime}}\right)$ implies that the elasticity of unit costs of production to firm productivity varies with sector skillintensity. Specifically, if $\phi>0$ and $\rho \neq 1$, then unit costs of production are more sensitive to firm productivity in skill-intensive sectors. ${ }^{14}$ Moreover, this increased sensitivity of unit costs to differences in firm productivities in skill-intensive sectors is magnified by a higher share of value added (i.e. a higher $\chi_{n}$ ). Intuitively, if $\phi>0$ and $\rho \neq 1$, a higher productivity makes a firm relatively more efficient employing skilled labor. This force is stronger in more skill-intensive sectors, where skilled labor accounts for a larger share of value added, and the higher is the share of value added (i.e. labor) in gross output, since skilled labor accounts for a larger share of total cost.

Mathematically, if $\phi>0$ and $\rho \neq 1$, then-according to equation (4)—the elasticity of

\footnotetext{
${ }^{13}$ Note that all continuing firms within a sector reduce their skill intensity proportionately in response to the rise in the skill premium caused by a reduction in trade costs. In contrast, Bustos (2011) finds that skill intensity rises for trading firms relative to domestic firms during Argentina's trade liberalization. Our model can be consistent with this evidence if we redefine firms as a set of productivity draws across products so that the SBP mechanism is active within firms.

${ }^{14}$ The condition that $\phi>0$ and $\rho \neq 1$ neither implies nor is implied by skill-biased productivity, $\phi(\rho-1)>0$.
} 
unit cost with respect to firm productivity is higher in more skill-intensive sectors, ${ }^{15}$

$$
\phi>0 \text { and } \rho \neq 1 \Rightarrow \frac{d}{d \alpha_{j}}\left|\frac{d \log c_{n i}(\omega, j)}{d \log z(\omega, j)}\right|>0 .
$$

As discussed above, greater dispersion in unit costs in skill intensive sectors implies a lower trade elasticity in those sectors and, hence, larger trade volumes for given trade costs. Thus, the interaction between the key assumptions behind the H-O and SBP mechanisms generates a force that increases trade in more skill-intensive sectors in all countries and, therefore, reduces sector-level prices in more skill-intensive sectors. If the elasticity of substitution across sectors is greater than one, $\sigma>1$, then this reduction in sector-level prices in more skill-intensive sectors will tend to increase expenditure in skill-intensive sectors in all countries. Thus, the between-sector SBP mechanism causes factors to reallocate towards more skill-intensive sectors and, therefore, raises the skill premium in all countries.

Moreover, this relationship between the elasticity of unit cost to productivity and sectoral skill intensity is more pronounced the higher is the share of value added in gross output, $\chi_{n}$,

$$
\phi>0 \text { and } \rho \neq 1 \Rightarrow \frac{d^{2}}{d \alpha_{j} d \chi_{n}}\left|\frac{d \log c_{n i}(\omega, j)}{d \log z(\omega, j)}\right|>0 \text {. }
$$

Hence, while incorporating intermediates, i.e. reducing $\chi_{n}$ from one, increases the gains from trade-as has been shown in, e.g., Arkolakis et al. (2012)_it mitigates the betweensector SBP mechanism and, therefore, reduces the impact of trade on the skill premium.

\section{Quantitative implementation}

In this section we describe how we parameterize our model. We first describe what features of the data we use to assign values to the model's parameters and describe the algorithm that we employ to solve and calibrate the model. We then discuss our model's fit in terms of the target moments and additional statistics in the data that we do not target in our calibration. Additional details are available in Appendix B.

\footnotetext{
${ }^{15}$ These comparative statics are most clear in the extreme cases in which value added uses only unskilled or skilled labor. If value added uses only unskilled labor, i.e. $\alpha_{j}=0$, unit costs are proportional to $z(\omega, j)^{\left(\phi \chi_{n}-2\right) / 2}$, whereas if value added uses only skilled labor, i.e. $\alpha_{j}=1$, unit costs are proportional to $z(\omega, j)^{\left(-\phi \chi_{n}-2\right) / 2}$. Hence, the elasticity of unit costs to productivity is higher in the sector using only skilled labor than in the sector using only unskilled labor if $\phi>0$, since in this case $\left|\left(-\phi \chi_{n}-2\right) / 2\right|>\left|\left(\phi \chi_{n}-2\right) / 2\right|$. Moreover, the difference between these two elasticities is increasing in $\chi_{n}$.
} 


\subsection{Parameterization}

We parameterize the model using data between the years 2005-2007, where possible. For one of our counterfactual exercises we consider an alternative parameterization using data between the years 1975-1977, where possible. We consider a 61-country version of our model, with 60 countries $(n=1, \ldots, N-1)$ plus the rest of the world $(n=N)$, where the rest of the world (henceforth ROW) aggregates data from 88 countries. The 60 countries that we include, which are listed in Table 3 of Appendix B, account for approximately $93 \%$ of world GDP in our time period.

We define a skilled worker in the data as one who has completed at least a tertiary degree. We define merchandise sectors as tradable good producing industries (i.e. agriculture, mining, and manufacturing exclusive of recycling) and service sectors as the remaining sectors, using International Standard Industrial Classification (ISIC) Revision 3 industry classifications. This yields 76 merchandise sectors (17 in non-manufacturing and 60 in manufacturing) and 81 service sectors. In order to reduce the randomness in aggregates arising from the finite number of firms per sector, we include a large number of varieties per sector (4000 per merchandise sector and 1000 varieties per service sector). ${ }^{16}$ We use merchandise trade data from Comtrade, abstracting from trade in services. All of the output and trade measures that we use are denominated in current U.S. dollars.

Our general parameterization strategy is as follows. We group parameters into two categories. The first category includes parameters to which we can directly assign values without having to solve the model: the elasticities of substitution across goods, $\sigma$ and $\eta$, the sector-level skill intensity parameters, $\alpha_{j}$, and each country's skill endowment ratio, $H_{n} /\left(H_{n}+L_{n}\right),{ }^{17}$ merchandise share of absorption, $\gamma_{n}$, share of value added in intermediate inputs, $\chi_{n}$, and net exports relative to output, $n x_{n}$, in countries $n=1, \ldots, N-1$.

The second category includes parameters that we choose so that endogenous outcomes from the model match certain features of the data: the elasticity between skilled and unskilled workers at the firm level, $\rho$, the elasticity of skill intensity to firm productivity, $\phi(\rho-1)$, the dispersion of firm-level productivities, $\theta$, trade costs, $\tau_{i n}(j)$, which we write as $\tau_{\text {in }}(j) \equiv t_{\text {in }} \times t_{\text {in }}(j)$, and country-sector-level productivity parameters, $A_{n}(j)$, which we write as $A_{n}(j) \equiv a_{n} \times a_{n}(j)$ where $a_{n}$ denotes aggregate productivity and $a_{n}(j)$ denotes sectoral productivity in country $n$. To reduce the number of sectoral productivity parameters, $a_{n}(j)$, we partition all merchandise sectors, $j$, into 7 groups, $j \in \mathcal{J}(g)$.

\footnotetext{
${ }^{16}$ While services are non-traded, we need to include multiple varieties so that markups do not vary systematically between tradable and non-tradable industries (which would give rise to additional effects from trade on the skill premium). Our results are not very sensitive to further increases in the number of varieties.

${ }^{17}$ Without loss of generality, we normalize $H_{n}+L_{n}=1$.
} 
The 17 non-manufacturing sectors (agriculture, mining, etc.) are included in group $g=1$ and the remaining 59 sectors are partitioned into 6 groups of increasing skill intensity: if $j \in \mathcal{J}(g), j^{\prime} \in \mathcal{J}\left(g^{\prime}\right)$, and $1<g<g^{\prime}$, then $\alpha_{j}<\alpha_{j^{\prime}}$. We impose that all sectors within each group $g$ have the same $a_{n}(j)=\bar{a}_{n}(g)$ and normalize the average productivity across groups to one in each country. ${ }^{18}$ For service producing sectors we set $a_{n}(j)=1$. In sensitivity analysis we set $a_{n}(j)=1$ as well for all merchandise sectors.

While we allow $H_{n} /\left(H_{n}+L_{n}\right), A_{n}(j), \tau_{i n}(j), \gamma_{n}$, and $\chi_{n}$ to all vary across countries, we impose that $\theta, \rho, \phi$, and $\alpha_{j}$ are all constant across countries because of data availability. We show below that in spite of this parsimony, the model does reasonably well where data from a range of countries is available.

\subsubsection{Parameters assigned directly without solving the model}

We choose country skill endowments, $H_{n} /\left(H_{n}+L_{n}\right)$, to match the share of workers 25 years and older with a completed tertiary degree (i.e. university graduates and postgraduates) from the Barro and Lee (2013) dataset for the year 2005. We set $\alpha_{j}$ to match the share of hours worked in sector $j$ by workers with a completed tertiary degree in the U.S. (restricting the sample to respondents who are employed and are at least 25 years old), which we obtain from the 2007 American Community Survey (ACS) from IPUMS; see Ruggles et al. (2015). ${ }^{19}$ We set the sectoral, bilateral component of trade costs, $t_{\text {in }}(j)$, equal to bilateral import tariffs at the two digit level for manufacturing sectors (and $t_{\text {in }}(j)=1$ for non-manufacturing merchandise sectors) from UNCTAD Trade Analysis Information System (TRAINS) for the year 2007. ${ }^{20}$ We set $n x_{n}$ to match the ratio of merchandise net exports relative to total gross output in our 60 countries; $n x_{N}$ is endogenously determined to satisfy balanced trade at the world level. We set $\gamma_{n}$ using trade data and shares of mer-

\footnotetext{
${ }^{18}$ Identifying $a_{n}(j)$ for each country-sector pair directly by estimating productivity is impractical given data availability. Alternatively, we could estimate a sector-level gravity equation in the data and in our model, and choose $a_{n}(j)$ to match the resulting country fixed effects; see e.g. Levchenko and Zhang (2015). This approach, however, is computationally intensive since our model does not yield analytic gravity equations.

${ }^{19}$ Our model implies that factor intensities vary across firms within a sector because of skill-biased productivity and heterogeneous productivity. In the U.S., for example, the model's implied standard deviation of the log share of skilled workers across firms for the median merchandise sector is 0.1 - in comparison, the standard deviation of the log share of skilled workers across merchandise sectors is 0.46 . In practice firms with the same $z$ within a sector may also have heterogeneous skill intensities, so that the H-O mechanism is active within sectors; see Feenstra (2010). In our sensitivity analysis we consider a version of the model in which we allow for $\alpha$ to vary within sectors. We show that the SBP mechanism strengthens by more than the $\mathrm{H}-\mathrm{O}$ mechanism, so that trade increases the skill premium by more than in our baseline specification.

${ }^{20}$ In sensitivity analysis we show that the results are roughly unchanged if we assume that tariff revenues are rebated to consumers.
} 
chandise in total gross output from input-output tables and we set $\chi_{n}$ equal to the ratio of value added in gross output in the overall economy, also from input-output tables. These shares are imputed for the 10 countries for which the input-output tables are unavailable. Finally, we set $\sigma=\eta=2.7$ to match the median 5-digit SITC elasticity of substitution between 1990 and 2001 estimated by Broda and Weinstein (2006). ${ }^{21}$

\subsubsection{Parameters assigned to match endogenous outcomes from the model}

This leaves the following parameters, $a_{n}, \bar{a}_{n}(g), t_{i n}, \rho, \theta$, and $\phi$, which we choose simultaneously such that the model's outcomes match certain features of the data, which we now describe.

Aggregate bilateral exports and output: We assign values to $N-1$ relative aggregate productivities, $a_{n}$, and $N \times(N-1)$ aggregate bilateral trade costs, $t_{i n}$-yielding a total of $(N-1) \times(N+1)=3720$ parameters-by targeting $N-1$ relative outputs, $Y_{i} / \sum_{n} Y_{n}$, as well as $N^{2}$ exports from each origin $i$ to each destination $n$ relative to the sum of merchandise output in the two countries. As is well known-see e.g. Waugh (2010) and Allen et al. (2014) — trade models that yield analytic gravity equations are under-identified, and in the Parameterization Appendix we show that the same is true in our model: of the $N^{2}+N-1$ targets, only $N \times(N-1)$ are independent. In Appendix $C$ we describe a number of ways we solve this issue, all of which yield very similar results.

Aggregate elasticity of substitution between skilled and unskilled labor in the U.S.: Katz and Murphy (1992) estimate that this elasticity is 1.4 whereas Acemoglu and Autor (2010) estimate that it is between 1.6 and 1.8. We target a value for this elasticity of 1.5, calculating this aggregate elasticity in our model using the approach of the previously mentioned papers on data generated by our model: we feed in a one-time exogenous change in the stock of skilled labor in the U.S. in our baseline parameterization and calculate $\Delta\left[\log \left(\frac{H_{U S}}{L_{U S}}\right) / \log \left(\frac{w_{U S}}{s_{U S}}\right)\right]$. Note that if $\phi(\rho-1)=0$ and there is only one sector, then $\rho$, the elasticity of substitution between skilled and unskilled labor at the firm level, equals the aggregate elasticity in our model; in this case, we would have $\rho=1.5$. With $\phi(\rho-1)>0$ and many sectors, $\rho$ and the aggregate elasticity are still tightly linked. We obtain a value of $\rho=1.43$ because labor reallocation to skill-intensive firms and sectors produces a smaller decrease in the skill premium for the same increase in $H / L$.

\footnotetext{
${ }^{21}$ In our baseline specification we set $\sigma=\eta$ to avoid taking a stand on the relationship between average skill intensity in production and substitutability in demand. In the sensitivity analysis we consider lower values of the elasticity of substitution across sectors within merchandise and services, $\sigma$. Setting $\eta=2.7$ implies a maximum markup of roughly 59\%. However, in our baseline parameterization the weighted average markup across producers within each country ranges between $21.6 \%$ and $24.7 \%$ across countries.
} 
Aggregate elasticity of trade: There is a large literature estimating the aggregate elasticity of trade with respect to variable trade costs. A standard procedure to obtain an estimate of this elasticity is to regress $\log \left[X_{i n} X_{n i} /\left(X_{i i} X_{n n}\right)\right]$ on $\log \left(\bar{\tau}_{i n} \bar{\tau}_{n i}\right)$, where $\bar{\tau}_{i n}$ denotes a measure of an observable component of trade costs between $i$ and $n$. We run this regression on data generated by our model-where $\bar{\tau}_{\text {in }}$ is the average bilateral trade cost across merchandise industries-targeting a value of 5, which Head and Mayer (2013) report as the central value in the literature. Under a number of restrictions in our model-if $\phi(\rho-1)=0$, trade costs in each country are equal across sectors, and there are a continuum of firms - then the aggregate trade elasticity is simply the inverse of the dispersion of firm-level productivities, $\theta$; in this case, we would have $\theta=0.2$. In our parameterization, in which all of these restrictions are violated, $\theta$ and the aggregate trade elasticity are still tightly linked (and the relationship between $\log \left[X_{i n} X_{n i} /\left(X_{i i} X_{n n}\right)\right]$ and $\log \left(\bar{\tau}_{i n} \bar{\tau}_{n i}\right)$ is close to $\log$ linear). We obtain a value of $\theta=0.22$.

Elasticity of skill intensity with respect to plant size in Mexican manufacturing: We consider the following regression

$$
\log \left[\frac{h_{i}}{h_{i}+l_{i}}\right]=\psi_{0}+\psi_{1} \log \text { Sales }_{i}+\text { SectorFE }_{i}+\varepsilon_{i}
$$

where $h_{i} /\left(h_{i}+l_{i}\right)$ is the share of the workforce in plant $i$ that has completed a tertiary degree, Sales $s_{i}$ is plant $i$ sales, and SectorF $E_{i}$ is a sector fixed effect. From unpublished Mexican manufacturing plant-level data for 1998 (from the Encuesta Industrial Anual, which excludes maquiladoras), Verhoogen $(2004,2008)$ estimates this elasticity to be $\psi_{1}=0.136$. To determine the value of this elasticity in our model, we estimate equation (17) on Mexican merchandise producers using simulated data. Note that in our model if $\phi(\rho-1)=0$ then $\psi_{1}=0$, and if $\phi(\rho-1)>0$ then $\psi_{1}>0$. We obtain a value of $\phi(\rho-1)=0.43$; given $\rho=1.43$, this implies $\phi=1$.

Sectoral trade balance and skill intensity: In each country, we choose the sectoral component of productivity for each group of sectors, $\bar{a}_{n}(g)$, targeting the ratio of net exports normalized by total trade summed across all sectors $j$ in group $g$ relative to the average across groups, $v_{n}(g)-\bar{v}_{n}$, where

$$
v_{n}(g)=\frac{\sum_{j \in \mathcal{J}(g)} \sum_{i}\left[X_{n i}(j)-X_{i n}(j)\right]}{\sum_{j^{\prime} \in \mathcal{J}(g)} \sum_{i}\left[X_{i n}\left(j^{\prime}\right)+X_{n i}\left(j^{\prime}\right)\right]}
$$

and $\bar{v}_{n}=\frac{1}{7} \sum_{g} v_{n}(g)$. Recall that manufacturing sectors are sorted into groups by their skill intensities, $\alpha_{j}$. Therefore, this statistic captures the extent to which countries have 
a revealed comparative advantage (i.e. they have relatively higher net exports) in sector groups that are more or less skill intensive. We target the systematic relationship between comparative advantage and skill intensity because in our model the impact of trade on the skill premium caused by between-sector factor reallocation depends on the extent to which factors reallocate towards or away from skill-intensive sectors on average, rather than the extent to which factors reallocate towards or away from each individual sector. ${ }^{22}$

\subsubsection{Calibration procedure and solution algorithm}

Our procedure to assign parameter values and solve the model given parameter values, which we describe in detail in Appendix B.2, involves three nested loops. In the outer loop we iterate over $\rho, \theta$, and $\phi$ to match targets described above: the aggregate elasticity of substitution between skilled and unskilled labor, the aggregate elasticity of trade, and the elasticity of skill intensity with respect to size. In the middle loop, we iterate over $a_{n}$, $t_{i n}$, and $\bar{a}_{n}(g)$ to match targets described above: aggregate bilateral exports and output as well as the relationship between sectoral trade balance and skill intensity. Given parameter values, the inner loop solves the equilibrium of our model numerically, iterating over $w_{n}, s_{n}, P_{n}$, and the aggregate profit share in labor income $\pi_{n}=\Pi_{n} /\left(w_{n} L_{n}+s_{n} H_{n}\right)$, to satisfy the equilibrium conditions. We use the inner loop alone to solve our counterfactual exercises.

\subsection{Model fit}

Table 1 displays the fit of the three moments we use to parameterize $\rho, \theta$, and $\phi$. We now discuss the fit of the model relative to the bilateral trade and output data that we targeted as well as a range of moments that we do not explicitly target.

\begin{tabular}{cccc}
\hline & Parameter & \multicolumn{2}{c}{ Moment } \\
& value & Target & Model \\
\hline$\rho$ & 1.43 & 1.50 & 1.49 \\
$\theta$ & 0.22 & 5.00 & 5.03 \\
$\phi$ & 1.00 & 0.136 & 0.136 \\
\hline
\end{tabular}

Table 1: Fit of the three moments we use to parameterize $\rho, \theta$, and $\phi$.

\footnotetext{
${ }^{22}$ In the data, countries that are relatively skill scarce tend to have relatively higher net exports in sectors that are less skill intensive. In our model, differences in skill endowments across countries generate this variation across sectors even if $\bar{a}_{n}(g)=1$ for all $n$ and $g$, as in a standard H-O model. We consider this alternative parameterization - which is consistent with empirical evidence in Morrow (2010) for a smaller set of countries and for more aggregated sectors-in the sensitivity analysis.
} 


\subsubsection{Bilateral trade and output}

Figure 1 plots the model's fit relative to the data for three moments that we target directly. In panel A we plot exports/output and imports/output in merchandise. In panel $B$ we plot demeaned net exports relative to total trade (normalized net exports) for each country in each of the seven sector groupings, $v_{n}(g)-\bar{v}_{n}$. The fit of each of these plots is almost perfect in the sense that regressing the model's implied values on the values in the data yields an $R^{2}$ very close to one in each case (the same is true for the fit of output). In panel $C$ we plot log bilateral exports for all origin-destination pairs for which the model does not imply zero trade. ${ }^{23}$ The model yields predictions that are very close to the values in the data-regressing $\log \left(X_{i n}\right)$ in the data on the value predicted by the model yields an $R^{2}$ equal to 0.998 - especially for large trade flows.
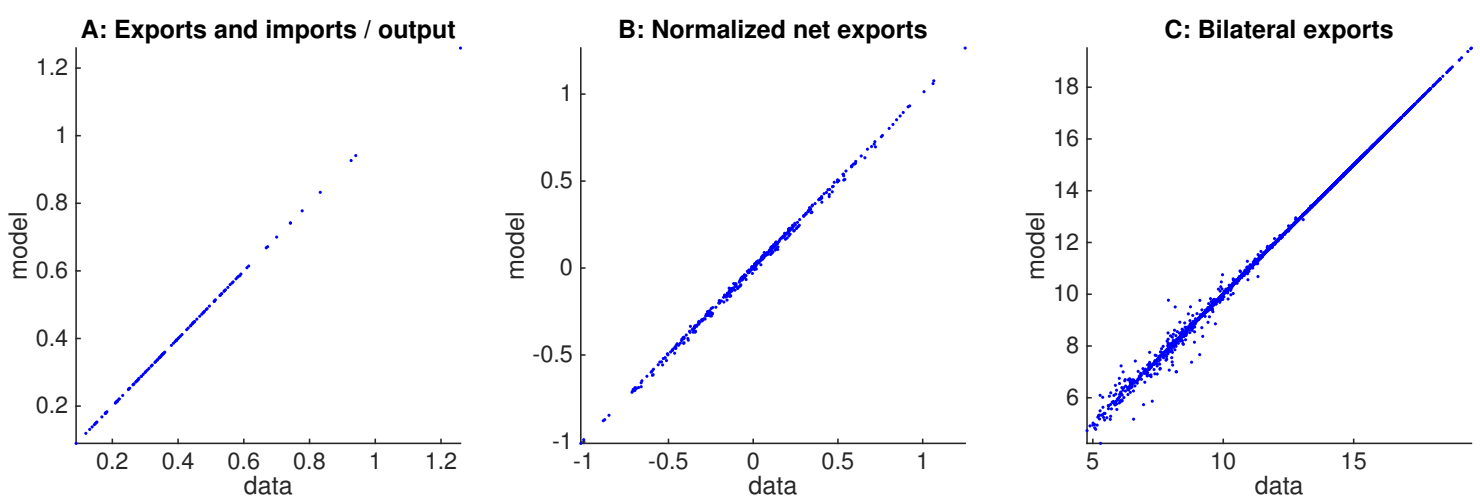

Figure 1: Model's fit in terms of (A) exports/output and imports/output in merchandise, (B) demeaned net exports relative total trade for each country-sector group, and (C) $\log$ bilateral exports.

\subsubsection{Skill-biased productivity}

Whereas in parameterizing the strength of skill-biased productivity, $\phi$, we target the elasticity of plant skill intensity to plant sales (controlling for sector) using Mexican manufacturing data, we can also compare our model's predictions both qualitatively and quantitatively in other countries and for other related moments.

\footnotetext{
${ }^{23}$ Out of the $M \times(M-1)=3660$ origin-destination pairs, the model implies zero trade for the 106 origin-destination pairs for which we set $t_{i n}=\infty$ (those with very small bilateral trade levels, as described in the Appendix) as well as for an additional 23 origin-destination pairs with finite trade costs (similar to Eaton et al. (2012), our model with a discrete number of varieties can generate zero bilateral exports even with finite trade costs). The origin-destination pairs with zero trade account for less $0.001 \%$ of total world trade between our 61 countries (including the rest of the world).
} 
We begin by considering an alternative moment shaped by $\phi$ in Mexico. We calculate the exporter skill-intensity premium (controlling for sector) by running the following regression at the producer level,

$$
\log \left[\frac{h_{i}}{h_{i}+l_{i}}\right]=\psi_{0}+\psi_{1} \text { Exporter }_{i}+\text { SectorFE }_{i}+\varepsilon_{i}
$$

in both the model and the data. Here, $h_{i} /\left(h_{i}+l_{i}\right)$ is the share of the workforce in plant $i$ that has completed a tertiary degree, Exporter $r_{i}$ is a plant-level exporter dummy variable, and $\operatorname{Sector} F E_{i}$ is a sector fixed effect. Using data generated by the model we find that $\psi_{1}=0.23$ for Mexican merchandise firms. From unpublished Mexican manufacturing plant-level data for 1998, Verhoogen (2008) estimates $\psi_{1}=0.21$. Hence, our model also does reasonably well in matching the exporter skill intensity premium in Mexico.

Our model yields predictions for all 60 countries in our sample, not only for Mexico. We now consider our model's quantitative implications for Brazil. Using data for Brazilian merchandise firms generated by the model, we obtain an elasticity of firm skill intensity to sales controlling for sector-equivalent to the target moment used to calibrate $\phi$ but for Brazil instead of Mexico-equal to 0.22. In unpublished results, Menezes-Filho et al. (2008)—using data from the 1995 Pesquisa Industrial Anual survey of large manufacturing Brazilian firms-estimate that this elasticity is 0.36 in the data. We also calculate the elasticity of firm skill intensity to domestic sales (as opposed to total sales) controlling for sector. Using data for Brazilian merchandise producers generated by the model we obtain an elasticity equal to 0.30 . In unpublished results, Menezes-Filho et al. (2008) estimate that this elasticity is 0.34 in the data. Therefore, our model does reasonably well in accounting for the relationship between firm-level skill intensity and firm-level outcomes in Brazil as well. Moreover, the model predicts correctly that the elasticity of firm skill intensity to firm sales is higher in Brazil than in Mexico. ${ }^{24}$

We can also compare our model's predictions for U.S. producers with U.S. data. The model over-predicts the share of U.S. merchandise producers that export, which is $54 \%$ in the model. Bernard et al. (2007a) report that the fraction of exporting firms in U.S. trad-

\footnotetext{
${ }^{24}$ Eslava et al. (2015) report a similar relationship using data on a cross-section of manufacturing plants in Colombia in 1988. They find that the share of white-collar workers is higher across plants with larger domestic sales within sectors. We obtain a similar qualitative pattern, although quantitatively their numbers are not directly comparable to those implied by our model because Eslava et al. (2015) do not observe worker education and the share of white-collar workers in Colombian manufacturing is much higher than the share of college educated workers. Similarly, Bustos (2011) shows that exporting industrial firms are more college intensive than non-exporting firms in 4-digit ISIC manufacturing industries in Argentina. We obtain a similar qualitative pattern, although the regression coefficients are not directly comparable because Bustos (2011) conditions on being a continuing exporter, a new exporter, and an exiting exporter.
} 
able goods industries and manufacturing in 2002 was $15 \%$ and $18 \%$, respectively. This overstatement of the fraction of exporters is similar to that found in BEJK. Matching the data on this margin would require incorporating a fixed cost of exporting into the model. However, the model does well in predicting the share of exporters' revenues in total merchandise revenues. In the model, this share is $67 \%$ in the U.S., whereas from BEJK it can be inferred that it is $60 \%$ for U.S. plants in manufacturing using the 1992 Census of Manufactures. ${ }^{25}$ Similarly, the model does well in predicting the exporter premium for value added per worker in the U.S. Specifically, if we regress the log of value added per worker on an export status indicator and a sector fixed effect in U.S. merchandise producer-level data generated by the model, we obtain an exporter premium of 0.14 log points. ${ }^{26}$ Bernard et al. (2007a) run the same regression on U.S. manufacturing firm-level data from the 2002 Census of Manufactures and obtain an exporter premium of 0.11 .

We can also calculate the elasticity of U.S. producer skill intensity to sales controlling for sector, equivalent to the target moment used to calibrate $\phi$ but for the U.S. instead of Mexico. Using data generated by our model, we obtain an elasticity of 0.08 for U.S. merchandise producers. Bernard et al. (2007a) run the same regression for U.S. manufacturing firms using the 2002 Census of Manufactures-but using the share of non-production workers rather than the share of workers with a college degree-and obtain an elasticity of 0.11 . While our model's implications are qualitatively consistent with this data, the two numbers are not directly comparable because of the different definitions of skilled workers. ${ }^{27}$

In summary, although we parameterize a single value of $\phi$ for all countries using Mexican data, our model does reasonably well in accounting for a range of quantitative facts in Mexico, Brazil, and the U.S. and qualitative patterns elsewhere.

\footnotetext{
${ }^{25}$ In particular, BEJK report, using the 1992 Census of Manufactures, that the average exporting plant's sales is 5.6 times larger than those of the average non-exporting plant, and $21 \%$ of plants are exporters. From these two observations, it follows that the share of exporters revenues in total revenues is equal to $\left([5.6 *(0.21 / 0.79)]^{-1}+1\right)^{-1} \approx 0.6$.

${ }^{26}$ This variation in value added per worker stems mostly from differences in markups across producers, as in BEJK, and not from variation in skill intensity across producers within sectors. With perfect competition, the difference in value added per worker between exporters and non-exporters in the U.S. is positive but close to zero.

${ }^{27}$ Relatedly, in Figure 10 in Appendix B we use the March CPS to show that the share of workers with a college degree is larger in larger firms (where firms are grouped into size bins). While our model is qualitatively consistent with this pattern, we do not attempt to match it quantitatively given the small number of firm size bins in the data.
} 


\subsubsection{Skill intensities, trade shares, and trade elasticities across sectors}

As described in Section 3.3, the interaction between $\phi>0$ (combined with $\rho>1$ ) and skill-intensity variation across sectors implies that unit costs of production are more sensitive to differences in firm productivities in skill-intensive sectors. This implies a lower absolute value of the elasticity of trade to variable trade costs and higher trade volumes (given trade costs) in more skill-intensive sectors in all countries. Here we document two novel empirical patterns that provide support for these implications.

The first pattern that we document is the relationship in each country between sectoral trade normalized by absorption-the ratio of exports plus imports to absorption in country $i$ and sector $j$-and sectoral skill intensity in 3-digit manufacturing ISIC sectors. Specifically, for each country $i$ and manufacturing sector $j$ pair, we use sectoral exports and imports (Comtrade) and sectoral gross output data (UNIDO) to construct the log of normalized trade in 2007 and regress this-separately for each country $i$ - on the log of U.S. skill intensity of sector $j$ in 2006, defined as the share of hours worked in sector $j$ by college educated workers,

$$
\log \frac{\sum_{n}\left[X_{i n}(j)+X_{n i}(j)\right]}{P_{i}(j) Q_{i}(j)}=\psi_{0 i}+\psi_{1 i} \log \frac{H_{U S}(j)}{H_{U S}(j)+L_{U S}(j)}+\varepsilon_{i}(j)
$$

To maximize the number of countries for which we run this regression (the data limitation is on gross output at the 3-digit level), we do not restrict the sample to the 60 countries in our baseline exercise; see Table 4 in Appendix B for a list of countries considered and results. In the data, all but one of the 46 countries with at least 30 manufacturing sector observations have a positive coefficient on sectoral skill intensity, $\psi_{1 i}>0$, the exception being Mexico. For instance, the U.S. and the U.K. have coefficients of 0.92 and 0.31 , respectively. Moreover, in 14 (19) of these 45 countries the coefficients are statistically significant at the $5 \%(10 \%)$ level, while the one negative coefficient is both insignificant and close to zero.

When we run this regression using simulated data from our model's baseline parameterization, all but 4 of the 60 countries have a positive coefficient. For instance, the U.S. and the U.K. have coefficients of 0.31 and 0.33 , respectively. Of the 56 countries with a positive coefficient, 52 are significant at the $5 \%$ level, and of the 4 countries with a negative coefficient none is statistically significant at the $10 \%$ level. In contrast, in the absence of skill-biased productivity (setting $\phi=0$ ) the model predicts a positive and significant coefficient in only 4 (5) of the 60 countries at the $5 \%(10 \%)$ significance level. For the remaining 56 countries (including the U.S.), the coefficient is either negative or not statis- 
tically different from zero.

In our model, the relationship between normalized trade and sectoral skill intensity is driven by endogenous differences across sectors in the absolute value of the elasticity of trade to variable trade costs (the sectoral trade elasticity). Specifically, more skill-intensive sectors have lower trade elasticities (in absolute value). The second pattern that we document is the relationship between the sectoral trade elasticity and sectoral skill intensity. Although our model does not generate a closed-form sector-level gravity equation, we can estimate such an equation both in the data and the model,

$$
\log \frac{X_{\text {in }}(j)}{X_{n i}(j)}=F E_{i}(j)-F E_{n}(j)-\psi_{1}\left(1+\psi_{2} \frac{H_{U S}(j)}{H_{U S}(j)+L_{U S}(j)}\right) \log \frac{\tau_{\text {in }}(j)}{\tau_{n i}(j)}+\varepsilon_{\text {in }}(j),
$$

where $F E_{i}(j)$ is a country-sector fixed effect. In the previous equation we take the ratio of $X_{i n}(j) / X_{n i}(j)$ because-in a model with a closed-form gravity equation-this cancels out any symmetric components of trade costs between $i$ and $n$ in sector $j$. A positive value of $\psi_{2}$ implies that the absolute value of the trade elasticity is lower in more skillintensive sectors. In the data, where we use tariffs as our measure of observable trade costs, we estimate the previous equation using our sample of 60 countries and using 2 digit manufacturing ISIC sectors (15-36) for 2005, 2006, and 2007. We report our results in Table 2. More skill-intensive sectors have lower trade elasticities (in absolute value) in the data in every year, and this difference is statistically significant in 2006 and 2007, although not in 2005. The same qualitative relationship holds in our baseline model. However, if we impose that productivity is not skill biased by setting $\phi=0$, then the model predicts that the trade elasticity is actually weakly higher (but insignificantly so) in more skillintensive sectors.

\begin{tabular}{|c|c|c|c|c|}
\hline & & Data & & Model \\
\hline & 2005 & 2006 & 2007 & \\
\hline$\psi_{1}$ & $3.7^{* * *}$ & $4.94^{* * *}$ & $4.6^{* * *}$ & $5.04^{* * *}$ \\
\hline$\psi_{2}$ & -2.8 & $-9.70^{* * * *}$ & $-6.2^{*}$ & $-1.99 * * *$ \\
\hline
\end{tabular}

Table 2: Sectoral trade elasticities in the data and the model.

Notes: Estimated using 2 digit manufacturing ISIC sectors: $15-36 .{ }^{* * *}$ indicates statistically significantly different from zero at the $1 \%$ level; ${ }^{* *}$ at the $5 \%$ level; ${ }^{*}$ at the $10 \%$ level.

In summary, our model is consistent with two related and novel empirical patterns: there is more trade (relative to absorption) in more skill-intensive sectors and the (absolute value of the) trade elasticity is lower in more skill-intensive sectors. Our model rationalizes these qualitative patterns through the interaction between skill-biased productivity and sectoral variation in skill intensity. In order to fully account quantitatively 
for these patterns, we would have to allow for additional sources of heterogeneity across sectors (e.g. dispersion of firm productivities) which we omit from our baseline model.

\section{Counterfactuals}

We use the parameterized model to conduct a series of counterfactuals in which we vary trade costs. We consider a change in trade costs such that countries move from autarky to the baseline 2006 parameterization as well as a reduction in trade costs such that countries move from autarky to an alternative 1976 parameterization. We also reduce trade costs $10 \%$ from our baseline parameterization. Across these exercises we find that reducing trade costs increases real wages for both factors of production in almost all countries, but tends to raise the skilled real wage more than the unskilled real wage; i.e., the skill premium rises in almost all countries. Whereas our first three counterfactuals focus on changes in trade costs, in our final two exercises we focus on technical change. First we study the implications of growth in China's TFP on the skill premium of its trading partners. Finally, we study the implications of global skill-biased technical change on trade shares.

\subsection{Autarky to Baseline Parameterization}

We consider a reduction in trade costs, moving each country from autarky to the baseline parameterization.

Panel A of Figure 2 plots $100 \times$ the log change in the real wage in the baseline parameterization relative to autarky (henceforth either the log change or the percentage change) for skilled and unskilled labor plotted against the aggregate trade share (the average of exports and imports relative to total gross output in 2006) for each country, excluding the rest of the world. Note that the real wage rises for both skilled and unskilled workers in all countries. As in standard quantitative trade models, real wage gains of moving away from autarky are rising in trades shares; see e.g. Arkolakis et al. (2012). ${ }^{28}$

Panel A of Figure 2 also highlights that the gains from trade liberalization are unevenly distributed within countries in our model. For instance, whereas a skilled worker's real wage rises by approximately $27 \%$ and $5 \%$ in Costa Rica and the U.S., an unskilled worker's real wage rises by only $17 \%$ and $3 \%$, respectively.

\footnotetext{
${ }^{28}$ In our model, the change in the real wage of the representative consumer differs from the change in welfare because profits and net exports are not zero.
} 


\section{A: Real wage}

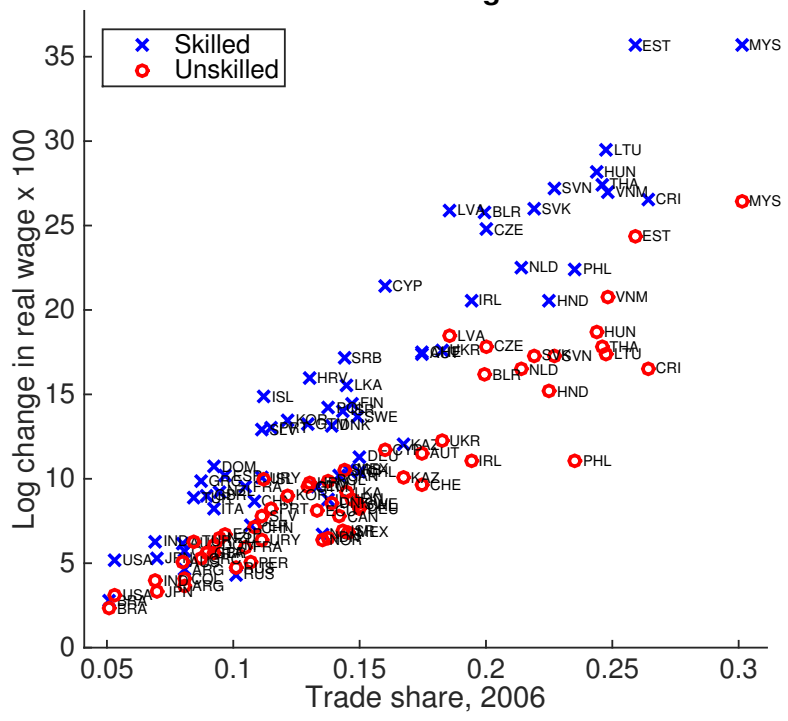

B: Skill premium

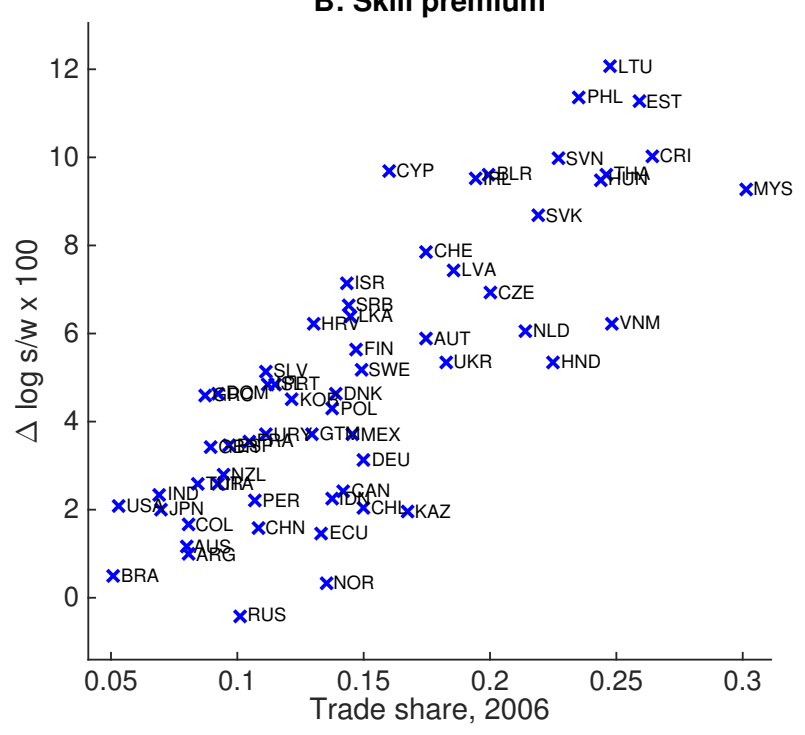

Figure 2: Log changes in real wages for skilled and unskilled labor (Panel A) and in the skill premium (Panel B) resulting from moving from autarky to the 2006 baseline parameterization against the 2006 aggregate trade share.

The log change in the skill premium is simply the difference between the change in the real wage of skilled and unskilled workers. Panel B of Figure 2 plots the log change in the skill premium, $100 \times \Delta \log \left(s_{n} / w_{n}\right)$, against the aggregate trade share in the baseline for each country. The skill premium rises in all but one country (Russia), implying that the combination of the SBP and the between-sector SBP mechanisms dominates the $\mathrm{H}-\mathrm{O}$ mechanism. The skill premium rises by $5.1 \%$ on average (excluding the rest of the world), but the effect varies widely across countries. The skill premium rises by as much as $12 \%$ in Lithuania, 11\% in the Philippines and Estonia, and 10\% in Slovenia and Costa Rica and by as little as $2 \%$ in U.S., $0.5 \%$ in Brazil, $0.3 \%$ in Norway, and $-0.4 \%$ in Russia.

Panel B of Figure 2 demonstrates a clear correlation between the predicted skill premium change in this counterfactual and the baseline trade share. To understand more generally which sources of variation across countries in the data that we targeted help account for the large variation in the model's predicted impact of trade on the skill premium, we regress the predicted change in the log skill premium across countries on log gross output in our baseline year, the log aggregate trade share, and a measure of the degree to which the country is a net exporter of skill-intensive sectors. ${ }^{29}$ The $R^{2}$ of this

\footnotetext{
${ }^{29}$ The measure of the degree to which the country is a net exporter of skill-intensive sectors is the average
} 
regression is 0.88 . The coefficient on output is negative whereas the coefficients on the trade share and the measure of the degree to which the country is a net exporter in the skill-intensive sectors are both positive; all coefficients are significantly different from zero at the one percent level. The skill premium changes more moving from autarky to the baseline in a country with relatively higher net exports in skill-intensive sectors because factor reallocation towards skill-intensive sectors is greater there, in a country with a higher trade share because overall factor reallocation is greater there, and in a smaller country because factors reallocate only towards the very productive skill-intensive firms there. Finally, regressing the predicted change in the log skill premium across countries on skill abundance, $H_{n} /\left(H_{n}+L_{n}\right)$, yields a coefficient that is insignificantly different from zero at the $10 \%$ level (and the $R^{2}$ of this regression is only 0.06 ).

In summary, reductions in trade costs tend to raise real wages for skilled and unskilled labor, but more so for skilled labor; i.e. the skill premium increases in almost all countries. The rise in the skill premium is particularly large in small countries, countries that trade more, and countries that tend to be relatively larger net exporters in more skill-intensive sectors, but not necessarily in skill-abundant countries.

Understanding the $\mathrm{H}-\mathrm{O}$ mechanism. The skill premium rises in almost all countries because the combination of the SBP and the between-sector SBP mechanisms is stronger than the $\mathrm{H}-\mathrm{O}$ mechanism. To understand what shapes the strength of the $\mathrm{H}-\mathrm{O}$ mechanism in our model, we consider three alternative re-parameterizations, the results of which are displayed in Figure 3.

First, we re-calibrate the model imposing $\phi=0$ (without targeting the elasticity of skill intensity with respect to plant size in Mexican manufacturing), so that the SBP mechanism and the between-sector SBP mechanism are both inactive. As shown in Panel A of Figure 3 , the skill premium then falls in 36 out of 60 countries (those with a comparative advantage in unskill-intensive sectors, which are not necessarily those abundant in unskilled workers, as can be seen in Figure 3), the average change in the absolute value of the skill premium is $1.5 \%$, and the maximum and minimum changes in the skill premium are $+3.4 \%$ and $-5.4 \%$, respectively. Second, we re-calibrate the model additionally imposing $a_{n}(j)=1$ for all $n$ and $j$ so that $A_{n}(j)=A_{n}$ for all $j$ (without targeting the relationship between sectoral trade balance and skill intensity), thereby abstracting from Ricardian comparative advantage. As shown in Panel B of Figure 3, we find that the average change in the absolute value of the skill premium is $1.1 \%$ rather than $1.5 \%$, which-according to Proposition 2-implies that Ricardian comparative advantage is positively correlated

of $v_{n}(g)$-this is the ratio of net exports normalized by total trade summed across all sectors $j$ in group $g$-across groups 5,6, and 7 minus the average of $v_{n}(g)$ across groups 2,3 , and 4 . 
with skill-abundance-induced comparative advantage. Ricardian comparative advantage is very important for the impact of trade on the skill premium in some countries. For instance, in Chile the change in the skill premium induced by trade goes from $-4.7 \%$ when Ricardian comparative advantage is active to $-1.7 \%$ when it is not; this is because Chile's normalized net exports are relatively higher in unskill-intensive sectors in the data and our baseline model accounts for this in part with a relatively high productivity there. Finally, we re-calibrate the model additionally imposing $\theta=0.05$ (which implies an aggregate trade elasticity of roughly 20 rather than our target of 5), thereby lowering the dispersion of productivity across firms. As shown in Panel $\mathrm{C}$ of Figure 3, we find that the average change in the absolute value of the skill premium rises from $1.1 \%$ to $2.2 \%$, and that the maximum and minimum changes in the skill premium are $+6.2 \%$ and $-7.4 \%$, respectively. Moreover, the increase in the skill premium is now strongly correlated with the country's abundance of skilled workers. This is consistent with Proposition 2, according to which a lower value of $\theta$ strengthens the $\mathrm{H}-\mathrm{O}$ effect.
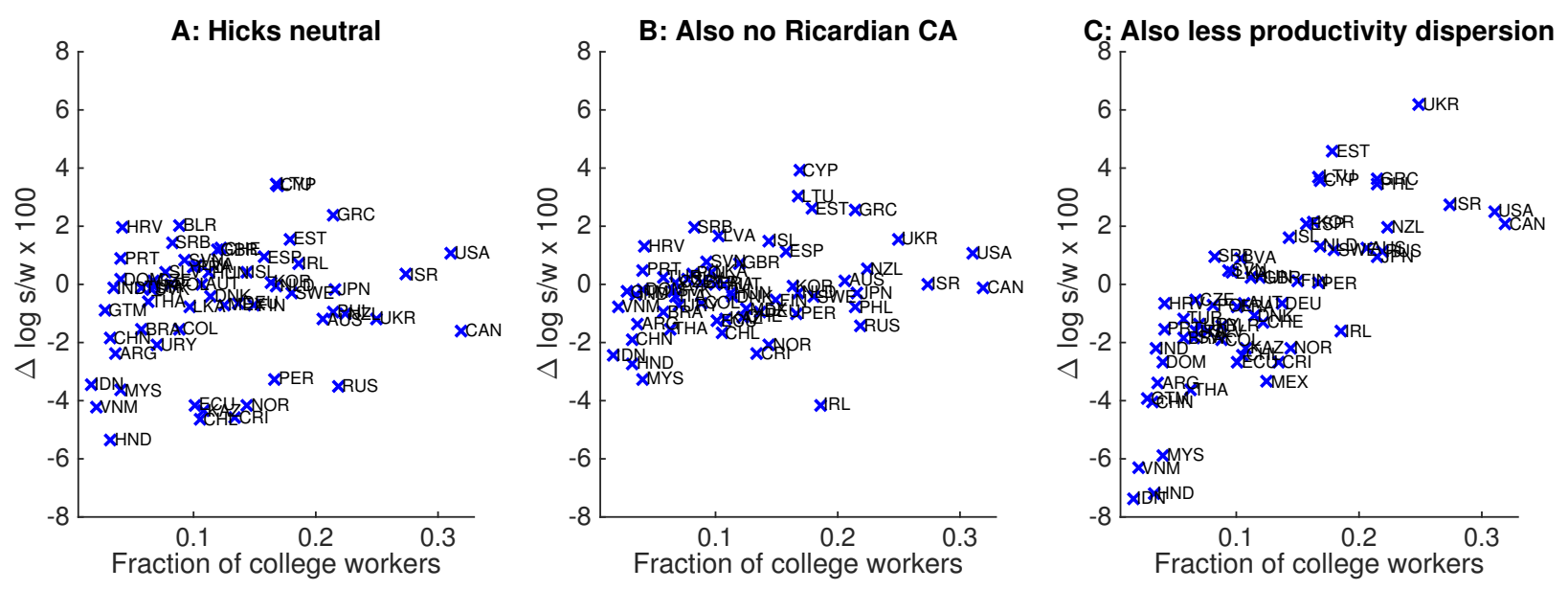

Figure 3: The log change in the skill premium moving from autarky to 2006 in three alternative parameterizations imposing (A) $\phi=0$, (B) $\phi=0$ and $a_{n}(j)=1$, and (C) $\phi=0, a_{n}(j)=1$, and $\theta=0.05$.

\subsection{Impact of international trade: 1976 versus 2006}

In the previous exercise we calculated the counterfactual change in the skill premium in each country resulting from reductions in trade costs from infinity (i.e. autarky) to their baseline levels in 2006. We now compare these results with those using data from three decades earlier, 1975-1977 (henceforth 1976), a time period featuring (among many other differences) smaller trade volumes as a share of output. This exercise is intended to 
shed light on the extent to which the worldwide increase in trade between 1976 and 2006 contributed to changes in the skill premium across countries.

We partially re-calibrate our model using the following data over the period 19751977: bilateral aggregate exports (to re-calibrate bilateral trade costs, $\left.t_{i n}\right)$, GDP $\left(a_{n}\right)$, the share of merchandise in gross output $\left(\gamma_{n}\right)$, the share of value added in gross output $\left(\chi_{n}\right)$, sectoral skill intensity $\left(\alpha_{j}\right)$, and the share of college workers $\left(H_{n} /\left(H_{n}+L_{n}\right)\right)$. Given data availability, this leaves us with 43 countries in 1976 (out of our 60 baseline countries) plus the rest of the world; we list these countries in Table 3 in Appendix B. We hold fixed at their baseline levels the elasticity of substitution between skilled and unskilled at the level of the firm $(\rho)$, the dispersion in productivity across firms within a sector $(\theta)$, and the skill bias of productivity $(\phi)$. We assume that (in both 1976 and 2006) sectoral productivities are common across sectors within a country $\left(a_{n}(j)=1\right.$ for all $n$ and $j$ so that $A_{n}(j)=A_{n}$ for all $j$ ) and that trade costs are equal across sectors $\left(t_{\text {in }}(j)=1\right.$ for all $j$ so that $\left.\tau_{\text {in }}(j)=\tau_{\text {in }}\right)$.

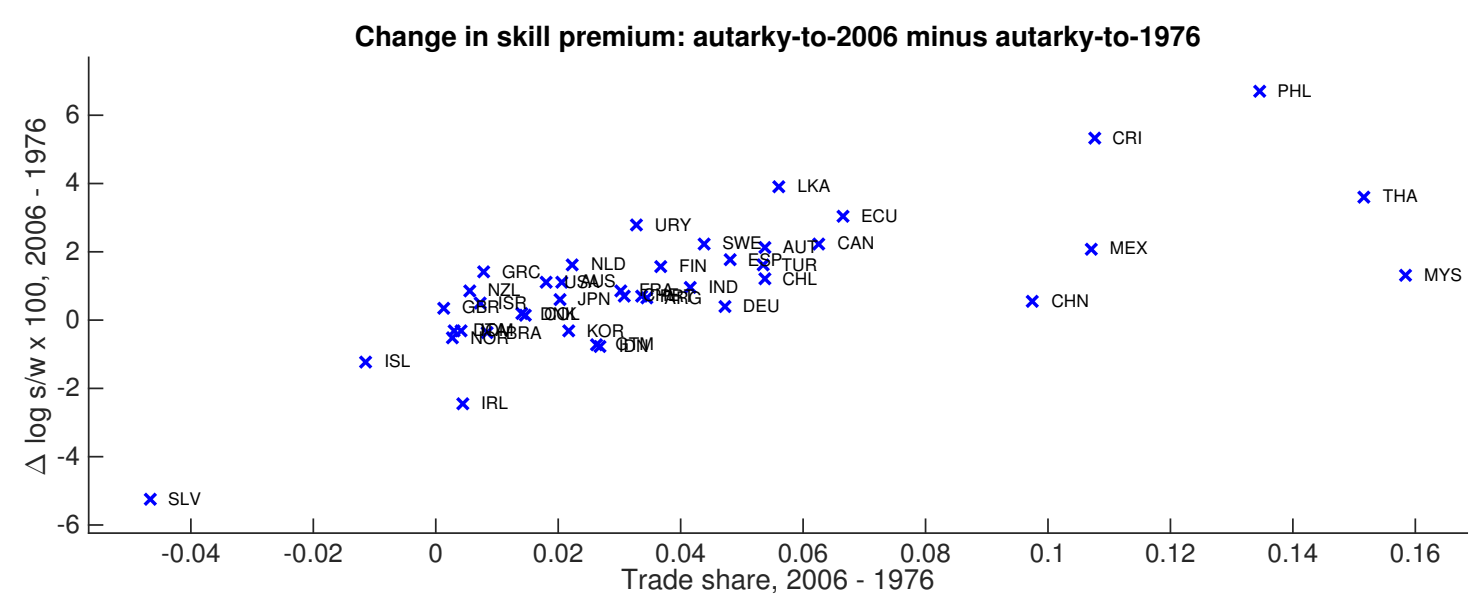

Figure 4: The $y$ axis displays the log change in the skill premium moving from autarky to 2006 minus that of moving from autarky to 1976. The $x$ axis displays the trade share in 2006 minus the trade share in 1976.

Figure 4 displays on the y-axis the log change in the skill premium of reducing trade costs moving from their autarky levels to their baseline levels in 2006 (given the other 2006 primitives) minus the log change in the skill premium of moving from autarky to the levels of trade costs in 1976 (given the other 1976 primitives) and on the x-axis the trade share in 2006 minus the trade share in $1976 .{ }^{30}$ There is a great deal of heterogeneity in this difference across countries. In the U.S., for example, moving from autarky to the

\footnotetext{
${ }^{30}$ Burstein et al. (2015) show that calculating wage changes caused by moving to autarky in each period and taking the difference in these wage changes across periods answers the following question about the impact of international trade on relative wages between any two non-autarkic time periods: What are the differential effects on wages in a given country of changes in primitives (i.e. worldwide technologies, labor supplies, and trade costs) between two time periods relative to the effects of the same changes in primitives
} 
calibrated level of trade costs increases the skill premium by $0.9 \%$ in 1976 and by $2 \%$ in 2006 (it is $2.1 \%$ in the 2006 baseline with variation in productivities across sectors); hence, the difference displayed in Figure 4 is roughly $1 \%$. The corresponding numbers in the Philippines are 5.8\% in 1976 and 12.6\% in 2006 (it is 11.4\% in the 2006 baseline); hence, the difference displayed in Figure 4 is roughly $7 \%$. While the difference displayed in Figure 4 is much higher for the Philippines than the U.S., in both cases the impact of trade on the skill premium is twice as large in 2006 than it is in 1976.

While the impact of trade (i.e., going from autarky to observed trade shares) on the skill premium is higher in 2006 than in 1976 for the majority of countries, there are 8 countries for which it is lower despite the fact that trade shares grew. This is because, as discussed above, in our model featuring multiple sources of country heterogeneity, trade shares are not a sufficient statistic for the impact of trade on the skill premium.

\subsection{Ten Percent Reduction in Trade Costs}

We now consider a simultaneous 10\% reduction in all bilateral trade costs, starting from the baseline parameterization; that is, $\tau_{i n}^{\prime}(j)=\tau_{\text {in }}(j) / 1.1$ for all $i \neq n$ and $j$. In the counterfactual equilibrium we assume that net exports relative to total output, $n x_{n}$, remains at the same level as in our baseline parameterization for each country except ROW (recall that net exports in ROW are chosen as a residual, such that there is balanced trade at the world level). We perform this counterfactual both with our baseline assumption of full labor mobility between sectors (to capture the long-run effects) and with limited labor mobility (to capture the short-run effects). ${ }^{31}$ In the case of limited mobility, in which we fix the stocks of skilled and unskilled labor in the merchandise and service sectors at their baseline levels, we report the change in the skill premium in merchandise sectors (the skill premium is roughly unchanged in service sectors).

The real wage rises for skilled and unskilled workers in all countries both with full and limited mobility. As in the previous counterfactual exercises, the gains for workers who have completed tertiary degrees are larger than for those who have not. Figure 5

if that country were a closed economy? In order to provide a full decomposition of the underlying sources of observed changes in the skill premium across countries (a multi-country extension of the accounting exercise carried out by Burstein et al. (2015) for the U.S.), we would require comparable measures of changes in the skill premium in all countries, which are not readily available.

${ }^{31}$ In particular, we assume that labor is immobile between the set of merchandise sectors and the set of service sectors, but is mobile within the set of merchandise sectors and within the set of service sectors. Specifically, we take the amount of each factor employed in merchandise and services as fixed at the initial equilibrium levels and allow skilled and unskilled wages to vary across these aggregate sectors. See e.g. Cosar (2013) and Dix-Carneiro (2014) for micro-founded dynamic models of trade liberalizations with limited factor mobility. 

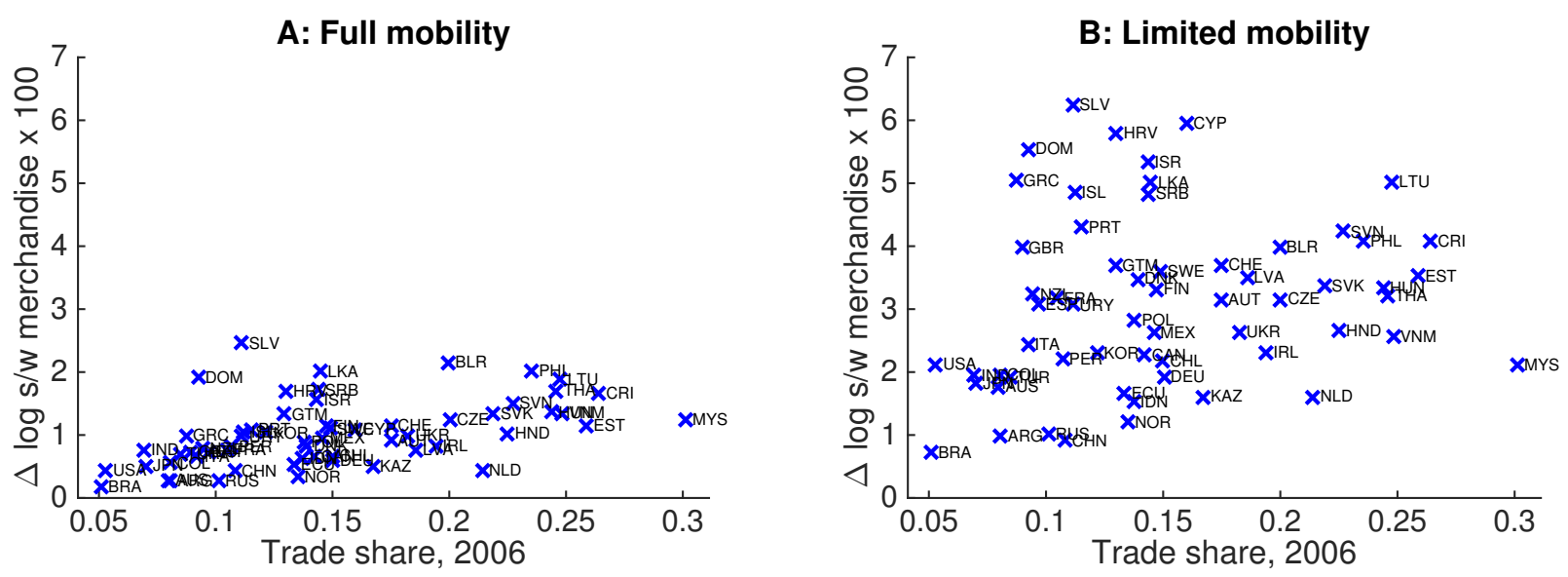

Figure 5: The log change in the skill premium, both with full (Panel A) and limited (Panel B) factor mobility, resulting from a $10 \%$ reduction in trade costs against the aggregate trade share in 2006.

plots the log change in the skill premium against the aggregate trade share in 2006, both with full (in Panel A) and limited (Panel B) factor mobility. Changes in the skill premium with limited mobility are roughly 3 times larger than those with full mobility. The mean rise in the skill premium is $3.1 \%$ with limited mobility and $1 \%$ with full mobility. We find that the skill premium rises in all countries, but the effect varies widely across countries in our sample. For example, the skill premium rises by as much as $6.3 \%$ in El Salvador with limited factor mobility. ${ }^{32}$

\subsection{Growth in China}

We now aim to illustrate the implications of structural transformation in China for the skill premium of its trading partners. In particular, we consider a rise in China's TFP such that China's share of world gross output rises from roughly $8 \%$ (China's share in 2006 ) to roughly $20 \%$. As in the previous exercise, in the counterfactual equilibrium we assume that net exports relative to total output, $n x_{n}$, remains at the same level as in our baseline parameterization for all countries except ROW. Figure 6 plots the log change in the skill premium in the other 59 countries-both with full (in Panel A) and limited (in

\footnotetext{
${ }^{32} \mathrm{To}$ assess the maximum effects from further reductions in trade costs, we consider an extreme counterfactual in which we set all bilateral trade costs equal to 1 . The maximum, minimum, and mean change in the skill premium with full mobility are $15.1 \%, 0.8 \%$, and $5.2 \%$, respectively.
} 
Panel B) factor mobility—-that results from the increase in Chinese TFP.
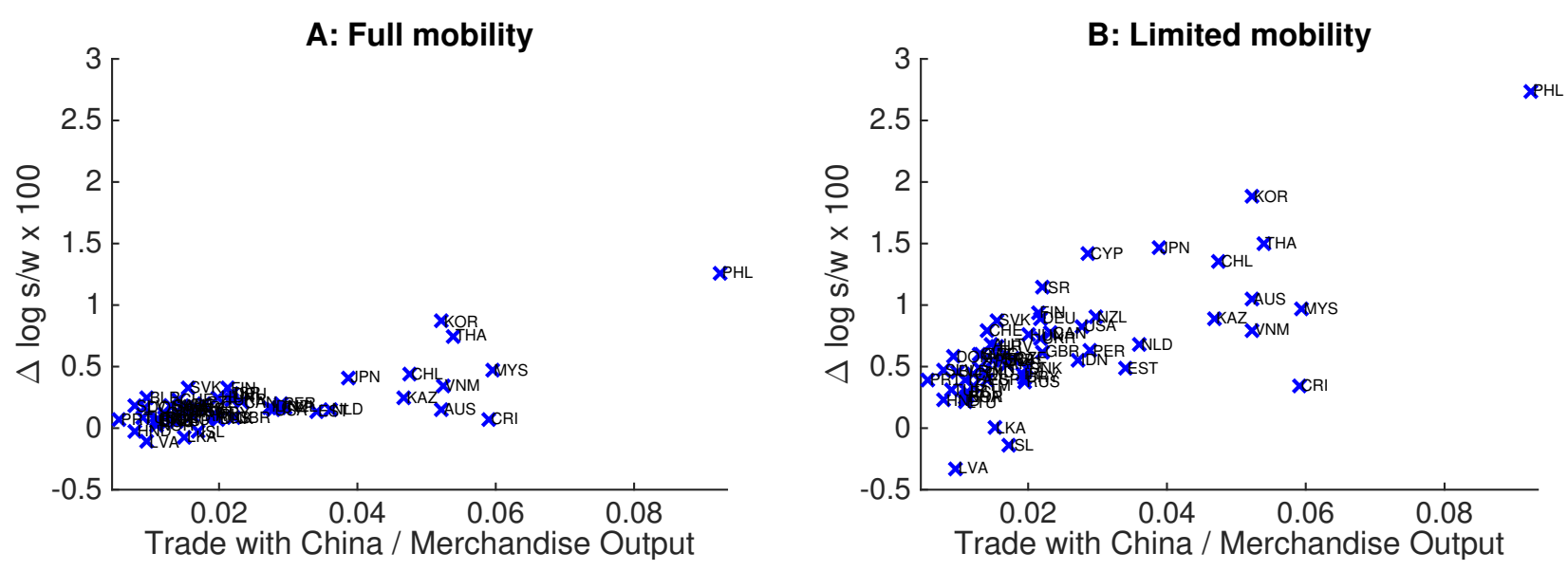

Figure 6: The impact of an increase in China's TFP on the skill premium in the other 59 countries both with full (Panel A) and limited (Panel B) factor mobility.

The SBP mechanism and the between-sector SBP mechanism raise the skill premium in all of China's trading partners since trade shares tend to rise for China's trading partners. Because China has a comparative advantage in unskill-intensive sectors on average, the $\mathrm{H}-\mathrm{O}$ mechanism increases the skill premium in most, but not all countries. The combined effect of these three mechanisms is an increase in the skill premium in 55 out of 59 countries of $0.2 \%$ on average with full mobility. The increase is largest in the countries that trade the most with China, such as Korea, Malaysia, Philippines and Thailand, where the skill premium goes up by as much as $1.3 \%$. The effect is roughly 3 times larger with limited factor mobility.

\subsection{Global Skill-Biased Technical Change}

Here we introduce a simple extension to our baseline model—skill-biased technical change-as follows. In equation (3) we replace the $\alpha_{j}$ in front of skill labor with $A^{H} \alpha_{j}$, where $A^{H}$ represents the productivity of skilled relative to unskilled labor in all countries. A firm's choice of skill intensity becomes

$$
\frac{h_{i}(\omega, j)}{l_{i}(\omega, j)}=A^{H} \frac{\alpha_{j}}{1-\alpha_{j}}\left(\frac{s_{i}}{w_{i}}\right)^{-\rho} z_{i}(\omega, j)^{\phi(\rho-1)}
$$

so that an increase in $A^{H}$ represents global skill-biased technical change, increasing the demand for skilled labor by all firms and, therefore, raising the skill premium in all countries. 
Here, we consider a counterfactual increase in $A^{H}$ that raises the skill premium by roughly $23 \%$ in all countries. This increase in $A^{H}$ raises trade shares (i.e. the average of exports and imports relative to merchandise gross output) in all countries, by about 2 percentage points on average. In contrast, if $A^{H}$ increases but firm-level productivity is not skill biased, $\phi=0$, then trade shares are essentially unchanged. The intuition for why skill-biased technical change (i.e. an increase in $A^{H}$ ) raises trade shares is similar to the intuition behind the between-sector SBP mechanism. For the same reason that an industry with higher skill intensity, $\alpha_{j}$, has more dispersed unit costs across firms, skill-biased technical change raises dispersion in unit costs across firms in all sectors. Specifically, we have

$$
\phi>0 \text { and } \rho \neq 1 \Rightarrow \frac{d}{d A^{H}}\left|\frac{d \log c_{i n}(\omega, j)}{d \log z(\omega, j)}\right|>0 .
$$

More dispersed unit costs generate more trade for given trade costs.

In summary, if $\phi>0$ (combined with $\rho \neq 1$ ), then skill-biased technical change (an increase in $A^{H}$ ) has aggregate implications that are qualitatively similar to reductions in trade costs: both will cause an increase in the skill premium and an increase in trade shares across countries. ${ }^{33}$

\section{Alternative Approaches}

In this section we discuss, through the lens of our model, three alternative approaches that have been used in the literature to study the impact of trade on the skill premium. These alternative approaches, rather than specifying a full GE model as we do, focus on: (i) the factor content of trade, (ii) the extent of between-sector factor reallocation, and (iii) the extent of sector-level relative price changes. We show that using these alternative approaches, if our model is correct, would typically lead one to underestimate the impact of trade on the skill premium in both skill-abundant and skill-scarce countries.

\subsection{The Factor Content of Trade}

In Appendix E we use an accounting framework to show that under some mild assumptions (that are satisfied in our model) the skill premium in country $n$ can be decomposed

\footnotetext{
${ }^{33}$ We thank Jonathan Eaton for suggesting this counterfactual.
} 
into three sufficient statistics,

$$
\frac{s_{n}}{w_{n}}=\frac{L_{n}}{H_{n}} \times \frac{\Phi_{n}(H)}{\Phi_{n}(L)} \times \frac{1-F C T_{n}(L) / L_{n}}{1-F C T_{n}(H) / H_{n}} .
$$

The first sufficient statistic, $L_{n} / H_{n}$, is the employment of unskilled labor relative to skilled labor. In our model, $L_{n} / H_{n}$ is unaffected by changes in trade costs.

The second sufficient statistic, $\Phi_{n}(H) / \Phi_{n}(L)$, is the factor payments for domestic absorption for skilled labor, $\Phi_{n}(H)$, relative to the factor payments for domestic absorption for unskilled labor, $\Phi_{n}(L)$. The term $\Phi_{n}(L)$ represents the payment to unskilled labor that would result if all of country $n$ 's expenditure (regardless of in which country each good is produced) were allocated to domestic factors (evaluated at current factor shares of domestic production for the domestic market in each sector). The definition of $\Phi_{n}(H)$ is analogous. Under strong restrictions discussed in Appendix E, which in general are violated in our model, $\Phi_{n}(H) / \Phi_{n}(L)$ is unaffected by changes in trade costs.

The third sufficient statistic is the trade adjustment to the employment of unskilled labor, $1-F C T_{n}(L) / L_{n}$, relative to the trade adjustment to the employment of skilled labor, $1-F C T_{n}(H) / H_{n}$. The term $F C T_{n}(L)$ denotes the factor content of trade (FCT) for unskilled labor in country $n$, representing the units of factor $L$ embodied in country $n$ 's exports minus the counterfactual units of factor $L$ that would be employed in country $n$ if it were to have to produce for itself the value of the goods it imports (evaluated at current wages and current factor shares of domestic production for the domestic market). ${ }^{34}$ The definition of $F C T_{n}(H)$ is analogous. Under autarky, $F C T_{n}(L)=F C T_{n}(H)=0$.

Under assumptions discussed in Appendix E, $F C T_{n}(L)$ can be measured using readilyavailable sector-level data as

$$
F C T_{n}(L)=\sum_{j}\left(\text { Employment of } L_{n} \text { in sector } j\right) \frac{N X_{n}(j)}{Y_{n}(j)} .
$$

where $Y_{n}(j)=\sum_{i} X_{n i}(j)$ denotes gross output in sector $j$, and where $F C T_{n}(H)$ can be measured analogously. A key assumption under which equation (20) is the appropriate measure of the FCT is that factor intensity is independent of the destination to which goods within a sector are shipped. This assumption is inconsistent with evidence discussed extensively in Section 4-that exporting firms within a sector are, on average,

\footnotetext{
${ }^{34}$ This definition of the factor content differs from that used to study the pattern of global factor trade; see e.g. Trefler (1995) and Davis and Weinstein (2001). Constructing the sufficient statistics in the accounting identity in equation (19) requires only information from the domestic economy whereas to construct measures of global factor trade requires information on technologies and factors of production used in each country-sector pair.
} 
more skill intensive than domestic firms-and with our model parameterized with skill biased productivity.

Note that if both $L_{n} / H_{n}$ and $\Phi_{n}(H) / \Phi_{n}(L)$ are unaffected by changes in trade costs (recall that the latter is not generally satisfied in our model), the change in the skill premium induced by moving from autarky to the current equilibrium depends only on the potentially measurable values of $F C T_{n}(L) / L_{n}$ and $F C T_{n}(H) / H_{n}$ in the current equilibrium,

$$
\frac{s / w}{s^{\prime} / w^{\prime}}=\frac{1-F C T_{n}(L) / L_{n}}{1-F C T_{n}(H) / H_{n}},
$$

where $s^{\prime} / w^{\prime}$ and $s / w$ are the skill premia in autarky and the current equilibrium, respectively. A number of papers have measured the impact of international trade on the skill premium using the restricted accounting identity in equation (21) and measuring the factor content of trade using equation (20); see e.g. Katz and Murphy (1992). We now assess, using data generated by our model, the biases induced by the assumptions which give rise to the simplified expressions (20) and (21).
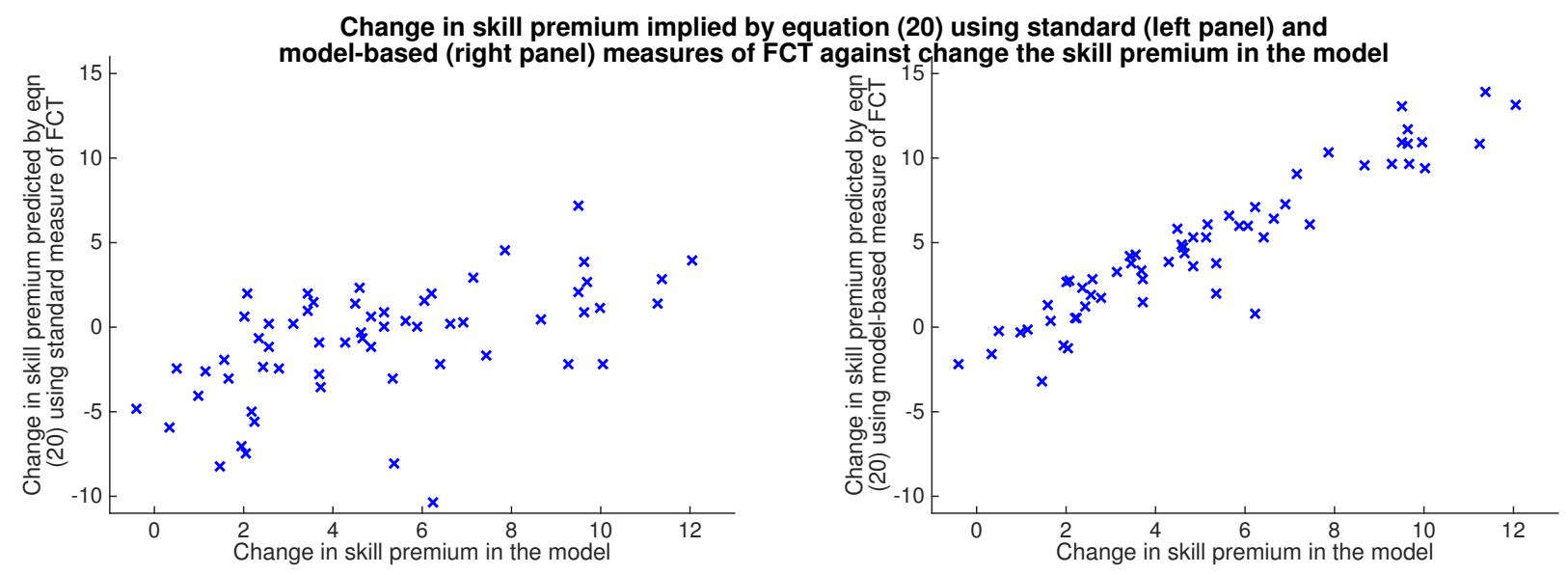

Figure 7: Changes in the skill premium across countries from autarky to the 2006 baseline parameterization predicted by equation (21) using the standard measure of the FCT displayed in equation (20) (in the left panel) and using the model-based measure of the FCT (in the right panel) against change in the skill premium predicted by the model.

In the left panel of Figure 7, we plot the change in the skill premium implied by the restricted accounting identity in equation (21) (that is, assuming that $\Phi_{n}(H) / \Phi_{n}(L)$ is unchanged with trade costs) where FCT is measured using equation (20), against the model's predicted change in the skill premium. Whereas this standard approach in the literature to measuring the impact of trade on the skill premium predicts that the skill premium falls in 30 out of 60 countries (we do not include the rest of the world in these calculations), those that are net exporters of unskill-intensive sectors, the model predicts that the 
skill premium rises in all countries except for one. Moreover, for those 30 countries in which the standard approach correctly predicts that the skill premium should rise, the rise in the skill premium implied by equations (21) and (20) is far from the actual rise in the skill premium implied by the model.

In the right panel of Figure 7 we plot the change in the skill premium predicted by the restricted accounting identity in equation (21) (that is, incorrectly assuming that $\Phi_{n}(H) / \Phi_{n}(L)$ is fixed) but-unlike in the left panel of Figure 7-correctly measuring the FCT in the simulated data against the model's predicted change in the skill premium. This alternative approach predicts the right sign in the change of the skill premium for 53 out of 60 countries. Moreover, for those countries in which it predicts the right sign, the gap between the prediction and the actual rise in the skill premium in the modelgenerated data is small.

In summary, through the lens of our model there are two issues associated with standard approaches of measuring the impact of trade on inequality based on expression (20) and using the FCT in expression (21). First, changes in trade costs affect relative wages through other channels that affect $\Phi_{n}(H) / \Phi_{n}(L)$. Second, and more importantly, the standard measure of the FCT systematically understates in all countries the rise in the skill premium caused by international trade.

\subsection{Factor reallocation}

A number of empirical papers measure the extent of between-sector factor reallocation to assess the impact of international trade on inequality; see e.g. Berman et al. (1994) in the U.S. and Attanasio et al. (2004) in Colombia. Intuitively, if $\phi=0$ in our baseline model - as in the standard H-O model - then only between-sector factor reallocation affects the relative demand for skill and the skill premium. However, these and other studies—see e.g. the Goldberg and Pavcnik (2007) literature review-document relatively little systematic between-sector labor reallocation during trade liberalizations. Moreover, other studies document substantially more within-sector than between-sector labor reallocation; see e.g. Haltiwanger et al. (2004) for results in several Latin American countries. These findings have been interpreted through the lens of the $\mathrm{H}-\mathrm{O}$ model as evidence that international trade is not responsible for much of the rise in inequality.

In our model, however, the rise in the skill premium is accompanied by more withinsector than between-sector labor reallocation. Figure 8 illustrates this pattern for manufacturing sectors using data generated by the model from our autarky-to-baseline counterfactual for Mexico. In this counterfactual, the skill premium in Mexico rises by 3.7\%. 


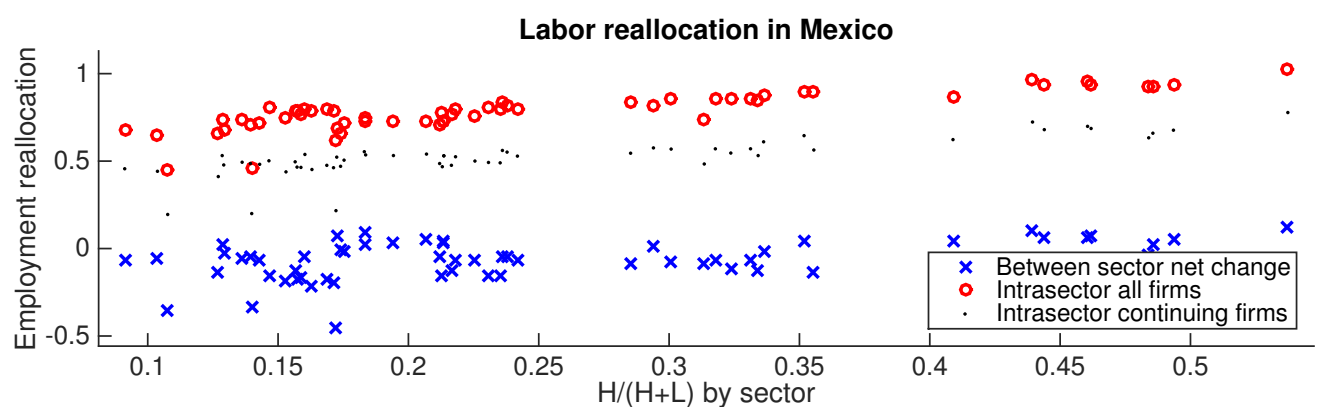

Figure 8: Net employment change and within-sector employment change (for all firms and for continuing firms) by sector in Mexico implied by the model, moving from autarky to the 2006 baseline parameterization.

Figure 8 reports net employment changes and within-sector reallocation by sector. The net employment change in a sector is defined, following Haltiwanger et al. (2004), as the net employment change between two dates divided by the average employment in that sector across those two dates. Within-sector reallocation in a sector is defined as the weighted average across firms within a sector of the absolute firm-level employment change between two dates divided by the average employment in that firm across those two dates. We report separately within-sector reallocation for all firms and for continuing firms (those producing in both dates).

Three patterns emerge from Figure 8. First, sector-level net employment changes are not strongly related to sectoral factor intensity for Mexico. While skill-intensive sectors expand on average, there is extensive heterogeneity in net employment changes across sectors with similar factor intensities. Second, within-sector reallocation-using both measures-is larger than net employment changes for all sectors. Third, within-sector reallocation is larger for skill-intensive sectors. While there is some variation across countries in the extent to which net employment changes are related to factor intensities, the results that within-sector reallocation is greater than between-sector reallocation and that within-sector reallocation is larger in skill-intensive sectors is quite robust across countries.

The first two of these patterns stem from the fact that, with substantial productivity dispersion within sectors our model predicts relatively more within-sector reallocation than between-sector reallocation. The third pattern stems from the between-sector SBP mechanism. According to equation (15), within-sector dispersion in costs is larger in more skill-intensive sectors. This implies that there is a force in our model that generates more selection-both on the export margin and the exit margin-in skill-intensive sectors in all countries. Specifically, there is more exporting and, therefore, more firms that exit in 
sectors with greater unit cost dispersion. By equation (15), these are the skill-intensive sectors. $^{35}$

We conclude that our model can generate a sizable impact of trade liberalization on the skill premium that is accompanied by more pronounced within- than between-sector factor reallocation.

\subsection{Prices}

Other empirical papers use changes in producer prices of skill-intensive relative to unskillintensive sectors to measure the impact of international trade on inequality; see e.g. Lawrence and Slaughter (1993), Sachs and Shatz (1994), and Feenstra and Hanson (1999). This approach builds on the assumption of perfect competition (or, more generally, constant markups) so that changes in goods prices reflect changes in marginal costs, which depend on only factor intensities and changes in productivities and factor prices. If international trade raises the relative price of skill-intensive sectors then, all else equal, it raises the skill premium.

In our model with Bertrand competition, markups are not constant. In response to reductions in trade costs, markups fall relatively more in skill-intensive sectors (since, due to the SBP mechanism, unit costs are more dispersed and trade increases by more in those sectors). Therefore, if we take changes in goods-level price data from our model and incorrectly assume that markups are fixed (as they are with perfect competition), then we will infer that costs fell relatively more in skill-intensive sectors and we will underestimate the increase in the skill premium.

To illustrate this point, figure 9 plots the average change (moving from autarky to 2006 baseline trade levels) in manufacturing sector producer prices-a weighted average of log domestic price changes by U.S. producers-using simulated data from two distinct parameterizations of the model. In the first parameterization in Panel A, we consider the perfectly competitive version of our model, in which markups are constant so that changes in producer prices are driven only by changes in factor prices. In this case, there is a clear positive relationship between skill-intensities and changes in producer prices. The second parameterization in Panel B is our baseline, in which markups fall in more skill-intensive sectors so that changes in producer prices are pushed in opposite directions by changes in factor prices and markups. In this case, the reduction in skill-intensive markups dominates the rise in the skill premium, inducing a negative (but

\footnotetext{
${ }^{35}$ Note that this result differs from that in Bernard et al. (2007b), which predicts that selection is greater in a country's comparative advantage sector.
} 

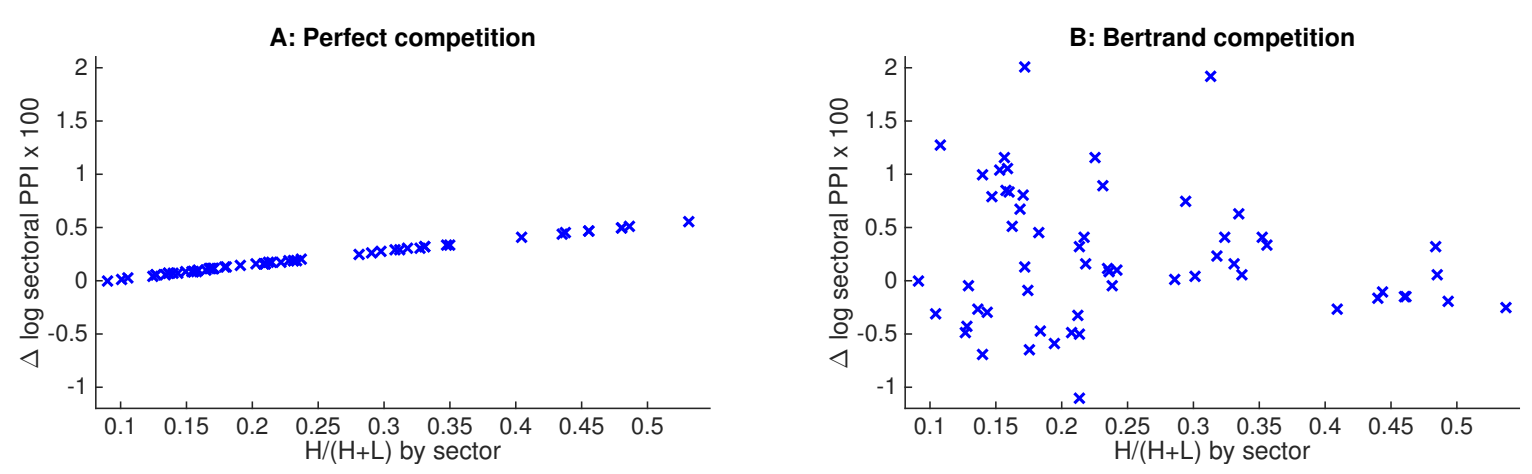

Figure 9: Changes in producer prices in manufacturing sectors in the U.S., moving from autarky to the 2006 baseline parameterization both with perfectly competitive goods markets (Panel A) and in our baseline with Bertrand competition (Panel B).

Notes: We normalize the log change in the price of the least skill-intensive sector to zero.

noisy) relationship between skill-intensities and changes in producer prices.

We conclude that in our model with variable markups and skill-biased productivity, trade liberalization can result in a simultaneous rise in the skill premium and fall in the relative price of skill-intensive goods. Hence, through the lens of our model, empirical approaches based on the premise that international trade moves the relative price of skill-intensive sectors and the skill premium in the same direction will underestimate the impact of trade on the skill premium.

\section{Conclusions}

In this paper we have embedded into an otherwise standard quantitative trade model two of the central mechanisms proposed in the theoretical and empirical trade literature through which international trade shapes the skill premium: (i) trade reallocates factors towards a country's comparative advantage sectors, increasing the skill premium in countries with a comparative advantage in skill-intensive sectors and decreasing it elsewhere, and (ii) trade reallocates factors towards skill-intensive producers within sectors, increasing the skill premium in all countries. We show that the interaction between the assumptions that give rise to these two mechanisms generates a third mechanism, in which trade reallocates factors towards skill-intensive sectors in all countries, increasing the skill premium everywhere.

Because our model accounts for the fact that more productive, larger, and exporting firms are more skill intensive than less productive, smaller, and domestic firms, it does not yield an analytic gravity equation at any level of aggregation. To deal with this complication, we use a computational approach that does not require an analytic gravity equation 
at any level of aggregation.

Parameterized to 60 countries and the rest of the world, we find that gains from trade are larger for skilled than unskilled workers in most countries. We revisit three alternative approaches that have been used in the literature to study the impact of trade on the skill premium. Using data generated by our model we show that each of these approaches underestimates the rise in the skill premium generated by trade cost reductions.

In our analysis we have abstracted from multinational production (MP), another major form of globalization. MP has implications for the skill premium through the $\mathrm{H}-\mathrm{O}$ and SBP mechanisms. Specifically, MP promotes the international diffusion of technology, as high productivity firms are not constrained to produce domestically. By reducing the dispersion of productivity across countries, MP strengthens the $\mathrm{H}-\mathrm{O}$ mechanism (like a reduction in $\theta$ in Proposition 2). By raising the productivities used in all countries, MP strengthens the SBP mechanism. It would be interesting to extend our analysis to incorporate MP.

\section{References}

Acemoglu, Daron, "Patterns of Skill Premia," Review of Economic Studies, 04 2003, 70 (2), 199-230.

_ , Introduction to Modern Economic Growth, Princeton University Press, 2009.

Adao, Rodrigo, "Distributional Effect of International Trade and Comparative Advantage in Labor Markets," Technical Report 2015.

Alcala, Francisco and Pedro Hernandez, "Firms' main market, human capital, and wages," SERIEs, September 2010, 1 (4), 433-458.

Allen, Treb, Costas Arkolakis, and Xiangliang Li, "On the Existence and Uniqueness of Trade Equilibria," Mimeo Yale University 2015.

_, , , and Yuta Takahashi, “Universal Gravity," NBER Working Papers 20787, National Bureau of Economic Research, Inc December 2014.

Alvarez, Fernando and Robert Jr. Lucas, "General equilibrium analysis of the EatonKortum model of international trade," Journal of Monetary Economics, September 2007, $54(6), 1726-1768$. 
Arkolakis, Costas, Arnaud Costinot, and Andres Rodriguez-Clare, "New Trade Models, Same Old Gains?," American Economic Review, February 2012, 102 (1), 94-130.

Attanasio, Orazio, Pinelopi K. Goldberg, and Nina Pavcnik, "Trade reforms and wage inequality in Colombia," Journal of Development Economics, August 2004, 74 (2), 331-366.

Barro, Robert J. and Jong Wha Lee, "A new data set of educational attainment in the world, 1950-2010," Journal of Development Economics, 2013, 104 (C), 184-198.

Berman, Eli, John Bound, and Zvi Griliches, "Changes in the Demand for Skilled Labor within U.S. Manufacturing: Evidence from the Annual Survey of Manufactures," The Quarterly Journal of Economics, May 1994, 109 (2), 367-97.

Bernard, Andrew B., J. Bradford Jensen, Stephen J. Redding, and Peter K. Schott, "Firms in International Trade," Journal of Economic Perspectives, Summer 2007, 21 (3), 105-130.

_ , Jonathan Eaton, J. Bradford Jensen, and Samuel Kortum, "Plants and Productivity in International Trade," American Economic Review, September 2003, 93 (4), 1268-1290.

_, Stephen J. Redding, and Peter K. Schott, "Comparative Advantage and Heterogeneous Firms," Review of Economic Studies, 2007, 74 (1), 31-66.

Broda, Christian and David E. Weinstein, "Globalization and the Gains from Variety," The Quarterly Journal of Economics, May 2006, 121 (2), 541-585.

Buera, Francisco, Joseph Kaboski, and Richard Rogerson, "Skill-Biased Structural Change," NBER Working Papers 21165, National Bureau of Economic Research, Inc 2015.

Burstein, Ariel and Jonathan Vogel, "Factor Prices and International Trade: A Unifying Perspective," NBER Working Papers 16904, National Bureau of Economic Research, Inc March 2011.

_ and _ , "Factor Prices and International Trade: A Unifying Perspective," NBER Working Papers 16904, National Bureau of Economic Research, Inc March 2011.

_ , Eduardo Morales, and Jonathan Vogel, "Accounting for Changes in Between-Group Inequality," NBER Working Papers 20855, National Bureau of Economic Research, Inc January 2015. 
_ , Javier Cravino, and Jonathan Vogel, "Importing Skill-Biased Technology," American Economic Journal: Macroeconomics, April 2013, 5 (2), 32-71.

Bustos, Paula, "The Impact of Trade Liberalization on Skill Upgrading Evidence from Argentina," Working Papers 559, Barcelona Graduate School of Economics April 2011.

Chor, Davin, "Unpacking sources of comparative advantage: A quantitative approach," Journal of International Economics, November 2010, 82 (2), 152-167.

Cosar, Kerem., "Adjusting to Trade Liberalization: Reallocation and Labor Market Policies," Mimeo University of Chicago, 2013.

Costinot, Arnaud and Jonathan Vogel, "Matching and Inequality in the World Economy," Journal of Political Economy, 08 2010, 118 (4), 747-786.

Cravino, Javier and Sebastian Sotelo, "Trade Induced Structural Change and the Skill Premium," Technical Report 2015.

Danziger, Eliav, "Skill Acquisition and the Dynamics of Trade-Induced Inequality," Technical Report 2014.

Davis, Donald R., "Intra-industry trade: A Heckscher-Ohlin-Ricardo approach," Journal of International Economics, November 1995, 39 (3-4), 201-226.

- and David E. Weinstein, "An Account of Global Factor Trade," American Economic Review, December 2001, 91 (5), 1423-1453.

Deardorff, Alan V. and Robert W. Staiger, "An interpretation of the factor content of trade," Journal of International Economics, February 1988, 24 (1-2), 93-107.

Dekle, Robert, Jonathan Eaton, and Samuel Kortum, "Global Rebalancing with Gravity: Measuring the Burden of Adjustment," IMF Staff Papers, July 2008, 55 (3), 511-540.

Dix-Carneiro, Rafael, "Trade Liberalization and Labor Market Dynamics," Econometrica, 2014, $82(3), 825-885$.

- and Brian K. Kovak, "Trade Liberalization and the Skill Premium: A Local Labor Markets Approach," American Economic Review, 2015, 105 (5), 551-557.

Eaton, Jonathan and Samuel Kortum, "Technology, Geography, and Trade," Econometrica, September 2002, 70 (5), 1741-1779. 
_ , Samuel S. Kortum, and Sebastian Sotelo, "International Trade: Linking Micro and Macro," NBER Working Papers 17864, National Bureau of Economic Research, Inc February 2012.

Eeckhout, Jan and Philipp Kircher, "Sorting and Decentralized Price Competition," Econometrica, 03 2010, 78 (2), 539-574.

Epifani, Paolo and Gino Gancia, "Increasing Returns, Imperfect Competition, and Factor Prices," The Review of Economics and Statistics, November 2006, 88 (4), 583-598.

Eslava, Marcela, Ana Cecilia Fieler, and Daniel Yi Xu, "Trade, competition and qualityupgrading: A theory with evidence from Colombia," Technical Report 2015.

Feenstra, Robert C., Offshoring in the Global Economy: Microeconomic Structure and Macroeconomic Implications, Vol. 1 of MIT Press Books, The MIT Press, June 2010.

- and Gordon H. Hanson, "The Impact Of Outsourcing And High-Technology Capital On Wages: Estimates For The United States, 1979-1990," The Quarterly Journal of Economics, August 1999, 114 (3), 907-940.

Goldberg, Pinelopi Koujianou and Nina Pavcnik, "Distributional Effects of Globalization in Developing Countries," Journal of Economic Literature, March 2007, 45 (1), 39-82.

Haltiwanger, John, Adriana Kugler, Maurice Kugler, Alejandro Micco, and Carmen Pages, "Effects of tariffs and real exchange rates on job reallocation: evidence from Latin America," Journal of Economic Policy Reform, 2004, 7 (4), 191-208.

Harrigan, James and Ariell Reshef, "Skill Biased Heterogeneous Firms, Trade Liberalization, and the Skill Premium," Canadian Journal of Economics, Forthcoming.

Head, Keith and Thierry Mayer, "Gravity Equations: Workhorse, Toolkit, and Cookbook," CEPR Discussion Papers 9322, C.E.P.R. Discussion Papers January 2013.

Helpman, Elhanan, Oleg Itskhoki, Marc-Andreas Muendler, and Stephen J. Redding, "Trade and Inequality: From Theory to Estimation," NBER Working Papers 17991, National Bureau of Economic Research, Inc April 2012.

Hsieh, Chang-Tai and Ralph Ossa, "A Global View of Productivity Growth in China," Working Papers, Chicago Booth 2015.

Katz, Lawrence F and Kevin M Murphy, "Changes in Relative Wages, 1963-1987: Supply and Demand Factors," The Quarterly Journal of Economics, February 1992, 107 (1), 35-78. 
Lawrence, Robert Z. and Matthew J. Slaughter, "Technology, trade and factor prices," Brookings Papers on Economic Activity, 1993, (2), 161-226.

Levchenko, Andrei A. and Jing Zhang, "The evolution of comparative advantage: measurement and implications," UBS Center Working Papers 011, Mimeo University of Zurich April 2015.

Matsuyama, Kiminori, "Beyond Icebergs: Towards a Theory of Biased Globalization," Review of Economic Studies, 2007, 74 (1), 237-253.

Melitz, Marc J., "The Impact of Trade on Intra-Industry Reallocations and Aggregate Industry Productivity," Econometrica, November 2003, 71 (6), 1695-1725.

Menezes-Filho, Narcio Aquino, Marc-Andreas Muendler, and Garey Ramey, "The Structure of Worker Compensation in Brazil, with a Comparison to France and the United States," The Review of Economics and Statistics, May 2008, 90 (2), 324-346.

Molina, Danielken and Marc-Andreas Muendler, "Preparing to Export," NBER Working Papers 18962, National Bureau of Economic Research, Inc April 2013.

Morrow, Peter M., “Ricardian-Heckscher-Ohlin comparative advantage: Theory and evidence," Journal of International Economics, November 2010, 82 (2), 137-151.

Parro, Fernando, "Capital-Skill Complementarity and the Skill Premium in a Quantitative Model of Trade," American Economic Journal: Macroeconomics, April 2013, 5 (2), $72-117$.

Romalis, John, "Factor Proportions and the Structure of Commodity Trade," American Economic Review, March 2004, 94 (1), 67-97.

Ruggles, Steven, Katie Genadek, Ronald Goeken, Josiah Grover, and Matthew Sobek, “Integrated Public Use Microdata Series: Version 6.0 [Machine-readable database]," Technical Report 2015.

Sachs, Jeffrey D. and Howard J. Shatz, "Trade and Jobs in Manufacturing," Brookings Papers on Economic Activity, 1994, 25 (1), 1-84.

Sattinger, Michael, "Assignment Models of the Distribution of Earnings," Journal of Economic Literature, June 1993, 31 (2), 831-80.

Trefler, Daniel, "The Case of the Missing Trade and Other Mysteries," American Economic Review, December 1995, 85 (5), 1029-46. 
Vannoorenberghe, Gonzague, "Trade between symmetric countries, heterogeneous firms, and the skill premium," Canadian Journal of Economics, February 2011, 44 (1), 148-170.

Verhoogen, Eric A., "Trade, Quality Upgrading and Wage Inequality in the Mexican Manufacturing Sector: Theory and Evidence from an Exchange Rate Shock," Mimeo Center for Labor Economics, UC Berkeley 67 January 2004.

_ , "Trade, Quality Upgrading, and Wage Inequality in the Mexican Manufacturing Sector," The Quarterly Journal of Economics, 05 2008, 123 (2), 489-530.

Waugh, Michael E., "International Trade and Income Differences," American Economic Review, December 2010, 100 (5), 2093-2124.

Yeaple, Stephen Ross, "A simple model of firm heterogeneity, international trade, and wages," Journal of International Economics, January 2005, 65 (1), 1-20. 


\section{A Equilibrium characterization details}

Lowest and second lowest unit costs. In the pricing equation (5), the lowest and secondlowest costs of supplying variety $(\omega, j)$ to country $n$ are given by

$$
C_{n}(\omega, j)=\min _{i}\left\{c_{i n}(\omega, j)\right\}
$$

and

$$
C_{n}^{\prime}(\omega, j)=\min \left\{c_{i^{*}(\omega, j, n) n}^{\prime}(\omega, j), \min _{i \neq i^{*}(\omega, j, n)}\left\{c_{i n}(\omega, j)\right\}\right\},
$$

where $i^{*}(\omega, j, n) \equiv \arg \min _{i}\left\{c_{i n}(\omega, j)\right\}$ is the country from which the lowest-cost supplier to country $n$ of variety $(\omega, j)$ originates and where $c_{i}^{\prime}(\omega, j)$ denotes the second-lowest unit cost of producing $(\omega, j)$ in country $i$.

Firm-level factor demand. The country $n$ firm producing variety $(\omega, j)$ demands $l_{n}(\omega, j)$, $h_{n}(\omega, j)$, and $m_{n}(\omega, j)$ units of unskilled labor, skilled labor, and intermediates, given by

$$
\begin{gathered}
l_{n}(\omega, j)=b_{n}(\omega, j) \times\left(1-\alpha_{j}\right) w_{n}^{-\rho} z_{n}(\omega, j)^{\frac{-\phi(\rho-1)}{2}} y_{n}(\omega, j) \\
h_{n}(\omega, j)=b_{n}(\omega, j) \times \alpha_{j} s_{n}^{-\rho} z_{n}(\omega, j)^{\frac{\phi(\rho-1)}{2}} y_{n}(\omega, j)
\end{gathered}
$$

and

$$
m_{n}(\omega, j)=c_{n n}(\omega, j)\left(1-\chi_{n}\right) P_{n}^{-1} y_{n}(\omega, j)
$$

where

$$
b_{n}(\omega, j) \equiv \chi_{n}^{\rho}\left(\frac{P_{n}}{1-\chi_{n}}\right)^{\frac{\left(\chi_{n}-1\right)(\rho-1)}{\chi_{n}}}\left(z_{n}(\omega, j) A_{n}(j)\right)^{\frac{\rho-1}{\chi_{n}}} c_{n n}(\omega, j)^{\frac{\rho-1}{\chi_{n}}+1} .
$$

Aggregate prices. Aggregate prices are given by

$$
P_{n}=\frac{\gamma_{n}^{-\gamma_{n}}}{\left(1-\gamma_{n}\right)^{1-\gamma_{n}}}\left(\sum_{j=1}^{J_{M}} P_{n}(j)^{1-\sigma} d \omega\right)^{\frac{\gamma_{n}}{1-\sigma}}\left(\sum_{j=J_{M}+1}^{J} P_{n}(j)^{1-\sigma} d \omega\right)^{\frac{1-\gamma_{n}}{1-\sigma}}
$$

and

$$
P_{n}(j)=\left(\int_{0}^{1} p_{n}(\omega, j)^{1-\eta} d \omega\right)^{1 /(1-\eta)} .
$$




\section{B Parameterization}

\section{B.1 Data}

Here we provide additional details on the data used in our parameterization as well as how we inferred missing values. See Appendix Table 1 for a list of the 61 countries (including the rest of the world) and a subset of the country-specific data used in parameterizing the model in 2006.

Gross output: Given measures for country $n$ on $G D P_{n}$ in dollars, the ratio of gross output to value added $\chi_{n}^{-1}=\frac{Y_{n}}{V A_{n}}$, and the ratio of merchandise gross output to total gross output $\frac{Y_{n}^{\text {merch }}}{Y_{n}}$, we measure total gross output as

$$
Y_{n}=G D P_{n} \times \frac{Y_{n}}{V A_{n}}
$$

and merchandise gross output as

$$
Y_{n}^{\text {merch }}=Y_{n} \times \frac{Y_{n}^{\text {merch }}}{Y_{n}}
$$

We obtain $G D P_{n}$ from World Development Indicators (WDI) or International Financial Statistics if the WDI data is unavailable. For 2006 we use an annual average between 2005 and 2007, and for 1976 we use an average between 1975 and 1977.

Gross output / value added and and merchandise gross output / total gross output: We obtain measures of $Y_{n} / V A_{n}$ and $Y_{n}^{\text {merch }} / Y_{n}$ from OECD's input output tables for the years 2005 and 2008 (we use an average of these two years). The merchandise aggregate is defined as the sum of industries 1-37. OECD input tables are not available for 12 of our 60 countries (Belarus, Dominican Republic, Ecuador, El Salvador, Guatemala, Honduras, Kazakhstan, Peru, Serbia, Sri Lanka, Ukraine and Uruguay). For Peru we use the 2008 input output table from INEI, the national statistical agency. For the remaining 11 countries we impute these ratios by separately projecting $Y_{n} / V A_{n}$ and $Y_{n}^{\text {merch }} / Y_{n}$ (for countries for which this data is available) on $\log$ (GDP per capita PPP adjusted), the service share of GDP, and the manufacturing share of GDP (all from the WDI). The $R^{2}$ of this regression is 0.90 for $Y_{n}^{\text {merch }} / Y_{n}$ and 0.38 for $Y_{n} / V A_{n}$. We use this predicted relationship to impute $Y_{n} / V A_{n}$ and $Y_{n}^{m e r c h} / Y_{n}$ for those countries with missing data. For the rest of the world we calculate these two ratios for the aggregate of 60 countries available in the OECD's input output database. To construct these ratios in 1976 for our 43 countries, we use data from OECD STAN and EU KLEMS Growth and Productivity Accounts (which contains infor- 
mation for Australia, Austria, Canada, Denmark, Finland, France, Germany, Greece, Ireland, Italy, Japan, Netherland, New Zealand, Norway, Portugal, Spain, Sweden, United Kingdom, and the U.S.) and impute the missing values using a similar procedure to the one we use for 2006. For the rest of the world we use an average of the ratio for our 43 countries.

Exports and imports: We obtain exports and imports (by pair of countries and by sector) from UN Comtrade World Integrated Solutions (WITS). When calculating exports from $i$ to $n$, we use imports from $i$ reported by country $n$, and when this is not available we use exports to $n$ by reporting country $i$. If neither of these two measures are available, we set this trade flow to zero. The value of exports from $i$ to the rest of the world is the sum of exports by $i$ to all countries with available data that are not included in $n=1, \ldots, M-1$. We use this measure of exports 'and imports to calculate net exports.

Sectoral absorption: Our regression (18) in Section 4.2.3 requires data on absorption by country-sector pair for 3-digit ISIC manufacturing industries. We construct sectoral absorption as sectoral output minus exports plus imports. We obtain sectoral output from UNIDO, valued using either producer prices (code 13) or, when not available, using undefined valuations (code 14). We use 2007 output data where available. When not available, we use 2006 values and when neither 2007 nor 2006 is available, we use 2005 values.

Tariffs: We measure bilateral import tariffs for 2 digit manufacturing ISIC sectors (15 to 36) from UNCTAD Trade Analysis Information System (TRAINS) for the year 2007 or the closest year with available information. That is, we use the first available observation in the following sequence of years: 2007, 2006, 2008, 2005, 2009, 2004 and 2003. For importerexporter-sector triplets with no tariff data in any year between 2003 and 2009, we impute a tariff as follows. Using importer-exporter-sector triplets with observed tariffs, we project these tariffs on an exporter-sector fixed effect and an importer-sector fixed effect. We then use the predicted tariffs from this regression for missing tariff observations.

Merchandise share of absorption: We construct the ratio of merchandise absorption to total absorption, $\gamma_{n}$, as

$$
\gamma_{n}=\frac{Y_{n}^{\text {merch }}-n x_{n} Y_{n}}{Y_{n}\left(1-n x_{n}\right)}
$$

where we used $P_{n} Q_{n}=\sum_{i} X_{i n}=Y_{n}\left(1-n x_{n}\right)$ and we abstracted from trade in services.

Sectoral skill intensities: We set $\alpha_{j}$ to match the share of hours employed in sector $j$ by those with a tertiary degree in the U.S. (i.e. those who have completed a college degree), which we obtain from the American Community Survey (ACS) from IPUMS for the year 2007 (and from the 1980 Census for our 1976 parameterization). The 2007 ACS reports 


\begin{tabular}{|c|c|c|c|c|c|c|c|c|c|}
\hline Country & Code & $\mathrm{H} /(\mathrm{H}+\mathrm{L})$ & $\begin{array}{l}\text { Share of } \\
\text { merch. in } \\
\text { absorption }\end{array}$ & $\begin{array}{c}\text { Share of VA } \\
\text { in gross } \\
\text { output }\end{array}$ & $\begin{array}{c}\text { Share of } \\
\text { world } \\
\text { GDP }\end{array}$ & $\begin{array}{l}\text { Exports / } \\
\text { (output } \\
\text { in merch.) }\end{array}$ & $\begin{array}{l}\text { Imports / } \\
\text { (output } \\
\text { in merch.) }\end{array}$ & $\begin{array}{c}\text { Net exp. / } \\
\text { (total } \\
\text { output) }\end{array}$ & 1976 \\
\hline Argentina & ARG & 0.037 & 0.434 & 0.526 & 0.005 & 0.213 & 0.145 & 0.031 & yes \\
\hline Australia & AUS & 0.206 & 0.246 & 0.489 & 0.015 & 0.321 & 0.332 & -0.003 & yes \\
\hline Austria & AUT & 0.107 & 0.324 & 0.489 & 0.007 & 0.532 & 0.584 & -0.016 & yes \\
\hline Belarus & BLR & 0.089 & 0.609 & 0.400 & 0.001 & 0.294 & 0.386 & -0.054 & no \\
\hline Brazil & BRA & 0.058 & 0.409 & 0.487 & 0.022 & 0.151 & 0.090 & 0.026 & yes \\
\hline Canada & CAN & 0.319 & 0.330 & 0.533 & 0.026 & 0.440 & 0.400 & 0.013 & yes \\
\hline Chile & CHL & 0.105 & 0.361 & 0.495 & 0.003 & 0.450 & 0.299 & 0.061 & yes \\
\hline China & $\mathrm{CHN}$ & 0.032 & 0.588 & 0.337 & 0.055 & 0.232 & 0.119 & 0.069 & yes \\
\hline Colombia & $\mathrm{COL}$ & 0.088 & 0.377 & 0.549 & 0.003 & 0.216 & 0.210 & 0.002 & yes \\
\hline Costa Rica & CRI & 0.134 & 0.359 & 0.500 & 0.000 & 0.742 & 0.540 & 0.083 & yes \\
\hline Croatia & HRV & 0.042 & 0.382 & 0.482 & 0.001 & 0.250 & 0.558 & -0.099 & no \\
\hline Cyprus & CYP & 0.168 & 0.260 & 0.573 & 0.000 & 0.588 & 1.259 & -0.117 & no \\
\hline Czech Rep. & CZE & 0.067 & 0.450 & 0.366 & 0.003 & 0.431 & 0.486 & -0.024 & no \\
\hline Denmark & DNK & 0.114 & 0.263 & 0.501 & 0.006 & 0.527 & 0.544 & -0.004 & yes \\
\hline Dominican Rep. & DOM & 0.040 & 0.437 & 0.474 & 0.001 & 0.181 & 0.264 & -0.035 & yes \\
\hline Ecuador & ECU & 0.101 & 0.427 & 0.496 & 0.001 & 0.336 & 0.263 & 0.033 & yes \\
\hline El Salvador & SLV & 0.077 & 0.490 & 0.462 & 0.000 & 0.180 & 0.301 & -0.056 & yes \\
\hline Estonia & EST & 0.179 & 0.376 & 0.430 & 0.000 & 0.668 & 0.941 & -0.088 & no \\
\hline Finland & FIN & 0.150 & 0.370 & 0.459 & 0.004 & 0.412 & 0.355 & 0.022 & yes \\
\hline France & FRA & 0.100 & 0.288 & 0.507 & 0.047 & 0.354 & 0.395 & -0.011 & yes \\
\hline Germany & DEU & 0.137 & 0.351 & 0.504 & 0.061 & 0.449 & 0.353 & 0.036 & yes \\
\hline Greece & GRC & 0.214 & 0.296 & 0.597 & 0.006 & 0.179 & 0.576 & -0.092 & yes \\
\hline Guatemala & GTM & 0.028 & 0.494 & 0.473 & 0.001 & 0.214 & 0.348 & -0.062 & yes \\
\hline Honduras & HND & 0.032 & 0.463 & 0.478 & 0.000 & 0.495 & 0.457 & 0.018 & yes \\
\hline Hungary & HUN & 0.112 & 0.430 & 0.420 & 0.002 & 0.564 & 0.581 & -0.007 & no \\
\hline Iceland & ISL & 0.143 & 0.280 & 0.445 & 0.000 & 0.349 & 0.591 & -0.058 & yes \\
\hline India & IND & 0.034 & 0.500 & 0.496 & 0.020 & 0.131 & 0.149 & -0.009 & yes \\
\hline Indonesia & IDN & 0.016 & 0.505 & 0.515 & 0.007 & 0.306 & 0.211 & 0.050 & yes \\
\hline Ireland & IRL & 0.185 & 0.233 & 0.423 & 0.005 & 0.778 & 0.380 & 0.133 & yes \\
\hline Israel & ISR & 0.274 & 0.283 & 0.517 & 0.003 & 0.512 & 0.472 & 0.012 & yes \\
\hline Italy & ITA & 0.067 & 0.338 & 0.468 & 0.039 & 0.272 & 0.276 & -0.001 & yes \\
\hline
\end{tabular}

Table 3: Country names and characteristics 


\begin{tabular}{|c|c|c|c|c|c|c|c|c|c|}
\hline Country & Code & $\mathrm{H} /(\mathrm{H}+\mathrm{L})$ & $\begin{array}{l}\text { Share of } \\
\text { merch. in } \\
\text { absorption }\end{array}$ & $\begin{array}{c}\text { Share of VA } \\
\text { in gross } \\
\text { output }\end{array}$ & $\begin{array}{c}\text { Share of } \\
\text { world } \\
\text { GDP }\end{array}$ & $\begin{array}{l}\text { Exports / } \\
\text { (output } \\
\text { in merch.) }\end{array}$ & $\begin{array}{l}\text { Imports / } \\
\text { (output } \\
\text { in merch.) }\end{array}$ & $\begin{array}{l}\text { Net exp. / } \\
\text { (total } \\
\text { output) }\end{array}$ & 1976 \\
\hline Japan & JPN & 0.215 & 0.341 & 0.516 & 0.087 & 0.220 & 0.179 & 0.015 & yes \\
\hline Kazakhstan & KAZ & 0.108 & 0.405 & 0.497 & 0.002 & 0.438 & 0.342 & 0.041 & no \\
\hline Korea, Rep. & KOR & 0.163 & 0.511 & 0.390 & 0.020 & 0.249 & 0.221 & 0.014 & yes \\
\hline Latvia & LVA & 0.103 & 0.294 & 0.426 & 0.000 & 0.615 & 0.927 & -0.075 & no \\
\hline Lithuania & LTU & 0.167 & 0.453 & 0.516 & 0.001 & 0.476 & 0.833 & -0.135 & no \\
\hline Malaysia & MYS & 0.041 & 0.596 & 0.326 & 0.003 & 0.567 & 0.357 & 0.137 & yes \\
\hline Mexico & MEX & 0.125 & 0.424 & 0.583 & 0.019 & 0.344 & 0.345 & -0.001 & yes \\
\hline Netherlands & NLD & 0.168 & 0.288 & 0.480 & 0.015 & 0.742 & 0.700 & 0.012 & yes \\
\hline New Zealand & NZL & 0.224 & 0.313 & 0.453 & 0.002 & 0.287 & 0.337 & -0.015 & yes \\
\hline Norway & NOR & 0.144 & 0.332 & 0.548 & 0.007 & 0.445 & 0.278 & 0.063 & yes \\
\hline Peru & PER & 0.167 & 0.455 & 0.510 & 0.002 & 0.266 & 0.183 & 0.039 & no \\
\hline Philippines & PHL & 0.215 & 0.464 & 0.509 & 0.002 & 0.541 & 0.394 & 0.074 & yes \\
\hline Poland & POL & 0.081 & 0.401 & 0.448 & 0.007 & 0.318 & 0.407 & -0.034 & no \\
\hline Portugal & PRT & 0.041 & 0.323 & 0.477 & 0.004 & 0.311 & 0.488 & -0.051 & yes \\
\hline Russian Fed. & RUS & 0.218 & 0.365 & 0.496 & 0.020 & 0.330 & 0.168 & 0.066 & no \\
\hline Serbia & SRB & 0.082 & 0.473 & 0.486 & 0.001 & 0.215 & 0.478 & -0.109 & no \\
\hline Slovak Rep. & SVK & 0.066 & 0.426 & 0.408 & 0.001 & 0.510 & 0.529 & -0.008 & no \\
\hline Slovenia & SVN & 0.093 & 0.398 & 0.448 & 0.001 & 0.551 & 0.672 & -0.045 & no \\
\hline Spain & ESP & 0.157 & 0.325 & 0.476 & 0.026 & 0.253 & 0.403 & -0.044 & yes \\
\hline Sri Lanka & LKA & 0.097 & 0.474 & 0.480 & 0.001 & 0.280 & 0.352 & -0.033 & yes \\
\hline Sweden & SWE & 0.180 & 0.317 & 0.481 & 0.009 & 0.480 & 0.426 & 0.018 & yes \\
\hline Switzerland & CHE & 0.122 & 0.290 & 0.512 & 0.009 & 0.610 & 0.533 & 0.023 & yes \\
\hline Thailand & THA & 0.062 & 0.553 & 0.402 & 0.004 & 0.466 & 0.395 & 0.040 & yes \\
\hline Turkey & TUR & 0.057 & 0.503 & 0.442 & 0.011 & 0.138 & 0.209 & -0.034 & yes \\
\hline Ukraine & UKR & 0.249 & 0.475 & 0.472 & 0.002 & 0.359 & 0.443 & -0.038 & no \\
\hline United Kingdom & GBR & 0.119 & 0.236 & 0.517 & 0.052 & 0.345 & 0.510 & -0.035 & yes \\
\hline United States & USA & 0.310 & 0.271 & 0.537 & 0.272 & 0.153 & 0.273 & -0.030 & yes \\
\hline Uruguay & URY & 0.070 & 0.390 & 0.486 & 0.000 & 0.289 & 0.280 & 0.003 & yes \\
\hline Vietnam & VNM & 0.020 & 0.631 & 0.393 & 0.001 & 0.396 & 0.391 & 0.003 & no \\
\hline Rest of World & ROW & 0.081 & 0.378 & 0.491 & 0.073 & 0.446 & 0.513 & endogenous & yes \\
\hline
\end{tabular}

Table 3: Country names and characteristics 
hours worked in the previous year, so our measure is for 2006. We match Census industries to 3 digit ISIC Rev. 3 sectors.

The five most skill-intensive merchandise sectors are Reproduction of recorded media, Processing of nuclear fuel, Publishing, Manufacture of other chemical products, and Manufacture of office accounting and computing machinery, each of which has a college intensity of roughly $50 \%$. The five least skill-intensive merchandise sectors are Casting of metals, Quarrying of stone sand and clay, Extraction and agglomeration of peat, Mining and agglomeration of lignite, and Sawmilling and planing of wood, each of which has a college intensity of roughly $10 \%$. The 17 non-manufacturing sectors have uniformly low skill intensities (the two exceptions are sectors 111, the extraction of crude petroleum and natural gas, and 112, service activities incidental to oil and gas extraction excluding surveying).

Given our production function, the share of skilled workers in sector $j$ in our model does not exactly equal $\alpha_{j}$. However, the share of workers in sector $j$ with a tertiary degree in the U.S. in the model is very close to that in the data. The maximum and mean absolute differences between these two ratios in merchandise (service) sectors, in percentage points, are $0.8 \%$ and $0.4 \%(2.5 \%$ and $1.3 \%)$, respectively. Moreover, the share of workers in the U.S. merchandise and service sectors with a completed tertiary degree in the model are roughly $23 \%$ and $34 \%$, whereas in the data they are $24 \%$ and $36 \%$, respectively. The model slightly under predicts the share with a tertiary degree in the U.S. because the share of employed U.S. workers with a tertiary degree in ACS, 34\%, is higher than the share in Barro and Lee (2013), 31\%. We use Barro and Lee (2013) to measure the skill abundance of the U.S. because it provides a comparable measure for the other countries. Given this discrepancy, it is impossible to choose $\alpha_{j}$ s to exactly match the share of workers with a tertiary degree in each sector in the U.S. In order to match both aggregate and sector-specific measures of skill intensity observed in the data, we would have to allow for exogenous differences in sector sizes, introducing an additional set of parameters. We choose to abstract from differences in sector size since our simple procedure already produces sector-specific skill intensities that are quite close to those in the data.

Skill intensity and firm size in the U.S. (not used in parameterization): In footnote 25 we stated that the share of workers with a college degree is larger in larger firms in the U.S. Here we substantiate this claim. The March CPS in the U.S. asks about the total number of people who worked for the respondent's employer during the preceding calendar year, including all locations where the employer operated; see e.g. Danziger (2014). Responses are grouped into six broad categories: under 10, 10-24, 25-99, 100-499, 500-999, and 1000+ employees. We construct the skill intensity-the share of college hours worked in total 


\begin{tabular}{|c|c|c|c|c|c|}
\hline Country & Obs. & Coefficient & Country & Obs. & Coefficient \\
\hline Armenia & 50 & 0.148 & Kazakhstan & 55 & 0.226 \\
\hline Australia & 52 & $0.545^{*}$ & Korea, Rep. & 57 & $0.805^{* *}$ \\
\hline Austria & 54 & $0.595^{* *}$ & Lebanon & 38 & 0.404 \\
\hline Belgium & 53 & 0.306 & Malaysia & 53 & $0.640^{* *}$ \\
\hline Bulgaria & 53 & 0.120 & Mexico & 51 & -0.027 \\
\hline Canada & 52 & 0.432 & Netherlands & 52 & $1.986^{* *}$ \\
\hline China & 55 & 0.353 & Norway & 52 & $0.498^{* *}$ \\
\hline Cyprus & 34 & $0.658^{* *}$ & Oman & 36 & 0.088 \\
\hline Czech Republic & 50 & $0.462^{* *}$ & Pakistan & 54 & 0.203 \\
\hline Denmark & 47 & 0.078 & Peru & 52 & $0.521^{*}$ \\
\hline Ecuador & 48 & 0.175 & Philippines & 56 & 0.428 \\
\hline Estonia & 40 & 0.279 & Poland & 56 & 0.071 \\
\hline Finland & 51 & 0.389 & Portugal & 48 & 0.461 \\
\hline France & 54 & $0.585^{* *}$ & Senegal & 38 & 0.174 \\
\hline Georgia & 40 & 0.127 & Singapore & 35 & $1.330^{* *}$ \\
\hline Germany & 57 & $0.577^{* *}$ & Slovak Republic & 49 & 0.074 \\
\hline Greece & 57 & 0.252 & Spain & 55 & $0.545^{* *}$ \\
\hline Hungary & 56 & 0.210 & Sri Lanka & 50 & 0.353 \\
\hline India & 56 & 0.311 & Sweden & 49 & $0.572^{*}$ \\
\hline Ireland & 43 & $1.230^{* *}$ & Thailand & 55 & $0.674^{*}$ \\
\hline Italy & 55 & $0.490^{* *}$ & Turkey & 49 & 0.393 \\
\hline Japan & 56 & $0.648^{*}$ & United Kingdom & 56 & 0.311 \\
\hline Jordan & 41 & 0.113 & United States & 53 & $0.917^{* *}$ \\
\hline
\end{tabular}

Table 4: Relationship in each country between sectoral trade normalized by absorption and sectoral skill intensity in 3-digit manufacturing ISIC sectors.

Notes: Obs. is the number of observations (we restrict attention to countries with at least 30 observations). Coefficient is the estimate of $\psi_{1 i}$ for country $i$ from equation (18). ${ }^{* *}$ and * indicate statistically significantly different from zero at the $5 \%$ and $10 \%$ levels, respectively. 
hours worked - of each of these 6 size categories and plot the relationship in Figure 10. There is a clear positive relationship between self-reported firm size and skill intensity in the U.S., a fact with which our model is consistent.

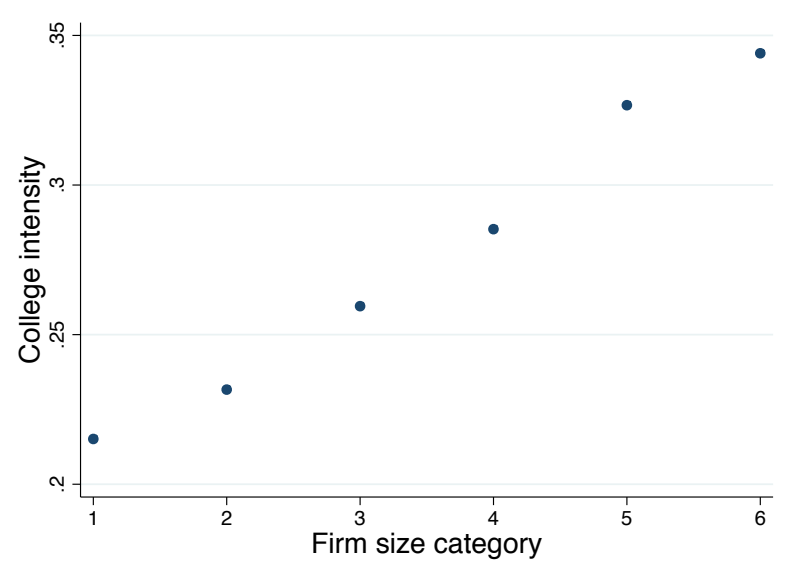

Figure 10: College intensity by firm size category in the U.S. in 2007.

Constructed using the 2008 March CPS. College intensity is the share of hours worked with a college degree. Firm employment by size category: <10 in category 1, 10-24 in 2, 25-99 in 3, 100-499 in 4, 500-999 in 5, 1000+ in 6.

\section{B.2 Solution algorithm}

Inner loop: In the inner loop, we take the values of all parameters as given and solve for the equilibrium values of $w_{n}, s_{n}, P_{n}$ and $\pi_{n}=\Pi_{n} /\left(w_{n} L_{n}+s_{n} H_{n}\right)$ in each country. This loop builds upon Alvarez and Lucas (2007), extending their approach in four respects: we have $(i)$ no analytic gravity equations, (ii) two factors, (iii) positive profits, and (iv) non-balanced trade.

Given an initial guess of $w_{n}, s_{n}, \pi_{n}$ in iteration number $k_{I}$, we first construct gross output $Y_{n}=\left(s_{n} H_{n}^{d}+w_{n} L_{n}^{d}\right)\left(\frac{1}{\chi_{n}}+\pi_{n}\right)$ in every country. Here $d$ denotes a variable observed directly rather than constructed in the model. We then construct the ratio of net exports to gross output in country $N, n x_{N}=-\sum_{n=1}^{N} n x_{n}^{d} Y_{n} / Y_{N}$. Then we calculate the value of aggregate absorption, $P_{n} Q_{n}$, for all countries using equation (11). For a fixed set of firm productivity draws $z$, we then calculate the indicator functions $\mathbb{I}_{i n}(\omega, j)$ finding the lowest-cost supplier in each country/variety, variety prices $p_{n}(\omega, j)$ after finding the second lowest cost supplier and using the price equation (5), and sectoral prices using equation (26). We can then calculate the aggregate price $P_{n}^{m}$ using equation (25), where $m$ denotes a variable constructed in the model that we will use to update our equilibrium guess. Given prices, we calculate aggregate absorption $Q_{n}$ (given $P_{n} Q_{n}$ calculated above), 
quantities $Q_{n}(j)$ and $q_{n}(\omega, j)$ using equations (1) and (2), and factor demands for individual varieties $l_{i}(\omega, j)$ and $h_{i}(\omega, j)$ using equations (22) and (23). We then construct the implied aggregate factor demands in the model, $L_{n}^{m}$ and $H_{n}^{m}$, using the right hand side of equations (9) and (10), and aggregate profits in the model using $\Pi_{n}^{m}=Y_{n}-\frac{s_{n} H_{n}^{d}+w_{n} L_{n}^{d}}{\chi_{n}}$. We similarly construct aggregate exports, $\sum_{i \neq n} X_{n i^{\prime}}^{m}$ and net exports, $N X_{n}^{m}$, in the model using equation (6) as well the definition of net exports.

Using $L_{n}^{m}$ and $H_{n}^{m}$ we construct the excess relative demand for skilled labor implied by the model,

$$
f_{n}^{1}=\left(\frac{H_{n}^{m}}{L_{n}^{m}}-\frac{H_{n}^{d}}{L_{n}^{d}}\right) /\left(\frac{H_{n}^{d}}{L_{n}^{d}}\right) .
$$

Similarly, we construct excess net exports,

$$
f_{n}^{2}=\frac{N X_{n}^{m}-\left(s_{n} H_{n}^{d}+w_{n} L_{n}^{d}\right)\left(\frac{1}{\chi_{n}}+\pi_{n}\right) n x_{n}^{d}}{\sum_{i \neq n} X_{n i}^{m}} .
$$

We then update our guess of equilibrium wages and profits (used in iteration $k_{I}+1$ ) as follows,

$$
\begin{aligned}
\left(\frac{s_{n}}{w_{n}}\right)^{k_{I}+1} & =\left(\frac{s_{n}}{w_{n}}\right)^{k_{I}} \times\left(1+\Delta^{s / w} f_{n}^{1}\right) \\
w_{n}^{k_{I}+1} & =w_{n}^{k_{I}} \times\left(1+\Delta^{w} f_{n}^{2}\right) \\
s_{n}^{k_{I}+1} & =w_{n}^{k_{I}+1} \times\left(\frac{s_{n}}{w_{n}}\right)^{k_{I}+1} \\
P_{n}^{k_{I}+1} & =P_{n}^{m} \\
\left(\pi_{n}\right)^{k_{I}+1} & =\Pi_{n}^{m} /\left(s_{n}^{k_{I}} H_{n}^{d}+w_{n}^{k_{I}} L_{n}^{d}\right)
\end{aligned}
$$

where factor prices are re-scaled such that $\sum_{n}\left(s_{i}^{k_{I}+1} H_{n}^{d}+w_{n}^{k_{I}+1} L_{n}^{d}\right)=1$; that is, we normalize $\sum_{n}\left(s_{n} H_{n}+w_{n} L_{n}\right)=1$. We terminate the loop when $\left|f_{n}^{1}\right|,\left|f_{n}^{2}\right|,\left|\left(P_{n}\right)^{k_{I}+1}-\left(P_{n}\right)^{k_{I}}\right|$, and $\left|\left(\pi_{n}\right)^{k_{I}+1}-\left(\pi_{n}\right)^{k_{I}}\right|$ are sufficiently small.

Middle loop: In the middle loop we take the values of $\phi, \theta$, and $\rho$ as given and assign values to the parameters $t_{i n}, a_{n}$, and $\bar{a}_{n}(g)$. Given a guess of these parameters in iteration $k_{M}$, we solve the inner loop and construct $(i)$ the ratio of exports from $n$ to $i$ relative to the 
sum of merchandise outputs in countries $n$ and $i, x_{n i}^{m}=X_{n i}^{m} /\left(Y_{i}^{\text {merch }}+Y_{n}^{m e r c h}\right)^{m}, 36$ (ii) the ratio of each country's output relative to world output, $Y_{n}^{m} / \sum_{i} Y_{i}^{m}$, and (iii) net exports normalized by total trade summed across all sectors $j$ in group $g$ (relative to its mean in each country), $v_{n}^{m}(g)-\bar{v}_{n}^{m}$. By comparing $(i)-(i i i)$ to the value of those variables in the data, we iterate over $t_{i n}, a_{n}$, and $\bar{a}_{n}(g)$ as follows. If the ratio of exports from $i$ to $n$ relative to the sum of merchandise outputs is higher in the model than in the data, we raise $t_{\text {in }}$. If the ratio of country n's output relative to world output is higher in the model than in the data, we lower $a_{n}$. Finally, if country $n$ 's normalized net exports in the group of sectors indexed by $g$ is higher in the model than in the data, we lower $\bar{a}_{n}(g)$. More precisely, we construct

$$
\begin{aligned}
f_{i n}^{t} & =x_{i n}^{m} / x_{i n}^{d}-1 \\
f_{n}^{a} & =\left(\frac{Y_{n}^{d}}{\sum_{i} Y_{i}^{d}}\right) /\left(\frac{Y_{n}^{m}}{\sum_{i} Y_{i}^{m}}\right)-1 \\
f_{n}^{\bar{a}}(g) & =\left(v_{n}^{d}(g)-\bar{v}_{n}^{d}\right)-\left(v_{n}^{m}(g)-\bar{v}_{n}^{m}\right)
\end{aligned}
$$

and obtain a new guess $t_{i n}, a_{n}$, and $\bar{a}_{n}(g)$ (used in iteration $\left.k_{M}+1\right)$ according to

$$
\begin{aligned}
t_{i n}^{k_{M}+1} & =1+\left(t_{i n}^{k_{M}}-1\right) \times\left[1+\Delta^{t} f_{i n}^{t}\right] \\
a_{n}^{k_{M}+1} & =a_{n}^{k_{M}} \times\left[1+\Delta^{a} f_{n}^{a}\right] \\
\bar{a}_{n}^{k_{M}+1}(g) & =\bar{a}_{n}^{k_{M}}(g)+\Delta^{\bar{a}_{n}} f_{n}^{\bar{a}}(g) .
\end{aligned}
$$

We terminate the loop when $\left|f_{n}^{a}\right|, f_{n}^{\bar{a}}(g)$, and the difference between aggregate country $n$ exports relative to merchandise output in the model and the data-i.e., $\left|\frac{\sum_{n \neq i} X_{i n}^{m}}{\left(Y_{i}^{m e r c h}\right)^{m}}-\frac{\sum_{n \neq i} X_{i n}^{d}}{\left(Y_{i}^{\text {merch }}\right)^{d}}\right|$-are small. In practice, this implies that the difference between bilateral exports relative to merchandise output in the model and the data-i.e., $\left|f_{n i}^{t}\right| s$-are also small, as we show in Figure 1.

In this step of our algorithm, we choose not to match trade volumes that are sufficiently small. Specifically, we set $t_{i n}=\infty$ if the ratio of country $i$ 's exports to country $n$ relative to the sum of country $i^{\prime}$ 's and country $n^{\prime}$ s outputs is less than $10^{-6}$ in the data; this eliminates 106 bilateral trade costs out of a total of $M \times(M-1)=3660$ origin-destination pairs. The model implies zero trade (due to the discrete number of varieties) for an additional 23 origin-destination pairs. The origin-destination pairs with zero trade account

\footnotetext{
${ }^{36}$ Targeting $X_{i n} /\left(Y_{n}^{\text {merch }}+Y_{i}^{\text {merch }}\right)$ rather than $X_{i n} / Y_{n}^{\text {merch }}$ significantly improves the efficiency of the numerical algorithm.
} 
for less $0.001 \%$ of total world trade between our 61 countries.

Outer loop: In the outer loop we iterate over $\rho, \theta$ and $\phi$ to match the moments described in Section 4. We raise $\rho$ if the model's implied aggregate elasticity of substitution between skilled and unskilled workers in the U.S. is too low, we raise $\theta$ if the model's implied elasticity of trade with respect to trade costs is too high, and we raise $\phi$ if the model's implied elasticity of plant skill intensity to plant sales is too low. 


\section{Online appendix}

\section{Under identification}

Recall that in our baseline parameterization we assign values to $N-1$ relative aggregate productivities, $a_{n}$, and $N(N-1)$ aggregate bilateral trade costs, $t_{i n}$-yielding a total of $(N-1) \times(N+1)$ parameters-by targeting $N-1$ relative outputs, $Y_{i} / \sum_{n} Y_{n}$, and $N^{2}$ exports from each origin $i$ to each destination $n$ relative to output, $x_{i n}=X_{i n} /\left(Y_{n}^{\text {merch }}+Y_{i}^{\text {merch }}\right)$. Here we show that of the $N^{2}+N-1$ targets, only $N \times(N-1)$ are independent. That is, we have $N-1$ more parameters than moments. We then describe four different ways of dealing this with under identification and show that the different procedures have a very small effect on the impact of trade on the skill premium.

Note first that equation (27) implies

$$
Y_{n}^{\text {merch }}=\kappa_{n} Y_{n}
$$

where $\kappa_{n}=\gamma_{n}+n x_{n}-\gamma_{n} n x_{n}$. Hence, given $n x_{n}$ and $\gamma_{n}, Y_{n}^{\text {merch }}$ uniquely determines $Y_{n}$.

The moments we take from the data are $x_{i n}=X_{i n} /\left(Y_{i}^{\text {merch }}+Y_{n}^{\text {merch }}\right)$ and $Y_{i} / \sum_{n} Y_{n}$. We first show that matching these moments is equivalent to matching the more standard moments $x_{i n}^{\prime}=X_{i n} / Y_{n}^{m e r c h}$. Clearly, $x_{i n}$ and $Y_{i} / \sum_{n} Y_{n}$ determine $x_{i n}^{\prime}$. Now, we show that $x_{i n}^{\prime}$ determines $Y_{i} / \sum_{n} Y_{n}$ and, hence, $x_{i n}$. The $x_{i n}^{\prime}$ s must satisfy the following restriction

$$
\sum_{i} x_{i n}^{\prime}=\frac{1}{Y_{n} \kappa_{n}} \sum_{i} X_{i n}=\frac{1}{Y_{n} \kappa_{n}}\left(Y_{n}-N X_{n}\right)=\frac{1}{\kappa_{n}}\left(1-n x_{n}\right),
$$

where the first equality follows from equation (28), the second equality follows from the definition of $N X_{n}$, and the final equality follows from the definition of $n x_{n}$. Note that the $x_{i n}^{\prime}$ s also satisfy the following restriction

$$
Y_{n}=\sum_{i} X_{n i}=\sum_{i} x_{n i}^{\prime} Y_{i}^{m e r c h}
$$

which implies

$$
\frac{Y_{n}}{Y_{N}}=\sum_{i} \frac{Y_{i}}{Y_{N}} \kappa_{i} x_{n i}^{\prime}
$$

While this is a system of $N$ equations in $(N-1)$ unknowns, $Y_{n} / Y_{N}$, only $(N-1)$ equations are independent because of restriction (29) and world trade balance, $\sum_{n} n x_{n} Y_{n} / Y_{N}=$ 0 . We can use these $N-1$ equations to solve for the $N-1$ relative outputs, $Y_{n} / Y_{N}$. 
Since $x_{i n}^{\prime}$ determines $Y_{n} / Y_{N}$, it also pins down $Y_{i} / \sum_{n} Y_{n}$. Thus, $x_{i n}^{\prime}$ determines $x_{i n}$ and $Y_{i} / \sum_{n} Y_{n}$. Finally, from restriction (29), of the $N \times N$ moments $x_{i n^{\prime}}^{\prime}$ only $N \times(N-1)$ are independent. Since $x_{i n}^{\prime}$ pins down $x_{i n}$ and $Y_{i} / \sum_{n} Y_{n}$, there are also only $N \times(N-1)$ independent targets in $x_{i n}$ and $Y_{i} / \sum_{n} Y_{n}$.

In our baseline approach we impose no additional restrictions and we find one, out of potentially many, set of trade costs and productivities that minimizes the distance between model outcomes and our target moments. We consider four alternative parameterizations in which we restrict trade costs to be symmetric for a subset of countries. First, we eliminate $N-1$ parameters by restricting trade costs to be symmetric for ROW (country $N)$. In this case, we still target $x_{i n}=X_{i n} /\left(Y_{n}^{\text {merch }}+Y_{i}^{\text {merch }}\right)$ for all $i, n \neq N$ as in the baseline approach. In order to choose symmetric trade costs with the ROW, we now target $x_{i N}+x_{N i}$ rather than targeting $x_{i N}$ and $x_{N i}$ independently. In this case, we have the same number of parameters and moments. Second, we eliminate $N-1$ parameters by restricting trade costs to be symmetric for the U.S. following the same approach. Third, we restrict all trade trade costs to be symmetric and target $x_{i n}+x_{n i}$ for all pair of countries $i \neq n$. Finally, we restrict all trade trade costs to be symmetric for all pair of countries $i \neq n$ and impose balanced trade in every country. Table 5 displays the mean, maximum and minimum change in the skill premium for our benchmark counterfactual in which we move each country from autarky to the baseline 2006 parameterization. The results do not change much in each of the alternative parameterizations that target the level of net exports in the data, and the rise in the skill premium is $2 \%$ higher on average if we impose balanced trade in each country.

\begin{tabular}{cccccc} 
& & \multicolumn{4}{c}{ Symmetric trade costs in } \\
& Baseline & ROW & U.S. & All $n$ & All $n \& n x_{n}=0$ \\
\hline mean & +5.1 & +5.1 & +5.1 & +5.1 & +5.4 \\
$\max$ & +12.1 & +12.1 & +12.1 & +12.3 & +14.2 \\
$\min$ & -0.3 & -0.3 & -0.4 & -0.4 & +0.9 \\
\hline
\end{tabular}

Table 5: Change in the skill premium moving from autarky to 2006 parameterization for different restrictions on trade costs and net exports.

\section{Proofs}

In this section we conduct a range of comparative static exercises under simplifying assumptions. Compared to the model described in Section 2, we assume that all firms in each variety $(\omega, j)$ within each country $n$ (but not across countries) have access to the same 
productivity $z_{n}(\omega, j)$ so that the Bertrand outcome is equivalent to the perfectly competitive outcome. Throughout this section we maintain the following additional simplifying assumptions:

1. There are two countries, $n=1,2$.

2. Trade costs are symmetric and independent of $j, \tau=\tau_{12}(j)=\tau_{21}(j)$.

3. The elasticity of substitution between sectors is one, $\sigma=1$.

4. Trade is balanced, which implies $Y_{i}=P_{i} Q_{i}$.

5. All sectors are tradable, $\gamma_{i}=1$ for all $i$ and $J_{M}=J$.

6. The share of value added in production is one, $\chi_{n}=1$, in each country.

Relative to the model presented in Section 2 , the price of variety $(\omega, j)$ in country $n$ simplifies to

$$
p_{n}(\omega, j)=\min _{i}\left\{c_{i n}(\omega, j)\right\} .
$$

Profits in each variety are zero with perfect competition and constant returns to scale. Hence, with balanced trade, the budget constraint in each country $n$ satisfies

$$
P_{i} Q_{i}=s_{i} H_{i}+w_{i} L_{i} .
$$

\section{D.1 The H-O mechanism}

In this section we study a special version of the model: a standard $\mathrm{H}-\mathrm{O}$ model extended to incorporate within- and across-sector productivity heterogeneity. We first show that our framework captures the key mechanisms of the $\mathrm{H}-\mathrm{O}$ model: comparative advantage is shaped (in part) by cross-country differences in endowment ratios, a country is a net exporter in its comparative advantage sector, and trade raises the relative wage of the factor intensive in its comparative advantage sector. Unlike the standard H-O model, in which countries share identical technologies, comparative advantage is also shaped by productivity heterogeneity in our model. Second, we show how the extent of productivity heterogeneity shapes the response of relative wages to trade liberalization.

In addition to assumptions 1-6 above, we also make the following assumptions:

7. There are two sectors $j=x, y$ with $\alpha_{y}<\alpha_{x}$.

8. Production functions are Cobb Douglas, $\rho=1$.

9. $\phi=0$.

Throughout this section we will also assume that country 1 has a comparative advantage in sector $x$. This is without loss of generality, as the condition on parameters 
(provided below) under which this is true must be satisfied for one of the two countries. Before presenting a set of results, we show how the model simplifies under these assumptions. Skilled labor's share of revenue in sector $j$ is equal to $\alpha_{j} . c_{i n}(\omega, j)$ simplifies to

$$
c_{\text {in }}(\omega, j)=\tau_{\text {in }} v_{i}(j) / z_{i}(\omega, j)
$$

where

$$
v_{i}(j) \equiv \tilde{\alpha}_{j} A_{i}(j)^{-1} s_{i}^{\alpha_{j}} w_{i}^{1-\alpha_{j}}
$$

represents the unit cost of production for a producer with productivity equal to one and where $\tilde{\alpha}_{j} \equiv \alpha_{j}^{-\alpha_{j}}\left(1-\alpha_{j}\right)^{\alpha_{j}-1}$. As in Eaton and Kortum (2002), we obtain simple analytic expressions that characterize the probability that country $i$ supplies country $n$ with an arbitrary variety $(\omega, j)$. This probability, denoted by $\pi_{i n}(j)$, is

$$
\pi_{i n}(j)=\frac{\left(\tau_{i n} v_{i}(j)\right)^{-1 / \theta}}{\left(\tau_{i n} v_{i}(j)\right)^{-1 / \theta}+\left(\tau_{-i n} v_{-i}(j)\right)^{-1 / \theta}} .
$$

Eaton and Kortum (2002) show that $\pi_{i n}(j)$ is also equal to the share of country $n$ 's expenditure in sector $j$ that is allocated to goods purchased from country $i$,

$$
\pi_{\text {in }}(j)=X_{\text {in }}(j) / \sum_{k=1}^{2} X_{k n}(j)
$$

where $X_{i n}(j)$ are the sales of country $i$ varieties of sector $j$ in country $n$. This implies that the amount of unskilled (and skilled) labor used in country $i$ sector $j$ to supply country $n$ can be written as a simple function of factor prices, aggregate prices, and aggregate quantities. Labor market clearing conditions for unskilled and skilled labor are simply

$$
\begin{aligned}
w_{i} L_{i} & =\frac{1}{2} \sum_{n=1}^{2} \sum_{j=\{x, y\}}\left(1-\alpha_{j}\right) \pi_{i n}(j) Q_{n} P_{n} \\
s_{i} H_{i} & =\frac{1}{2} \sum_{n=1}^{2} \sum_{j=\{x, y\}} \alpha_{j} \pi_{i n}(j) Q_{n} P_{n},
\end{aligned}
$$

where we have used the fact that $X_{i n}(j)=\pi_{\text {in }}(j) P_{n} Q_{n}$.

In this specification of the model, wages can be expressed in terms of what may be called the factor content of trade, which we define below in the context of this model and which we define more generally in Section E. Denote by $F C T_{i}(L)$ and $F C T_{i}(H)$ the units 
of unskilled and skilled labor, respectively, embodied in country $i$ 's net exports. That is,

$$
\begin{aligned}
F C T_{i}(L) & =\sum_{j} L_{i}(j) \omega_{i}(j) \\
F C T_{i}(H) & =\sum_{j} H_{i}(j) \omega_{i}(j),
\end{aligned}
$$

where $L_{i}(j)$ and $H_{i}(j)$ denote the employment of unskilled and skilled labor in country $i$ sector $j$, respectively, and where $\omega_{i}(j)$ equals the ratio of country $i$ 's net exports in sector $j$ to country $i$ 's total revenue in sector $j$,

$$
\omega_{i}(j) \equiv \frac{X_{i-i}(j)-X_{-i i}(j)}{X_{i i}(j)+X_{i-i}(j)}
$$

Equations (33) and (34) and the definitions of $F C T_{i}(L)$ and $F C T_{i}(H)$ imply

$$
\begin{aligned}
w_{i} & =\frac{1}{L_{i}-F C T_{i}(L)} \frac{1}{2} \sum_{j} \alpha_{j} Q_{i} P_{i} \\
s_{i} & =\frac{1}{H_{i}-F C T_{i}(H)} \frac{1}{2} \sum_{j}\left(1-\alpha_{j}\right) Q_{i} P_{i} .
\end{aligned}
$$

Hence, we obtain

$$
\frac{s_{i}}{w_{i}}=\frac{L_{i}-F C T_{i}(L)}{H_{i}-F C T_{i}(H)} \frac{\sum_{j}\left(1-\alpha_{j}\right)}{\sum_{j} \alpha_{j}} .
$$

Equation (35) gives us a simple relationship between the skill premium in countries 1 and 2 ,

$$
\frac{s_{1}}{w_{1}} / \frac{s_{2}}{w_{2}}=\frac{L_{1}-F C T_{1}(L)}{H_{1}-F C T_{1}(H)} / \frac{L_{2}-F C T_{2}(L)}{H_{2}-F C T_{2}(H)} .
$$

Finally, in order to study the effects of trade on the skill premium under the assumptions imposed in this section, we introduce the concept of comparative advantage. We say that country 1 has a comparative advantage in sector $x$ if, in autarky and for a common $z$, country 1's unit cost of production in sector $x$ relative to sector $y$ is relatively lower than country 2's: i.e., $v_{1}(x) / v_{1}(y) \leq v_{2}(x) / v_{2}(y)$. In general, we have

$$
\frac{v_{1}(x)}{v_{1}(y)} \leq \frac{v_{2}(x)}{v_{2}(y)} \Leftrightarrow a\left(\frac{s_{2}}{w_{2}} / \frac{s_{1}}{w_{1}}\right)^{\alpha_{x}-\alpha_{y}} \geq 1
$$

where the equivalence follows from the definition of $v_{i}(j)$ in equation (31) and from the definition

$$
a \equiv \frac{A_{1}(x) A_{2}(y)}{A_{1}(y) A_{2}(x)}
$$

where $a$ indexes country 1 's Ricardian comparative advantage (if $a>1$ ) or disadvantage 
(if $a<1$ ) in sector $x$. Note that in autarky $F C T_{i}(L)=F C T_{i}(H)=0$. Hence, according to equations 36 and (37), country 1 has a comparative advantage in sector $x$ if and only if

$$
a\left[\left(H_{1} / L_{1}\right) /\left(H_{2} / L_{2}\right)\right]^{\alpha_{x}-\alpha_{y}} \geq 1 .
$$

Note that equation (38) is a strict generalization of comparative advantage in the Ricardian and H-O models. If $a=1$, so that there is no Ricardian comparative advantage, then country 1 has a comparative advantage in sector $x$ if and only if $H_{1} / L_{1} \geq H_{2} / L_{2}$, exactly as in the Heckscher-Ohlin model. If endowment ratios are the same across countries, $H_{1} / L_{1}=H_{2} / L_{2}$, so that there is no H-O-based comparative advantage, then country 1 has a comparative advantage in sector $x$ if and only if $a \geq 1$, exactly as in the Ricardian model. We impose the inequality in equation (38) throughout this section; this is obviously without loss of generality.

While comparative advantage is defined as a condition on relative costs in autarky, it is straightforward to show that if country 1 has a comparative advantage in sector $x$, then $v_{1}(x) / v_{1}(y) \leq v_{2}(x) / v_{2}(y)$ also holds in any trade equilibrium.

Lemma 1. Under the assumptions of this section, $v_{1}(x) / v_{1}(y) \leq v_{2}(x) / v_{2}(y)$.

Proof. The proof requires one preliminary step.

Preliminary Step. Country $i$ has positive net exports in sector $x$ if and only if $F C T_{i}(H)>0>$ $F_{C} T_{i}(L)$.

We can re-express $F C T_{i}(L)$ as

$$
w_{i} F C T_{i}(L)=\sum_{j} \frac{w_{i} L_{i}(j)}{X_{i i}(j)+X_{i-i}(j)}\left[X_{i-i}(j)-X_{-i i}(j)\right] .
$$

Together with balanced trade, which implies

$$
X_{i-i}(x)-X_{-i i}(x)=X_{-i i}(y)-X_{i-i}(y),
$$

and Cobb-Douglas production functions, which imply

$$
1-\alpha_{j}=\frac{w_{i} L_{i}(j)}{X_{i i}(j)+X_{i-i}(j)},
$$

equation (39) yields

$$
w_{i} F C T_{i}(L)=\left(\alpha_{y}-\alpha_{x}\right)\left[X_{i-i}(x)-X_{-i i}(x)\right] .
$$


Since $\alpha_{y}<\alpha_{x}$, we obtain the result that $F C T_{i}(L)<0$ if and only if country $i$ is a net exporter in sector $x$ (i.e. if and only if $X_{i-i}(x)>X_{-i i}(x)$ ). Similarly,

$$
s_{i} F C T_{i}(H)=\left(\alpha_{x}-\alpha_{y}\right)\left[X_{i-i}(x)-X_{-i i}(x)\right],
$$

so that $F C T_{i}(H)>0$ if and only if country $i$ is a net exporter in sector $x$. This concludes the proof of the Preliminary Step.

We now proceed by contradiction. Suppose that $v_{1}(x) / v_{1}(y)>v_{2}(x) / v_{2}(y)$. This is equivalent to $\pi_{1 n}(x)<\pi_{1 n}(y)$ and $\pi_{2 n}(x)>\pi_{2 n}(y)$ for $n=1,2$ according to equation (32). By balanced trade, this implies $\omega_{1}(x), \omega_{2}(y)<0$ and $\omega_{1}(y), \omega_{2}(x)>0$. Hence, we have $X_{12}(x)<X_{21}(x)$ and $X_{12}(y)>X_{21}(y)$. By the Preliminary Step we therefore have $F C T_{1}(L)>0>F C T_{2}(H)$ and $F C T_{2}(L)<0<F C T_{2}(H)$. Together with equation (36), this implies

$$
\frac{s_{1}}{w_{1}} / \frac{s_{2}}{w_{2}}<\frac{L_{1}}{H_{1}} / \frac{L_{2}}{H_{2}}
$$

The previous inequality gives us

$$
\frac{v_{1}(x)}{v_{1}(y)} / \frac{v_{2}(x)}{v_{2}(y)}=\frac{1}{a}\left(\frac{s_{1}}{w_{1}} / \frac{s_{2}}{w_{2}}\right)^{\alpha_{x}-\alpha_{y}}<\frac{1}{a}\left(\frac{L_{1}}{H_{1}} / \frac{L_{2}}{H_{2}}\right)^{\alpha_{x}-\alpha_{y}} \leq 1,
$$

a contradiction. QED.

We are now equipped to study the effects of trade liberalization on the skill premium. Starting in autarky, a reduction in trade costs leads factors to reallocate towards the skillintensive $x$ sector in country 1 and towards the unskill-intensive $y$ sector in country 2 . This increases the relative demand and, therefore, the relative price of skilled labor in country 1 and unskilled labor in country 2. This result is summarized in the following Proposition.

Proposition 1. Under the assumptions of this section, moving from autarky to any positive level of trade increases $s_{1} / w_{1}$ and decreases $s_{2} / w_{2}$.

Proof. This proposition follows directly from Lemma 1. According to the Lemma 1, $v_{1}(x) / v_{1}(y) \leq v_{2}(x) / v_{2}(y)$ in any equilibrium. $v_{1}(x) / v_{1}(y) \leq v_{2}(x) / v_{2}(y)$ implies $\pi_{1 n}(x) \geq \pi_{1 n}(y)$ and $\pi_{2 n}(x) \leq \pi_{2 n}(y)$ for $n=1,2$ according to equation (32). Hence, country 1 has weakly positive net exports in sector $x$ while country 2 has weakly positive net exports in sector $y$. According to the Preliminary Step in the proof of Lemma 1, this implies $F_{C T}(H) \geq 0 \geq F C T_{1}(L)$ and $F C T_{2}(H) \leq 0 \leq F C T_{2}(L)$. Combined with 
equation (35), this implies

$$
\frac{s_{1}}{w_{1}} \geq \frac{L_{1}}{H_{1}} \frac{\sum_{j}\left(1-\alpha_{j}\right)}{\sum_{j} \alpha_{j}} \text { and } \frac{s_{2}}{w_{2}} \leq \frac{L_{2}}{H_{2}} \frac{\sum_{j}\left(1-\alpha_{j}\right)}{\sum_{j} \alpha_{j}},
$$

where $\frac{L_{1}}{H_{1}} \frac{\sum_{j}\left(1-\alpha_{j}\right)}{\sum_{j} \alpha_{j}}$ and $\frac{L_{2}}{H_{2}} \frac{\sum_{j}\left(1-\alpha_{j}\right)}{\sum_{j} \alpha_{j}}$ equal the skill premia in countries 1 and 2 in autarky, respectively. This concludes the proof of the Proposition. QED.

Proposition 2. Under the assumptions of this section, if $\tau$ and $A_{1}(1) / A_{2}(1)$ are chosen to match fixed values of trade shares in each country, then the increase in the $s_{1} / w_{1}$ and the decrease in $s_{2} / w_{2}$ caused by moving from autarky to these trade shares is decreasing in $\theta$ and increasing in a.

Proof. After setting out the necessary notation we provide two preliminary steps before proving the proposition. Denote by $\Delta_{i} \equiv \frac{1}{2}\left[\pi_{-i i}(x)+\pi_{-i i}(y)\right]$ for $i=1,2$ country $i$ 's expenditure share of trade and by $\Delta_{3}=\pi_{21}(y)-\pi_{21}(x)$ the difference in import shares between sector $x$ and sector $y$ in country 1 .

Step 1. If $\tau, \tau^{\prime}, a, a^{\prime}, \theta$, and $\theta^{\prime}$ are chosen such that $\Delta_{3}>\Delta_{3}^{\prime} \geq 0, \Delta_{1}=\Delta_{1}^{\prime}>0$, and $\Delta_{2}=\Delta_{2}^{\prime}$ $>0$, then the following conditions are satisfied: $(i) \pi_{12}(x)>\pi_{12}^{\prime}(x)$, (ii) $\pi_{12}(y)<\pi_{12}^{\prime}(y)$, (iii) $\pi_{21}(x)<\pi_{21}^{\prime}(x)$, (iv) $\pi_{21}(y)>\pi_{21}^{\prime}(y),(v) s_{1}^{\prime} / w_{1}^{\prime}<s_{1} / w_{1}$, and (vi) $s_{2}^{\prime} / w_{2}^{\prime}>s_{2} / w_{2}$.

We first show that $\Delta_{3}>\Delta_{3}^{\prime} \geq 0, \Delta_{1}=\Delta_{1}^{\prime}>0$, and $\Delta_{2}=\Delta_{2}^{\prime}>0$ imply conditions (i) - (iv). Conditions (iii) and (iv) follow directly from

$$
\pi_{21}(x)=\Delta_{1}-\frac{1}{2} \Delta_{3}<\Delta_{1}-\frac{1}{2} \Delta_{3}^{\prime}=\pi_{21}^{\prime}(x)
$$

and

$$
\pi_{21}(y)=\Delta_{1}+\frac{1}{2} \Delta_{3}>\Delta_{1}+\frac{1}{2} \Delta_{3}^{\prime}=\pi_{21}^{\prime}(y) .
$$

respectively. Equations (32), (40), and (41) yield

$$
\left(\frac{v_{2}(x)}{v_{1}(x)}\right)^{\frac{-1}{\theta}}\left(\frac{v_{1}^{\prime}(x)}{v_{2}^{\prime}(x)}\right)^{\frac{-1}{\theta^{\prime}}}<\frac{\left(\tau^{\prime}\right)^{-1 / \theta^{\prime}}}{\tau^{-1 / \theta}}<\left(\frac{v_{2}(y)}{v_{1}(y)}\right)^{\frac{-1}{\theta}}\left(\frac{v_{1}^{\prime}(y)}{v_{2}^{\prime}(y)}\right)^{\frac{-1}{\theta^{\prime}}} .
$$

Equation (32) and $\Delta_{2}=\Delta_{2}^{\prime}$ give us

$$
\gamma_{1}\left[1-\frac{\left(\tau^{\prime}\right)^{\frac{-1}{\theta^{\prime}}}}{\tau^{\frac{-1}{\theta}}}\left(\frac{v_{2}(x)}{v_{1}(x)}\right)^{\frac{-1}{\theta}}\left(\frac{v_{1}^{\prime}(x)}{v_{2}^{\prime}(x)}\right)^{\frac{-1}{\theta^{\prime}}}\right]=\gamma_{2}\left[\frac{\left(\tau^{\prime}\right)^{\frac{-1}{\theta^{\prime}}}}{\tau^{\frac{-1}{\theta}}}\left(\frac{v_{2}(y)}{v_{1}(y)}\right)^{\frac{-1}{\theta}}\left(\frac{v_{1}^{\prime}(y)}{v_{2}^{\prime}(y)}\right)^{\frac{-1}{\theta^{\prime}}}-1\right]
$$

where $\gamma_{1}>0$ and $\gamma_{2}>0$ are functions of $\tau, \tau^{\prime}$, and $v_{i}(j)$ for $i=1,2$ and $j=x, y$. The two 
previous equations yield

$$
\gamma_{1}\left[1-\frac{\left(\tau^{\prime}\right)^{\frac{-1}{\theta^{\prime}}}}{\tau^{\frac{-1}{\theta}}}\left(\frac{v_{2}(y)}{v_{1}(y)}\right)^{\frac{-1}{\theta}}\left(\frac{v_{1}^{\prime}(y)}{v_{2}^{\prime}(y)}\right)^{\frac{-1}{\theta^{\prime}}}\right]<-\gamma_{2}\left[1-\frac{\left(\tau^{\prime}\right)^{\frac{-1}{\theta^{\prime}}}}{\tau^{\frac{-1}{\theta}}}\left(\frac{v_{2}(y)}{v_{1}(y)}\right)^{\frac{-1}{\theta}}\left(\frac{v_{1}^{\prime}(y)}{v_{2}^{\prime}(y)}\right)^{\frac{-1}{\theta^{\prime}}}\right]
$$

which gives us

$$
\frac{\left(\tau^{\prime}\right)^{\frac{-1}{\theta^{\prime}}}}{\tau^{\frac{-1}{\theta}}}>\left(\frac{v_{1}(y)}{v_{2}(y)}\right)^{\frac{-1}{\theta}}\left(\frac{v_{2}^{\prime}(y)}{v_{1}^{\prime}(y)}\right)^{\frac{-1}{\theta^{\prime}}} .
$$

Equations (32) and (42) yield condition (ii), which, in turn, implies condition (i). To conclude Step 1, note that the skill premium in country 1 can be expressed as

$$
\frac{s_{1}}{w_{1}}=\frac{L_{1}}{H_{1}} \frac{\alpha_{x} R_{1}(x)+\alpha_{y} R_{1}(y)}{\left(1-\alpha_{x}\right) R_{1}(x)+\left(1-\alpha_{y}\right) R_{1}(y)},
$$

where $R_{i}(j)=X_{i i}(j)+X_{i-i}(j)$ denotes country $i$ 's revenue in sector $j$. Hence, $s_{1} / w_{1}>$ $s_{1}^{\prime} / w_{1}^{\prime}$ if and only if $R_{1}(x) R_{1}^{\prime}(y)>R_{1}^{\prime}(x) R_{1}(y) . \Delta_{1}=\Delta_{1}^{\prime}$ and $\Delta_{2}=\Delta_{2}^{\prime}$ imply $Q_{1} P_{1} / Q_{2} P_{2}=$ $Q_{1}^{\prime} P_{1}^{\prime} / Q_{2}^{\prime} P_{2}^{\prime}=\Delta_{2} / \Delta_{1}$ for $i=1,2$. Therefore, $R_{1}(j)=Q_{2} P_{2}\left[\pi_{12}(j)+\pi_{11}(j) \Delta_{2} / \Delta_{1}\right]$ and $R_{1}^{\prime}(j)=Q_{2}^{\prime} P_{2}^{\prime}\left[\pi_{12}^{\prime}(j)+\pi_{11}^{\prime}(j) \Delta_{2} / \Delta_{1}\right]$. Together with the definition of $R_{1}(j)$ and $R_{1}^{\prime}(j)$, conditions $(i)$ - (iv) imply $R_{1}(x) R_{1}^{\prime}(y)>R_{1}^{\prime}(x) R_{1}(y)$, concluding the proof of condition $(v)$. The proof of condition $(v i)$ is identical. This concludes the proof of Step 1.

Step 2. $\Delta_{3}>\Delta_{3}^{\prime} \geq 0, \Delta_{1}=\Delta_{1}^{\prime}>0$, and $\Delta_{2}=\Delta_{2}^{\prime}>0$ imply

$$
\left(\frac{1}{a^{\prime}} \times\left(\frac{s_{1}^{\prime} / w_{1}^{\prime}}{s_{2}^{\prime} / w_{2}^{\prime}}\right)^{\alpha_{x}-\alpha_{y}}\right)^{1 / \theta^{\prime}}>\left(\frac{1}{a} \times\left(\frac{s_{1} / w_{1}}{s_{2} / w_{2}}\right)^{\alpha_{x}-\alpha_{y}}\right)^{1 / \theta} .
$$

Condition (i) in Step 1, together with equation (32), implies

$$
\left(\tau^{\prime}\right)^{-1 / \theta^{\prime}} v_{2}(x)^{-1 / \theta} v_{1}^{\prime}(x)^{-1 / \theta^{\prime}}<\tau^{-1 / \theta} v_{2}^{\prime}(x)^{-1 / \theta^{\prime}} v_{1}(x)^{-1 / \theta}
$$

while condition (ii) in Step 1, together with equation (32), implies

$$
\left(\tau^{\prime}\right)^{-1 / \theta^{\prime}} v_{2}(y)^{-1 / \theta} v_{1}^{\prime}(y)^{-1 / \theta^{\prime}}>\tau^{-1 / \theta} v_{2}^{\prime}(y)^{-1 / \theta^{\prime}} v_{1}(y)^{-1 / \theta}
$$

The two previous inequalities give us

$$
\frac{v_{2}(x)^{-1 / \theta} v_{1}^{\prime}(x)^{-1 / \theta^{\prime}}}{v_{2}(y)^{-1 / \theta} v_{1}^{\prime}(y)^{-1 / \theta^{\prime}}}<\frac{v_{2}^{\prime}(x)^{-1 / \theta^{\prime}} v_{1}(x)^{-1 / \theta}}{v_{2}^{\prime}(y)^{-1 / \theta^{\prime}} v_{1}(y)^{-1 / \theta}}
$$


which is equivalent to inequality (43), concluding the proof of Step 2.

We now prove Proposition 2. We first prove the comparative static result for $\theta$. We proceed by contradiction. Suppose that $\theta>\theta^{\prime}, a=a^{\prime}$, and that $\Delta_{3}>\Delta_{3}^{\prime}>0$. Then

$$
\left(\frac{1}{a^{\prime}}\left(\frac{s_{1}^{\prime} / w_{1}^{\prime}}{s_{2}^{\prime} / w_{2}^{\prime}}\right)^{\left(\alpha_{x}-\alpha_{y}\right)}\right)^{\theta / \theta^{\prime}}>\frac{1}{a^{\prime}}\left(\frac{s_{1} / w_{1}}{s_{2} / w_{2}}\right)^{\left(\alpha_{x}-\alpha_{y}\right)} \geq \frac{1}{a^{\prime}}\left(\frac{s_{1}^{\prime} / w_{1}^{\prime}}{s_{2}^{\prime} / w_{2}^{\prime}}\right)^{\left(\alpha_{x}-\alpha_{y}\right)}
$$

where the first inequality follows from equation (43) and $a=a^{\prime}$ while the second weak inequality follows from parts $(v)$ and $(v i)$ of Step 1 . Inequality (44) and $\theta>\theta^{\prime}$ contradicts $\Delta_{3}^{\prime} \geq 0$, which implies

$$
\frac{1}{a^{\prime}} \times\left(\frac{s_{1}^{\prime} / w_{1}^{\prime}}{s_{2}^{\prime} / w_{2}^{\prime}}\right)^{\alpha_{x}-\alpha_{y}} \leq 1
$$

Thus, if $a=a^{\prime}$ and $\theta>\theta^{\prime}$, then $\Delta_{3} \leq \Delta_{3}^{\prime}$. Combined with conditions $(v)$ and (vi) in Step 1 , this yields the desired comparative static results for $\theta$.

Next, we prove the comparative static result for $a$. We proceed by contradiction. Suppose that $\theta=\theta^{\prime}, a \leq a^{\prime}$, and $\Delta_{3}>\Delta_{3}^{\prime}>0$. Then equation (43) yields

$$
\frac{1}{a^{\prime}} \times\left(\frac{s_{1}^{\prime} / w_{1}^{\prime}}{s_{2}^{\prime} / w_{2}^{\prime}}\right)^{\left(\alpha_{x}-\alpha_{y}\right)}>\frac{1}{a} \times\left(\frac{s_{1} / w_{1}}{s_{2} / w_{2}}\right)^{\left(\alpha_{x}-\alpha_{y}\right)} .
$$

With $a \leq a^{\prime}$, inequality (45) requires $\frac{s_{1}^{\prime} / w_{1}^{\prime}}{s_{2}^{\prime} / w_{2}^{\prime}}>\frac{s_{1} / w_{1}}{s_{2} / w_{2}}$, which contradicts conditions $(v)$ and $(v i)$ in Step 1. Thus, if $\theta=\theta^{\prime}$ and $a \leq a^{\prime}$, then $\Delta_{3} \leq \Delta_{3}^{\prime}$. Combined with conditions $(v)$ and (vi) in Step 1, this yields the desired comparative static results for $a$. QED.

\section{D.2 The skill-biased productivity mechanism}

In this section we focus on a one-sector, symmetric country model in which productivity is skill biased. Under certain assumptions, we show that a reduction in trade raises the skill premium. Specifically, in addition to assumptions 1-6 presented above, we also make the following assumptions:

7. There is one sector, $J=1$

8. The sector-level aggregator is Cobb Douglas, $\eta=1$

9. Productivity is skilled biased, $\phi(\rho-1)>0$

10. Countries are symmetric: $H \equiv H_{n}$ and $L \equiv L_{n}$ for $n=1,2$ and $A_{1}(j)=A_{2}(j)=1$ for $j=x, y$. 
The assumptions that countries are symmetric and that there is a single sector (we drop the sector-specific $j$ notation) allow us to abstract from the $\mathrm{H}-\mathrm{O}$ mechanism and isolate the skill-biased productivity mechanism; it also implies that $s \equiv s_{i}$ and $w \equiv w_{i}$ for $i=1,2$. The assumption that $\eta=1$ simplifies the algebra: a consequence of $\eta=1$ is that, in the factor demand equations, the direct effect of a reduction in trade costs-less labor is required to sell a given quantity of output in the foreign market-and the indirect effect-falling export prices increase the quantity sold in export markets—exactly offset.

Under these assumptions, we can write the unit cost of country $i$ firms supplying country $n$ as

$$
c_{\text {in }}(\omega ; \tau)=\tau_{\text {in }} w(1-\alpha)^{\frac{1}{1-\rho}} z(\omega)^{\frac{-\phi}{2}}\left(\frac{\alpha}{1-\alpha} z(\omega)^{\phi(\rho-1)}\left(\frac{s}{w}\right)^{1-\rho}+1\right)^{\frac{1}{1-\rho}}
$$

which we have written explicitly as a function of $\tau$. Denote by

$$
v_{\text {in }}(z ; \tau) \equiv \sum_{\omega \text { s.t. } z_{i}(\omega)=z} \mathbb{I}_{i n}(\omega ; \tau)
$$

the "number" of varieties with productivity $z$ in country $i$ that actively supply country $n$ in an equilibrium, written explicitly as a function of trade costs $\tau$. Let $v(z ; \tau)=$ $v_{i i}(z ; \tau)+v_{i-i}(z ; \tau)$, where $v(z ; \tau)$ is a density because-with symmetric countries-we have $v_{i-i}(k ; \tau)=v_{-i i}(k ; \tau)$, so that $\int_{0}^{\infty}\left[v_{i i}(k ; \tau) d k+v_{i-i}(k ; \tau)\right] d k=1$. With this notation, we can express the factor market clearing conditions as

$$
\begin{aligned}
& w L=\int_{0}^{\infty} l(z, w, s / w) v(z ; \tau) d z \\
& s H=\int_{0}^{\infty} h(z, s, s / w) v(z ; \tau) d z
\end{aligned}
$$

where

$$
\begin{aligned}
l(z, w, s / w) & =\frac{1}{w}\left[1+\frac{\alpha}{1-\alpha} z^{\phi(\rho-1)}\left(\frac{s}{w}\right)^{1-\rho}\right]^{-1} P Q \\
h(z, s, s / w) & =\frac{1}{s}\left[1+\left(\frac{1-\alpha}{\alpha}\right) z^{-\phi(\rho-1)}\left(\frac{s}{w}\right)^{\rho-1}\right]^{-1} P Q .
\end{aligned}
$$

Note that, as discussed above, conditional on supplying a country, the amount of skilled and unskilled labor employed is independent of trade costs because $\eta=1$. With skillbiased productivity, we cannot solve explicitly for $\pi_{i n}(j)$, unlike in the $\mathrm{H}-\mathrm{O}$ mechanism section above. However, we are able to obtain analytic comparative static results without this explicit solution. 
Proposition 3. Under the assumptions in this section, $s / w$ is strictly decreasing in $\tau$.

Proof. We normalize $w L+s H=1$ and we denote by $\Omega_{i n}(\tau)$ the set of varieties in which country $n$ is supplied by production in country $i$ as a function of trade costs. Before proving the proposition, we first outline our proof strategy.

Proof outline: We prove the proposition by contradiction. In the first three steps of the proof, we prove that if trade costs rise from $\tau$ to $\tau^{\prime}>\tau$ and the skill premium rises from $s / w$ to $s^{\prime} / w^{\prime} \geq s / w$, then the original distribution of productivities $v(z ; \tau)$ first-order stochastic dominates the new distribution of productivities $v\left(z ; \tau^{\prime}\right)$. Given this result, we show that $\tau^{\prime}>\tau$ and $s^{\prime} / w^{\prime} \geq s / w$ leads to a contradiction. Specifically, if $v(z ; \tau)$ first-order stochastic dominates $v\left(z ; \tau^{\prime}\right)$ and $s / w \leq s^{\prime} / w^{\prime}$, then the demand for unskilled labor must strictly rise from the original equilibrium to the new equilibrium. However, the supply of unskilled labor is fixed between equilibria, which yields our contradiction and proves our result.

Step 1: If $\tau<\tau^{\prime}, s^{\prime} / w^{\prime} \geq s / w, \omega \in \Omega_{n i}(\tau)$, and $\omega \in \Omega_{n^{\prime} i}\left(\tau^{\prime}\right)$ for $n^{\prime} \neq n$, then $z_{n}(\omega) \geq$ $z_{n^{\prime}}(\omega)$.

There are two cases to consider: $\omega \in \Omega_{i i}(\tau)$ and $\omega \in \Omega_{-i i}(\tau)$.

First consider $\omega \in \Omega_{i i}(\tau)$. In this case, we must have $\omega \in \Omega_{i i}\left(\tau^{\prime}\right)$, in which case the result holds vacuously. This is obvious if $z_{i}(\omega) \geq z_{-i}(\omega)$, since in this case $c_{i i}\left(\omega ; \tau^{\prime}\right)<$ $c_{-i i}\left(\omega ; \tau^{\prime}\right)$ so that $\omega \notin \Omega_{-i i}\left(\tau^{\prime}\right)$ for any $\tau^{\prime}>1$. It is also true if $z_{i}(\omega)<z_{-i}(\omega)$, since

$$
1 \geq \frac{c_{i i}(\omega ; \tau)}{c_{-i i}(\omega ; \tau)}>\frac{c_{i i}\left(\omega ; \tau^{\prime}\right)}{c_{-i i}\left(\omega ; \tau^{\prime}\right)}
$$

where the first weak inequality follows from $\omega \in \Omega_{i i}(\tau)$ and the second strict inequality follows from $\tau^{\prime}>\tau, s^{\prime} / w^{\prime} \geq s / w$, and $z_{i}(\omega)<z_{-i}(\omega)$. Since $c_{i i}\left(\omega ; \tau^{\prime}\right)<c_{-i i}\left(\omega ; \tau^{\prime}\right)$, we obtain $\omega \in \Omega_{i i}\left(\tau^{\prime}\right)$.

Second, consider $\omega \in \Omega_{-i i}(\tau)$. In this case, we must have $z_{-i}(\omega) \geq z_{i}(\omega)$; otherwise $c_{i i}(\omega ; \tau) \leq c_{-i i}(\omega ; \tau)$ for any $\tau \geq 1$, in which case $\omega \in \Omega_{i i}(\tau)$. Hence, if $\tau<\tau^{\prime}$, $s^{\prime} / w^{\prime} \geq s / w$, and the firms that supply country $i$ with variety $\omega$ switch from $n$ to $n^{\prime}$ as $\tau$ rises to $\tau^{\prime}$ (which, as we have just shown can only happen if $n=-i$ and $n^{\prime}=i$ ) then we must have $z_{n}(\omega) \geq z_{n^{\prime}}(\omega)$, which concludes the proof of Step 1 .

Step 2: If $\tau<\tau^{\prime}$ and $s^{\prime} / w^{\prime} \geq s / w$, then there is a positive measure of $\omega$ satisfying $\omega \in$ $\Omega_{-i i}(\tau), \omega \in \Omega_{i i}\left(\tau^{\prime}\right)$, and $z_{-i}(\omega)>z_{i}(\omega)$.

By Step 1 , if $\omega \in \Omega_{-i i}(\tau)$ and $\omega \in \Omega_{i i}\left(\tau^{\prime}\right)$, then $z_{-i}(\omega) \geq z_{i}(\omega)$. Since $z_{i}(\omega)$ and $z_{-i}(\omega)$ have full support on $(0, \infty)$ and $\tau$ is finite, there exists a positive measure of $\omega \in \Omega_{-i i}(\tau)$. 
Since $\tau^{\prime}>\tau$ and $s^{\prime} / w^{\prime} \geq s / w$, we have

$$
\frac{c_{i i}\left(\omega ; \tau^{\prime}\right)}{c_{-i i}\left(\omega ; \tau^{\prime}\right)}<\frac{c_{i i}(\omega ; \tau)}{c_{-i i}(\omega ; \tau)}
$$

Given that $z_{i}(\omega)$ and $z_{-i}(\omega)$ are i.i.d. and have full support on $(0, \infty)$, for any $\tau^{\prime}>\tau$ there exists a positive measure of $\omega$ for which

$$
\frac{c_{i i}\left(\omega ; \tau^{\prime}\right)}{c_{-i i}\left(\omega ; \tau^{\prime}\right)}<1<\frac{c_{i i}(\omega ; \tau)}{c_{-i i}(\omega ; \tau)}
$$

Hence, there is a positive measure of $\omega$ satisfying $\omega \in \Omega_{-i i}(\tau), \omega \in \Omega_{i i}\left(\tau^{\prime}\right)$, and $z_{-i}(\omega) \geq z_{i}(\omega)$. Finally, since $z_{i}(\omega)$ and $z_{-i}(\omega)$ are i.i.d. and atomless, there is a measure zero of $\omega$ satisfying $z_{-i}(\omega)=z_{i}(\omega)$. Hence, there is a positive measure of $\omega$ satisfying $\omega \in \Omega_{-i i}(\tau), \omega \in \Omega_{i i}\left(\tau^{\prime}\right)$, and $z_{-i}(\omega)>z_{i}(\omega)$, concluding the proof of Step 2.

Step 3: If $\tau<\tau^{\prime}$ and $s^{\prime} / w^{\prime} \geq s / w$, then $\int_{0}^{z} v(v ; \tau) d v \leq \int_{0}^{z} v\left(v ; \tau^{\prime}\right) d v$ for all $z>0$ and $\int_{0}^{z} v(v ; \tau) d v<\int_{0}^{z} v\left(v ; \tau^{\prime}\right) d v$ for $z$ sufficiently large.

We can write $\int_{0}^{z} v(v ; \tau) d v$ as

$$
\int_{0}^{z} v(v ; \tau) d v=\operatorname{Pr}\left[z_{i}(\omega)<z \& \omega \in \Omega_{i i}(\tau)\right]+\operatorname{Pr}\left[z_{-i}(\omega)<z \& \omega \in \Omega_{-i i}(\tau)\right]
$$

where we used the fact that $\operatorname{Pr}\left[z_{i}(\omega)<z \& \omega \in \Omega_{i-i}(\tau)\right]=\operatorname{Pr}\left[z_{-i}(\omega)<z \& \omega \in \Omega_{-i i}(\tau)\right]$ by symmetry across countries. For any $\omega$, we have either $\omega \in \Omega_{i i}(\tau)$ or $\omega \in \Omega_{-i i}(\tau)$. Hence, by Step 1 and equation (49) we have $\int_{0}^{z} v(v ; \tau) d v \leq \int_{0}^{z} v_{i}\left(v ; \tau^{\prime}\right) d v$ for all $z>0$. By Step 2 we therefore have $\int_{0}^{z} v(v ; \tau) d v<\int_{0}^{z} v\left(v ; \tau^{\prime}\right) d v$ for $z$ sufficiently large, which concludes the proof of Step 3.

We now use Step 3 to prove the proposition. We proceed by contradiction. Suppose that $\tau<\tau^{\prime}$ and $s^{\prime} / w^{\prime} \geq s / w$. According to the balanced trade condition and our normalization $w L+s H=1$, we have $w \geq w^{\prime}$ and $s \leq s^{\prime}$. Equation (46) and $w \geq w^{\prime}$ yield

$$
\int_{0}^{\infty} l(z, w, s / w) v(z ; \tau) d z=w L \geq w^{\prime} L=\int_{0}^{\infty} l\left(z, w^{\prime}, s^{\prime} / w^{\prime}\right) v\left(z ; \tau^{\prime}\right) d z
$$

while $\frac{\partial}{\partial w} l(z, w, s / w)<0$ and $\frac{\partial}{\partial(s / w)} l(z, w, s / w)>0$ together with $w \geq w^{\prime}$ and $s / w \leq$ $s^{\prime} / w^{\prime}$ yield

$$
\int_{0}^{\infty} l\left(z, w^{\prime}, s^{\prime} / w^{\prime}\right) v\left(z ; \tau^{\prime}\right) d z \geq \int_{0}^{\infty} l(z, w, s / w) v\left(z ; \tau^{\prime}\right) d z
$$


The previous two inequalities give us

$$
\int_{0}^{\infty} l(z, w, s / w) v(z ; \tau) d z \geq \int_{0}^{\infty} l(z, w, s / w) v\left(z ; \tau^{\prime}\right) d z
$$

Finally, $\frac{d}{d z} l(z, w, s / w)<0$ with $\phi(\rho-1)>0$, and Step 3 imply $^{37}$

$$
\int_{0}^{\infty} l(z, w, s / w) v(z ; \tau) d z<\int_{0}^{\infty} l(z, w, s / w) v\left(z ; \tau^{\prime}\right) d z
$$

which contradicts equation (50). Therefore, $\tau<\tau^{\prime}$ implies $s^{\prime} / w^{\prime}<s / w$. QED.

\section{E The factor content of trade}

Here we consider a general accounting framework that nests our baseline model as a special case. We make no assumption on the number factors in each country; there may be many types of labor and capital and other factors and types of labor or capital may be country specific. We index factors by $k=1, \ldots, K$. We make no assumption on the production function for producing variety $(\omega, j)$ in any country $i$ except we rule out joint production. We make no assumption on goods or labor market competition; it may be competitive or not.

With many factors we must modify the notation from our baseline model. We denote by $L_{n}(k)$ the number of employed units of factor $k$ and by $w_{n}(k)$ the average wage paid to employed units of factor $k$ in country $n$. As in our baseline, we denote by $X_{n i}(j)$ aggregate sector $j$ sales from country $n$ to country $i$. Revenue is used to pay factors of production, (potentially) to purchase intermediate inputs, and as profits for firm owners. We denote by $\alpha_{n i}(k, j)$ the share of $X_{n i}(j)$ that is paid to factor $k$; this share may be endogenous (and allows for the possibility of intermediate inputs and profits). Given this notation, we can write the following accounting identity

$$
w_{n}(k) L_{n}(k)=\sum_{j} \sum_{i} \alpha_{n i}(k, j) X_{n i}(j),
$$

which states that total factor income for factor $k$ in country $n$ must equal the payments to factor $k$ from sales in all countries and across all sectors.

\footnotetext{
${ }^{37}$ This follows from the fact that if $\int_{0}^{z} h(v) d v \leq \int_{0}^{z} g(v) d v$ for all $z>0, \int_{0}^{z} h(v) d v<\int_{0}^{z} g(v) d v$ for $z$ sufficiently large, and $f^{\prime}(z)<0$, then $\int_{0}^{\infty} h(v) f(v) d v<\int_{0}^{\infty} g(v) f(v) d v$.
} 
We define the factor content of exports for factor $k$ in country $n$ as

$$
F C X_{n}(k) \equiv \frac{1}{w_{n}(k)} \sum_{j} \sum_{i \neq n} \alpha_{n i}(k, j) X_{n i}(j)
$$

The term $w_{n}(k) F C X_{n}(k)$ represents the actual payments to the units of factor $k$ in country $n$ that are embodied in country $n$ 's exports across all sectors. In the special case in which all efficiency units of factor $k$ in country $n$ earn the wage $w_{n}(k), F C X_{n}(k)$ represents the amount of factor $k$ embodied in country $n$ 's exports across all sectors. We define the factor content of imports for factor $k$ in country $n$ as

$$
\operatorname{FCM}_{n}(k) \equiv \frac{1}{w_{n}(k)} \sum_{j} \alpha_{n n}(k, j) \sum_{i \neq n} X_{i n}(j)
$$

The term $w_{n}(k) F C M_{n}(k)$ represents the payments to factor $k$ if country $n$ were to allocate its expenditure on imports to domestic factors, in proportion to their factor shares in production for the domestic market in each good in the current equilibrium, $\alpha_{n n}(k, j)$. Since countries may have different production technologies and even different factors, $F C M_{n}(k)$ need not be related to the amount of factor $k$ that is embodied in any country $i \neq n$ 's exports to country $n$; this is an important distinction from the measurement in papers studying factor trade, such as Davis and Weinstein (2001). We define the factor content of trade (FCT) for factor $k$ in country $n$ as

$$
F C T_{n}(k) \equiv F C X_{n}(k)-F C M_{n}(k)
$$

Note that in autarky, $F_{C} T_{n}(k)=0$.

Finally, we define the factor payments for domestic absorption (FPD) for factor $k$ in country $n$ as

$$
\Phi_{n}(k) \equiv \sum_{j} \alpha_{n n}(k, j) \sum_{i} X_{i n}(j) .
$$

It represents the payment to unskilled labor that would result if the all of country $n$ 's expenditure (regardless of in which country each good is produced) were allocated to domestic factors, evaluated at current factor shares of domestic production for the domestic market in each sector, $\alpha_{n n}(k, j)$.

The accounting identity (51) and the two definitions, (52) and (53), give

$$
w_{n}(k)=\left(L_{n}(k)-F C T_{n}(k)\right)^{-1} \Phi_{n}(k)
$$


which can also be expressed as

$$
w_{n}(k)=\left(L_{n}(k)\right)^{-1} \Phi_{n}(k)\left(1-F C T_{n}(k) / L_{n}(k)\right)^{-1} .
$$

Equation (54) is equivalent to equation (21), where $s_{n}=w_{n}(H), w_{n}=w_{n}(L), L_{i}=L_{i}(L)$, and $H_{i}=L_{i}(H)$.

Clearly, $L_{n}(k)$ is independent of foreign shocks (such as changes in trade costs) in any model with fixed and inelastic factor supply (as is the case in our model). Relative factor payments for domestic absorption can be written as

$$
\frac{\Phi_{n}(k)}{\Phi_{n}\left(k^{\prime}\right)}=\frac{\sum_{j} \alpha_{n n}(k, j) \frac{\sum_{i} X_{i n}(j)}{\sum_{i} \sum_{j^{\prime \prime}} X_{i n}\left(j^{\prime \prime}\right)}}{\sum_{j^{\prime}} \alpha_{n n}\left(k^{\prime}, j^{\prime}\right) \frac{\sum_{i} X_{i n}\left(j^{\prime}\right)}{\sum_{i} \sum_{j^{\prime \prime}} X_{i n}\left(j^{\prime \prime}\right)}}
$$

where $\frac{\sum_{i} X_{i n}(j)}{\sum_{i} \sum_{j^{\prime \prime}} X_{i n}\left(j^{\prime \prime}\right)}$ denotes the share of domestic absorption on sector $j$ in total absorption in country $n . \frac{\Phi_{n}(k)}{\Phi_{n}\left(k^{\prime}\right)}$ is independent of foreign shocks if expenditure shares in country $n$ across sectors are fixed (as in a model in which the final good is a Cobb Douglas combination of sectoral absorption) and if factor revenue shares for domestic sales are fixed for every sector (as in a model with Cobb Douglas production functions and constant shares of costs in revenues).

Under the strong assumptions that both $L_{n}(k)$ for all $k$ and $\Phi_{n}(k) / \Phi_{n}\left(k^{\prime}\right)$ for all $k$ and $k^{\prime}$ are independent of all "foreign shocks", according to equation (55) a sufficient condition to solve for the impact of moving from the current equilibrium to autarky on $w_{n}(k)$ is $1-F C T_{n}(k) / L_{n}(k)$ evaluated at the current equilibrium. ${ }^{38}$

Finally, if factor intensities are independent of destination market, $\alpha_{n i}(k, j)=\alpha_{n}(k, j)$ for all $i$, then $F C T_{n}(k)$ simplifies to

$$
F C T_{n}(k)=\frac{1}{w_{n}(k)} \sum_{j} \alpha_{n}(k, j) N X_{n}(j)
$$

where $N X_{n}(j)$ denotes net exports in sector $j$. If all revenues are paid to factors of production then we have $\alpha_{n}(k, j)=w_{n}(k) L_{n}(k, j) / Y_{n}(j)$ where $L_{n}(k, j)$ denotes employment of factor $k$ in sector $j$ and $Y_{n}(j)=\sum_{i} X_{n i}(j)$ denotes the value of output in sector $j$. Hence,

\footnotetext{
${ }^{38}$ Deardorff and Staiger (1988) prove this result-that a sufficient condition to solve for the impact of moving to autarky on $w_{n}(k)$ is simply $1-F C T_{n}(k) / L_{n}(k)$ evaluated at the current equilibrium-in a perfectly competitive model under the conditions stated above. However, this result holds more generally. For instance, it can hold under monopolistic competition if the production (or utility) function that combines varieties to create sectoral output is CES (and varieties are not perfect substitutes) and if markups are constant, as shown in Burstein and Vogel (2011b).
} 
under these additional restrictions $F C T_{n}(k)$ can be expressed as

$$
F C T_{n}(k)=\sum_{j} L_{n}(k, j) \frac{N X_{n}(j)}{Y_{n}(j)} .
$$

\section{F Sensitivity}

Here we conduct a range of sensitivity analyses focusing on the counterfactual in which we move each country from autarky to the baseline 2006 parameterization. In all cases, we re-calibrate trade costs and aggregate productivities to match trade shares and relative GDPs and, with the exception of the first case (in which we set sectoral productivities to one), we re-calibrate sectoral productivities to match our sectoral measure or normalized trade. In each table below we report the mean, maximum ("max"), and minimum ("min") change in the skill premium moving from autarky.

Equal sectoral productivities within countries. In this exercise we consider an alternative parameterization of sectoral productivities, $A_{i}(j)$. Instead of choosing the sectoral component of productivity for each group of sectors, $\bar{a}_{n}(g)$, to target the ratio of net exports normalized by total trade, we set $\bar{a}_{n}(g)=1$, which implies $A_{n}(j)=A_{n}$ for all countries $n$ and sectors $j$. This is consistent with empirical evidence in Morrow (2010). Under this alternative parameterization, the skill premium rises in all countries (recall that in our baseline it falls in one country), and the increase is $1.5 \%$ larger, on average. In some countries like the U.S., the increase in the skill premium is very similar to our baseline, while in others (such as Honduras and Uruguay) the rise in the skill premium is more than twice as large.

\begin{tabular}{lcc} 
& Baseline & $A_{i}(j)=A_{i}$ for all $i$ and $j$ \\
\hline mean & +5.1 & +6.6 \\
$\max$ & +12.1 & +16.0 \\
$\min$ & -0.4 & +1.0 \\
\hline
\end{tabular}

No intermediate inputs. Here we abstract from intermediate inputs in production, and set $\chi_{n}=1$ in all countries. Recall from Section 3.3 that the higher is the share of value added in gross output, $\chi_{n}$, the more sensitive is the dispersion of costs within sectors to the skill-intensity of the sector. This strengthens the between-sector SBP mechanism and therefore increases the impact of trade on the skill premium. To illustrate these effects 
we proceed in two steps. We first keep the parameters $\rho, \theta$ and $\phi$ at our baseline levels $(\rho=1.43, \theta=0.22$ and $\phi=1)$. This variation increases the average rise in the skill premium from $5.1 \%$ to $5.7 \%$. The implied aggregate elasticity of substitution between skilled and unskilled labor in the U.S increases from our baseline target of 1.5 to 1.6. Next, in order to match our baseline targets we recalibrate the model and set $\rho=1.3, \theta=0.25$ and $\phi=1.31$. This variation further increases the average rise in the skill premium from $5.1 \%$ in our baseline to $7.3 \%$. Note that while reducing the share of intermediate inputs magnifies the impact of trade on the difference between the change in the real wage of skilled to unskilled workers, the magnitude of the change in the real wage of each worker group is smaller. Specifically, in the model with (without) intermediate inputs the average real wage for skilled and unskilled workers increases by $15.1 \%(10.4 \%)$ and $10.1 \%(3.1 \%)$, respectively.

\begin{tabular}{lccc} 
& Baseline & $\chi_{n}=1 \&$ baseline $\rho, \theta, \phi$ & $\chi_{n}=1 \&$ recalibrate $\rho, \theta, \phi$ \\
\hline mean & +5.1 & +5.7 & +7.3 \\
$\max$ & +12.1 & +12.6 & +16.6 \\
$\min$ & -0.4 & +0.5 & +1.1 \\
\hline
\end{tabular}

Varying $\theta$. In this table we consider alternative values for $\theta$ holding fixed $\rho$ and $\phi$. In addition to reporting the mean, max, and min change in the skill premium, we also report the implied trade elasticity ("elasticity"). The H-O mechanism becomes weaker and the skill-biased productivity and between-sector SBP mechanisms becomes stronger as we increase $\theta$. The overall effect of increasing $\theta$ is to increase the impact of trade on the skill premium, on average.

\begin{tabular}{lcccc} 
& Baseline & & & \\
& $\theta=0.22$ & $\theta=0.12$ & $\theta=0.17$ & $\theta=0.27$ \\
\hline mean & +5.1 & +2.2 & +3.7 & +6.5 \\
max & +12.1 & +8.0 & +10 & +14.2 \\
min & -0.4 & -2.2 & -1.2 & +0.5 \\
trade elasticity & 5.03 & 9.3 & 6.5 & 4.1 \\
\hline
\end{tabular}

Varying skill bias of productivity $\phi$. In this table we consider alternative values for $\phi$ holding fixed $\rho$ and $\theta$. In addition to reporting the mean, max, and min change in the skill premium, we also report the implied elasticity of firm skill intensity to firm size 
("elasticity"). As expected, the skill-biased productivity mechanism becomes stronger as we increase $\phi$.

\begin{tabular}{lccc} 
& Baseline & & \\
& $\phi=1$ & $\phi=0.6$ & $\phi=1.4$ \\
\hline mean & +5.1 & +2.5 & +7.8 \\
$\max$ & +12.1 & +8.3 & +16.9 \\
$\min$ & -0.4 & -1.7 & +1.1 \\
skill-intensity elasticity & 0.136 & 0.083 & 0.189 \\
\hline
\end{tabular}

Varying $\sigma$. In this table we consider alternative values for $\sigma$. Reducing $\sigma$ towards 1 mitigates the strength of the between-sector SBP mechanism because expenditure reallocates less towards skill-intensive sectors (whose relative prices are falling). On the other hand, a lower value of $\sigma$ strengthens the $\mathrm{H}-\mathrm{O}$ mechanism. This is because reductions in trade costs increase the relative price of a country's comparative advantage sector, and in response to this change in relative prices consumers are less willing to substitute away from the comparative advantage sector the lower is $\sigma$.

\begin{tabular}{lccc}
\multicolumn{3}{c}{ Baseline } & \\
& $\sigma=2.7$ & $\sigma=1.01$ & $\sigma=2$ \\
\hline mean & +5.1 & +4.4 & +4.8 \\
$\max$ & +12.1 & +12.4 & +12.1 \\
$\min$ & -0.4 & -2.9 & -0.9 \\
\hline
\end{tabular}

Varying elasticity of the CES final good aggregator of merchandise and services. In our baseline we assume that the elasticity of the final good aggregator between services and merchandise is one. This elasticity is typically estimated to be less than one; here, we consider an elasticity of 0.4 , in line with the range of parameters discussed in Buera et al. (2015). With an elasticity that is below one, a reduction in trade costs reallocates factors towards services. Given that services tend to be more skill intensive than merchandise (in the U.S., the share of workers with a completed tertiary degree in merchandise and services is $23 \%$ and $34 \%$, respectively in the model and $24 \%$ and $36 \%$, respectively, in the data), this will increase the relative demand for skill and, therefore, the increase in the 
skill premium; see e.g. Cravino and Sotelo (2015).

\begin{tabular}{lcc} 
& Baseline \\
& CES elasticity $=1$ & CES elasticity $=0.4$ \\
\hline mean & +5.1 & +5.5 \\
$\max$ & +12.1 & +12.6 \\
$\min$ & -0.4 & -0.06 \\
\hline
\end{tabular}

Heterogeneity in $\alpha$ within sectors: We now allow for heterogeneity in skill intensity within sectors that is uncorrelated with firm productivity. Specifically, we assume that

$$
\alpha_{j}(\omega)=\min \left\{\bar{\alpha}_{j} \exp (\varepsilon), 1\right\},
$$

where $\varepsilon \sim \ln \mathcal{N}\left(0, \sigma_{\alpha}\right)$. Note that if $\phi(\rho-1)=0$ and $\sigma_{\alpha}>0$, then in any given sector exporters are relatively less skill intensive than domestic firms in countries with $s / w>1$, resulting in a counterfactual negative elasticity of firm skill intensity to firm sales. As we increase $\sigma_{\alpha}$, in order to match a positive elasticity of skill intensity to size we need a higher value of $\phi>0$, which strengthens the SBP effect. On the other hand, a higher value of $\sigma_{\alpha}$ strengthens the $\mathrm{H}-\mathrm{O}$ mechanism, because $\mathrm{H}-\mathrm{O}$ forces now operate within sectors. In the following table we consider a range of values of $\sigma_{\alpha}-0.06,0.08$, and $0.1-$ in addition to our baseline value of $\sigma_{\alpha}=0$. For each value of $\sigma_{\alpha}$ we recalibrate $\phi$ to roughly match our target elasticity of skill intensity to size (our other target moments do not vary much as we change $\sigma_{\alpha}$ ). In this table we also report, for the U.S., the standard deviation of the log share of skilled workers across firms for the median merchandise sector relative to the standard deviation of the log share of skilled workers across merchandise sectors. Given data availability, one could use this information to assign a value to $\sigma_{\alpha}$. Increasing $\sigma_{\alpha}$ clearly results in a stronger impact of trade on the skill premium. This is because the SBP 
effect strengthens by more than the $\mathrm{H}-\mathrm{O}$ mechanism.

\begin{tabular}{lcccc}
\multicolumn{5}{c}{ Baseline } \\
& $\sigma_{\alpha}=0$ & $\sigma_{\alpha}=0.06$ & $\sigma_{\alpha}=0.08$ & $\sigma_{\alpha}=0.1$ \\
\hline $\begin{array}{l}\text { Standard deviation } \log h / l \\
\text { (median sector within) } / \mathrm{btw}\end{array}$ & 0.21 & 0.71 & 1.05 & 1.63 \\
& & & & \\
mean & +5.1 & +6.1 & +6.7 & +7.6 \\
$\max$ & +12.1 & +14.4 & +16.0 & +18.5 \\
$\min$ & -0.4 & +0.3 & +0.6 & +1.1 \\
\hline
\end{tabular}

Perfect competition. Recall that, following Bernard et al. (2003), we assume that firms producing individual varieties are engaged in Bertrand competition in order to have a well defined firm size distribution and calibrate our key parameter $\phi$ using firm-level data. Here we move away from this market structure and assume that all markets are perfectly competitive, that is that the price of each variety is equal to the marginal cost of the lowest cost supplier. We fix the parameter $\phi$ at our baseline, and calibrate the remaining parameters following our baseline procedure, which does not make use of firm- or plant-level data. This alternative market structure has a very small impact on the results. The maximum and mean absolute differences between the change in the skill premium in percentage points in our baseline and here are $0.6 \%$ and $0.1 \%$, respectively.

Tariff rebating. Here, instead of treating tariffs as physical trade costs as in our baseline model, we assume that import tariff revenues in each country are rebated to its consumers. This has a minimal impact on our results because tariff revenue constitutes a small share of income. Specifically, the maximum and mean absolute differences between the change in the skill premium in percentage points in our baseline and here are $0.39 \%$ and $0.05 \%$, respectively.

Equal trade costs across sectors. Here we do not make use of tariff data and assume that trade costs are equal across sectors, $\tau_{\text {in }}(j)=\tau_{\text {in }}$. This has a small impact on our results because, for the vast majority of exporter $\times$ importer $\times$ sector triplets, tariffs make up a small share of the overall trade cost in our baseline parameterization. The maximum and mean absolute differences between the change in the skill premium in percentage points in our baseline and here are $0.5 \%$ and $0.1 \%$, respectively. 